UNIVERSIDADE DE SÃO PAULO

ESCOLA DE ENGENHARIA DE SÃO CARLOS

DEPARTAMENTO DE ESTRUTURAS

\title{
Tabuleiro de madeira formado por duas camadas de peças ortogonais entre si e a $45^{\circ}$ com as bordas
}

MARCUS VINÍCIUS DE VASCONCELOS PAIVA

SÃO CARLOS, AGOSTO DE 1995. 
UNIVERSIDADE DE SÃO PAULO

ESCOLA DE ENGENHARIA DE SÃO CARLOS

DEPARTAMENTO DE ESTRUTURAS

\section{Tabuleiro de madeira formado por duas camadas de peças ortogonais entre si e a $45^{\circ}$ com as bordas}

MARCUS VINÍCIUS DE VASCONCELOS PAIVA Dissertação apresentada à Escola de Engenharia de São Carlos, da Universidade de São Paulo, como parte dos requisitos necessários à obtenção do Título de Mestre em Engenharia de Estruturas.

ORIENTADOR: Prof. Dr. João César Hellmeister 
P169t

Paiva, Marcus Vinícius de Vasconcelos

Tabuleiro de madeira formado por duas camadas de peças ortogonais entre si e a $45^{\circ}$ com as bordas / Marcus Vinícius de Vasconcelos Paiva. São Carlos, 19977.

Dissertação (Mestrado) - Escola de Engenharia de São Carlos - Universidade de São Paulo, 1995.

Orientador: Prof. Dr. João César Hellmeister.

1. Madeira - Pontes.

2. Madeira - Tabuleiro de pontes.

3. Madeira - Experimentação de estruturas. 
Àquele que, mesmo diante de nossas falhas, permanece sempre Fiel. 
A meus pais, José Joaquim e Maria Auxiliadora, pela sempre presença em minha vida. 


\section{Agradecimentos}

Ao Professor João César Hellmeister por sua orientação, sabedoria e amizade durante o tempo de convivência na EESC-USP.

Ao Conselho Nacional de Pesquisa e Desenvolvimento - CNPq, pela bolsa de estudos concedida.

Aos Colegas, professores e funcionários do SET-LaMEM da EESC-USP pela convivência e companheirismo. 


\section{Sumário}

Lista de figuras iv

Lista de tabelas vi

Lista de abreviaturas, siglas e símbolos viii

Resumo $x$

$\begin{array}{ll}\text { Abstract } & x i\end{array}$

Capítulo Um: Considerações iniciais

1.1. Introdução: Desenvolvimento Nacional, a questão Amazônica e as pontes de madeira 01

1.2. A madeira como matéria-prima na construção civil 03

1.3. Madeira: suas aplicações tecnológicas 06

Capítulo dois: $A$ razão de ser deste trabalho

2.1. Objetivos e justificativas 09

Capítulo três: Conceitos fundamentais

3.1. Propriedades físicas, de resistência e de elasticidade $\begin{array}{ll}\text { da madeira } & 10\end{array}$

3.2. Ligações em peças estruturais de madeira 16

3.2.1. Uso de pregos 17

3.2.2. Uso de cavilhas 19 
3.2.3. Pregos vs cavilhas - comportamento comparativo

\section{Capitulo quatro: Sobre pontes de madeira}

4.1. Pontes: algumas definições

4.2. Pontes de madeira: trabalhos do SET-LaMEM

Capítulo cinco: Tabuleiros de pontes de madeira

5.1. Arranjos ortótropos

5.2. Arranjos isótropos

5.2.1. Vigas de alma cheia

5.2.2. Tabuleiros ortogonais

40

Capitulo seis: Parte experimental

6.1. Objetivos

45

6.2. Descrição dos modelos

6.2.1. Materiais componentes dos modelos

6.2.1.1. Sarrafos de Peroba Rosa

6.2.1.2. Pregos lisos de aço e cavilhas de Ipê

6.2.2. Montagem dos modelos

6.3. Ensaios de flexão

Capítulo sete: Análise dos resultados

7.1. Variação da "rigidez" $k$ do modelo pregado com $o$ acréscimo de pontos de ligação

7.2. Comportamento comparativo entre arranjos solidarizados por pregos e com cavilhas 
7.3. Análise numérica do arranjo pregado, configuração II

7.4. Estimativa da capacidade de carga para um tabuleiro ortogonal solidarizado por meio de pregos com a configuração II

\section{Capitulo oito: Considerações finais}

8.1. Conclusões do estudo

8.2. Críticas e sugestōes para continuidade do estudo

do arranjo ortogonal

Obras consultadas e obras citadas

Anexo A: Resultados dos ensaios de flexão dos sarrafos de Peroba Rosa

Anexo B: Aplicação do método dos mínimos quadrados na análise dos resultados dos ensaios

Anexo C: Resultados dos ensaios de flexão do modelo pregado $1 A$

Anexo D: Resultados dos ensaios de flexão do modelo pregado $1 B$

Anexo E: Resultados dos ensaios de flexão do modelo cavilhado

Anexo F: Modelos numéricos de placa isótropa-Arquivos SAP90

Anexo G: Modelos numéricos de placa isótropa - Resultados obtidos 


\section{Lista de figuras}

Figura 3.1: Diagrama Umidade vs Densidade

Figura 3.2: Diagrama de variação da resistência à compressão paralela às fibras com a umidade e a densidade

Figura 3.3: Comportamento típico da madeira submetida à tração e à compressão paralelas às fibras

Figura 3.4: Distribuição das tensões de tração e compressão paralelas às fibras na madeira submetida à flexão

Figura 3.5: Distribuição das tensões de cisalhamento na madeira submetida à flexão

Figura 3.6: Espaçamento mínimo entre pregos

Figura 3.7: Comportamento de ligações pregadas

Figura 4.1: Alguns tipos estruturais de pontes de madeira

Figura 4.2: Ponte pênsil sobre o Rio Tietê, São Miguel Paulista -SP

Figura 4.3: Passarela pênsil sobre o Rio Piracicaba, Piracicaba-SP

Figura 5.1: Tabuleiro de postes de Eucalipto Citriodora

Figura 5.2: Modelo de tabuleiro de madeira laminada protendida

Figura 5.3: Modelo de tabuleiro de madeira laminada protendida

Figura 5.4: Viga de alma cheia cheia e sua aplicação ao projeto de uma ponte de madeira em arco lamelar 
Figura 5.5: Modelo de tabuleiro isótropo de madeira 41

Figura 5.6: Ponte sobre o Rio Sorocaba, Iperó - SP 43

Figura 6.1: Geometria dos modelos 46

Figura 6.2: Montagem dos ensaios de flexão dos sarrafos de Peroba Rosa

Figura 6.3: Detalhes das ligações por pregos e cavilhas 51

Figura 6.4: Configurações adotadas para as ligaç̃̃es dos modelos pregados

Figura 6.5: Montagem dos ensaios de flexão dos modelos

Figura 6.6: Condições de apoio adotadas nos ensaios de flexão dos modelos

Figura 6.7: Padrões de carregamento aplicados durante os ensaios

Figura 6.8: Placa quadrada submetida a carregamento em região retangular, e equação diferencial das placas elásticas

Figura 6.9: Modelo solidarizado por pregos

Figura 6.10: Modelo solidarizado com cavilhas

Figura 6.11: Carregamento pontual

Figura 6.12: Vinculo I

Figura 6.13: Carregamento 4 pontos $\quad 60$

Figura 6.14: Vinculo $2 \quad 60$

Figura 6.15: Carregamento linear excêntrico 61

Figura 7.1: Esquema de locação dos pontos de medida de deslocamentos 
Figura 7.2: Modelo $1 A$, vinculo 1, flecha em $B$

Figura 7.3: Modelo $1 B$, vínculo 1, flecha em $B$

Figura 7.4: Modelo 1A, vinculo 2, flecha em A 64

Figura 7.5: Modelo $1 B$, vínculo 2, flecha em $A$

Figura 7.6: Modelo $1 A$, vinculo 2, flecha em $B$

Figura 7.7: Modelo $1 B$, vinculo 2, flecha em B 66

Figura 7.8: Modelo 1A, vinculo 2, flecha em $C$

Figura 7.9: Modelo 1B, vínculo 2, flecha em $C$

Figura 7.10: Variação hiperbólica da rigidez do arranjo com o número de pontos ligados 


\section{Lista de tabelas}

Tabela 6.1: Resultados dos ensaios de flexão dos sarrafos de

Peroba Rosa

Tabela 6.2: Pares de leitura $P$ vs $w$ obtidos nos ensaios de flexão dos modelos

Tabela 7.1: "Rigidez" $k$ dos modelos pregados

Tabela 7.2: Relações entre os valores obtidos para a "rigidez" $k$ dos modelos pregado e cavilhado, na configuração II

Tabela 7.3 e 7.4: "Rigidez" $k$ do Modelo pregado 1 A em comparação com modelos numéricos de placa isótropa

Tabela 7.5: Valores obtidos para a espessura da placa equivalente 


\section{Lista de abreviaturas, siglas e símbolos}

\section{Siglas}

$A B N T$ - Associação Brasileira de Normas Técnicas

$D I N$ - Deustsches Institut Für Nurmung

IPT - Instituto de Pesquisas Tecnológicas do Estado de São Paulo

$M B$ - Método Brasileiro

$N B, N B R$ - Norma Brasileira

SAP90 - Structural Analysis Program by Finite Element

SET-LaMEM - Departamento de Estruturas, Laboratório de Madeiras e de Estruturas de Madeira, EESC-USP

\section{Símbolos}

$A$ - Área da seção transversal de uma viga prismática

$C$ - Constante elástica do anel dinamométrico

$D$ - Rigidez de uma placa

$E$ - Módulo de elasticidade longitudinal

$G$ - Módulo de elasticidade transversal

$I$ - Momento de inércia da seção transversal de uma viga prismática

$L$ - Vão de uma viga prismática; Dimensão dos lados de uma tabuleiro quadrado 
P - Carga total aplicada sobre o modelo de tabuleiro.

Padm - Idem, admissivel

Prup - Idem, de ruptura

Mrup - Momento de ruptura

$S_{X}$ - Desvio padrão

$X_{M E ́ D I O}$ - Valor médio

$X_{K 95 \%}$ - Valor característico acima do qual estão $95 \%$ dos valores da amostra

$X_{K 5 \%}$ - Valor característico acima do qual estão $5 \%$ dos valores da amostra

$W$ - Módulo de flexão da seção transversal de uma viga prismática

$a$ - Lados de uma placa quadrada; Dimensões laterais do modelo de tabuleiro

$b$ - Largura da seção transversal de uma peça componente das camadas que formam o modelo de tabuleiro

$c$ - Coeficiente de forma de uma seção, considerada na parcela de flecha devida à força cortante na flexão de vigas prismáticas

$d$ - Altura da seção transversal de uma peça componente das camadas que formam o modelo de tabuleiro

$e$ - Espessura de uma camada de peças, formadora do arranjo ortogonal

$f$ - Flecha; Tensão

$k$ - Constante que relaciona a carga total aplicada sobre o modelo e o correspondente valor da superfície elástica após a deformação, no ponto considerado

mrup - Momento de ruptura, por largura unitária

$u, v$ - Dimensões da área de atuação do carregamento sobre a placa

$w$ - Função que define a superfície elástica da placa deformada 
$\mathrm{x}, \mathrm{y}$ - Coordenadas de referência

$\Delta$ - Variação porcentual

$\varepsilon$ - Deformação

$\phi$ - Diâmetro; Função que depende das dimensões da placa, condições de vínculo e tipo de carregamento aplicado

$\eta, \xi$ - Posição do centro da área de aplicação de carga sobre a placa

$v$ - Coeficiente de Poisson

$\partial$ - Derivada parcial 


\section{Resumo}

PAIVA, M. V. V. Tabuleiro de madeira formado por duas camadas ortogonais entre si e a $45^{\circ}$ com as bordas. São Carlos, 1995. 88p. Dissertação (Mestrado) - Escola de Engenharia de São Carlos, Universidade de São Paulo.

Este trabalho apresenta o estudo de um arranjo estrutural de tabuleiro de ponte de madeira com comportamento de placa elástica isótropa. Ensaios com modelos reduzidos mostraram a tendência para o aumento da rigidez com o acréscimo de ligações entre as peças componentes. Este aumento ocorre de forma hiperbólica, tendendo assintóticamente a um valor máximo.

Comparações entre modelos pregados e modelos cavilhados mostram que o modelo cavilhado tem uma rigidez ligeiramente inferior $\grave{a}$ rigidez do modelo pregado.

Análise numérica mostra que o modelo pregado é equivalente a uma placa isótropa, com módulo de elasticidade considerado igual à média dos módulos de elasticidade das peças componentes, e espessura da ordem de $40 \%$ do valor da espessura do modelo real. 


\title{
Abstract
}

\author{
PAIVA, M. V. V. Tabuleiro de madeira formado por duas camadas \\ ortogonais entre si e a $45^{\circ}$ com as bordas. São Carlos, 1995. 88p. \\ Dissertação (Mestrado) - Escola de Engenharia de São Carlos, \\ Universidade de São Paulo.
}

\begin{abstract}
This work aims the study of timber bridge deck structural arrangement with isotropic plate behaviour. Tests with reduced models have shown the tendency to rigidity increase with increase of connections between component parts. This increase occurs with hipperbolic form tendend asymptotically to a maximum value.

Comparisons between nailed model and wood doweled model show that the wood doweled model have a rigidity lightly inferior to nailed model rigidity.

Numerical analysis show that the nailed model is equivalent to isotropic plate, with MOE admited equal to medium MOE of the component parts and the thickness value order as $40 \%$ of the real model thickness.
\end{abstract}




\section{Capítulo Um: Considerações iniciais}

\subsection{Introdução: Desenvolvimento nacional, a questão Amazônica e as pontes de madeira}

Em todo o País a demanda por obras que auxiliem o desenvolvimento das diversas regiões é muito grande. Tome-se por exemplo a Amazônia. Região com potenciais admiráveis, ainda não obteve por parte das autoridades governamentais e da iniciativa privada a atenção que merece.

Em seus quase 5 milhões de $\mathrm{km}^{2}$ de área (aproximadamente $55 \%$ da superfície total do Brasil) abriga uma população com menos de 13 milhões de habitantes, representando apenas cerca de $8,5 \%$ da população brasileira*. A imensa maioria da população do País está localizada no litoral e nos estados das regiões Sudeste e Sul, estando aquele interior do Brasil praticamente despovoado.

A política governamental ao longo da História do Brasil sempre se caracterizou por um abandono quase completo das regiões interioranas. A Amazônia é e tem sido alvo desse descaso que hoje, mais do que nunca, coloca as populações amazônidas em um estado de pobreza e isolamento sem igual em todas as demais regiões brasileiras. Isto de modo algum se justifica, dado ser a Amazônia possuidora das maiores riquezas existentes no planeta, tanto ao nível de sua biodiversidade quanto em relação suas fontes de matéria-prima.

\footnotetext{
" IBGE - Instituto Brasileiro de Geografia e Estatística. Censo de 1991, projeção para 1993.
} 
Esta riqueza incalculável está à disposição da sociedade brasileira para ser racional e eficientemente explorada a favor do desenvolvimento de nosso povo. Este é um fato reconhecido mundialmente e torna-se ainda mais importante se tomarmos em consideração a maior de todas as riquezas da região que é o ser humano que hoje habita a Amazônia.

É urgente a necessidade de execução de políticas governamentais visando tirar a Amazônia da atual fase de estagnação agravada pela crise econômica do País, e que tenham como objetivo gerar o desenvolvimento auto-sustentado da região. Entre os possíveis caminhos a serem seguidos por estas políticas públicas certamente estarão: a abertura de vias de acesso rodo ou ferroviário, melhoria das vias existentes, a otimização do uso das hidrovias naturais abundantemente distribuídas na região.

Isto certamente irá estimular as diversas atividades sócio-econônicas ali desenvolvidas. Além disso, deve-se buscar soluções para os problemas urbanos existentes, principalmente nas grandes cidades, cuja infraestrutura já se esgota devido ao êxodo rural.

Quando se pensa na abertura ou melhoria de estradas deve-se ter em mente a necessidade de construção e manutenção de pontes ao longo de seus traçado. Tratando-se do projeto, construção e manutenção de pontes na Amazônia, tornam-se relevantes peculiaridades somente a ela características tais como os grandes vãos a serem vencidos sobre os rios e igarapés, o regime hidrológico ali existente, e sua quase inesgotável reserva natural de madeira.

Assim, este trabalho visa colaborar para o desenvolvimento da Amazônia, contribuindo com o exame de novas propostas estruturais para o uso em pontes de madeira. 


\subsection{A madeira como matéria-prima na construção civil}

A necessidade de se gerar o desenvolvimento, ocupando regiões ainda inexploradas e, principalmente, melhorando as condições de vida naquelas já povoadas, impõe o aumento do consumo de matéria-prima regional com o passar do tempo.

Entre os materiais mais abundantes no País tem-se o solo e as rochas, dos quais a maior parte de nossos materiais de construção é obtida. Assim é com o cimento, o gesso, a cal e as britas, que são elementos formadores da maioria das argamassas e concretos, assim é com os metais, tais como o ferro, o aço e o alumínio, largamente utilizados na construção civil.

O Brasil tem a seu dispor uma fonte "inesgotável" proveniente da energia solar, da qual relativamente ainda pouco podemos aproveitar diretamente devido à falta de domínio de tecnologia adequada econômicamente viável, mas que está disponível indiretamente nos ventos, mares, cursos d'água, em nossas reservas de petróleo e carvão mineral, entre outras.

Estas últimas são de grande importância para a produção de plásticos e aço, materiais grandemente utilizados em toda a indústria nacional. Resultantes da decomposição de matéria orgânica animal e vegetal em um processo contínuo de milhões de anos, devem ser consideradas de interesse estratégico, pois já existem inúmeras referências à previsão de seu esgotamento a médio prazo.

Além disso, a energia solar é encontrada também sob a forma de abundante matéria verde viva, da qual queremos destacar a presença de nossas florestas, e nestas a das madeiras.

Estando tão claro nos dias de hoje que o uso indiscriminado e não-racional dos recursos existentes na natureza poderá levar a humanidade a um colapso, e em função disso ser necessário buscar e desenvolver novas fontes de matéria prima mais impas, 
menos degradantes ao meio ambiente, e de melhor manutenção ao longo do tempo, queremos aqui salientar alguns aspectos relevantes sobre a peculiar qualificação da madeira como material de construção por excelência, além de fonte viável de matéria-prima e de energia a relativo baixo custo.

É comum, ao se propor o uso da madeira como adequado à solução de inúmeros problemas, particularmente em construção civil, encontrar argumentos por vezes desavisados ou mal informados, ou até mesmo mal intencionados, de que o uso da madeira apresenta mais problemas que soluções. Dentre estes argumentos encontramos, por exemplo:

- A madeira é cara.

- A madeira apodrece e é atacada por cupim.

- A madeira é combustível e facilmente inflamável.

- A madeira é sujeita à grande retração e, consequentemente, fissuras.

- A exploração de madeira degrada o meio ambiente.

- Edificações de madeira duram pouco.

- As características das madeiras são inconstantes e imprevisíveis.

Analise-se objetivamente estes argumentos a partir da questão do meio ambiente.

Nosso País é, sem sombra de dúvidas, o mais bem dotado em termos de recursos florestais em todo o planeta. A Floresta Amazônica, a Mata Atlântica, o Pantanal Matogrossense, o Cerrado, os Manguezais e as zonas de reflorestamento conferem ao Brasil uma grande porcentagem das reservas florestais do mundo. É indiscutível haver nos dias de hoje uma exploração desenfreada, mal conduzida e que desperdiça estes recursos, mas ainda assim podemos considerá-los praticamente "inesgotáveis". Sendo as parcelas formadoras dessas massas verdes, e das madeiras 
por consequência, provenientes do ar atmosférico, da água e minerais do solo, e da luz solar, dos quais o Brasil é tão beneficiado, é possível admitir a hipótese, viável, de uma exploração permanente e auto-sustentada dos recursos florestais brasileiros.

Comparativamente à produção de cimento e de metais, causadoras de danos extensos e permanentes ao meio ambiente, consumindo ao mesmo tempo madeira como matéria prima e fonte de energia (leia-se carvão e lenha), a extração de toras de madeira das florestas pode ser acompanhada por um replantio paralelo que garanta ao longo do tempo a reposição das áreas exploradas, deixando-as em condições para uma nova fase de exploração racional.

Quanto ao fato incontestável de que as madeiras possuem características físicas e mecânicas variáveis e, sob certos aspectos, imprevisíveis, há a possibilidade destas variações serem estatísticamente previstas e determinadas, afim de serem levadas em consideração no uso da madeira.

Porém, não podemos aplicar às madeiras os mesmos valores e padrões de controle de qualidade admitidos para os concretos e os metais, cujos processos de produção são muito mais precisamente determinados, enquanto a produção de madeira na natureza é de certa forma aleatória, salvo em zonas de reflorestamento com manejo acompanhado.

Este porém é um argumento fortalecedor de uma posição favorável ao incentivo e aprofundamento de linhas de pesquisa a respeito de madeiras e de suas aplicações tecnológicas em nosso País.

O desconhecimento em relação às propriedades físicas e mecânicas das madeiras, bem como aos seus fatores de deterioração física e biológica, por exemplo a ação, combinada ou isolada, da umidade, do calor, de fungos e de insetos xilofágos, gera o que podemos denominar de preconceitos existentes em relação ao material. A 
madeira, uma vez submetida a tratamento adequado, pode perfeitamente obter grande resistência a estes agentes agressores.

Isso aliado a projetos, detalhamentos e manutenção bem elaborados e bem executados pode conferir às madeiras, nas suas diversas aplicações, um grau de funcionalidade, durabilidade, conforto e beleza comparáveis aos alcançados pelos concretos e pelos metais.

Podería-se ainda levar em conta, dentre outros, o fator segurança ao fogo, que nas edificações de madeira é sensivelmente maior que nas metálicas, por exemplo.

Quanto ao custo elevado da madeira, é ainda considerado principalmente a partir do custo de desdobro e de transporte. Se for realizada uma análise custo vs beneficio, a madeira já não estará em desvantagem relativa a outros materiais para muitas aplicações, e ainda assim esta desvantagem tende a diminuir com o aumento da oferta de mais e melhores projetos utilizando a madeira como matéria prima principal.

Para finalizar, é tecnicamente injustificada a posição na qual o uso da madeira tem sido mantida ao longo do tempo, tornando-se necessário um maior incentivo a seu uso, já que muitos problemas de ordem técnico-sócio-econômica poderiam ser solucionados de forma mais adequada com sua utilização.

\subsection{Madeira: suas aplicações tecnológicas}

Desde os primórdios da humanidade o uso da madeira tem sido ampliado e desenvolvido nas mais diversas atividades. Dos primitivos utensílios domésticos e de caça das idades pré-históricas até as modernas aplicações em grandes estruturas e na indústria de uma forma geral, passando pelo uso nas mais variadas manifestações artísticas e tecnológicas, hoje a madeira é sem sombra de dúvida um material 
essencial à manutenção da sociedade humana como a conhecemos. Senão veja-se algumas de suas aplicações.

A maioria das habitações humanas faz uso da madeira como material de construção. Seja como parte das estruturas principais das edificações, seja como estruturas secundárias ou mesmo equipamentos complementares, encontra-se a madeira sob a forma de vigas, pilares, pórticos, arcos, portas, janelas, pisos, paredes, forros, compondo a estrutura dos telhados, ou permitindo o detalhamento de alguma outra parte não menos importante.

Enfim, a maior parte das edificações residenciais não poderiam ser concebidas, pelo menos não a custo acessível, se não estivesse previsto em seus projetos o largo uso da madeira. Além disso, a madeira nas residências se torna indispensável na presença de móveis, utensílios domésticos e obras de arte.

Nas indústrias de transformação a madeira pode ser encontrada desde as siderurgias até às indústrias de papel e celulose, passando pelas indústrias de plásticos, química, medicamentos e de madeira compensada. Nas grandes estruturas pode-se encontrar telhados, arcos e pórticos que vencem grandes vãos, inimagináveis para muitas das estruturas de concreto armado.

Há pontes de madeira das mais variadas dimensões e soluções estruturais. Desde pontes de vigas simplesmente apoiadas, pontes de vigas contínuas, pontes em treliça, pontes em arco, em pórtico, pontes suspensas - pênseis ou estaiadas - no uso para passagem de pedestres ou de veículos, com estrutura principal em toras de madeira, madeira serrada, madeira compensada, madeira laminada colada, madeira laminada pregada, madeira laminada protendida ou combinações entre elas.

Fica claro então ser justificada a defesa do estudo aprofundado do uso da madeira em diversas aplicações tecnológicas, devendo-se sempre ter em mente a 
busca por melhores soluções estruturais, estéticas e de funcionalidade nos vários usos da madeira nas atividades humanas.

Neste trabalho apresenta-se alguns estudos em pontes de madeira, suas características, o estudo da superestrutura, particularmente quanto ao tabuleiro sobre o qual movimentam-se tanto pedestres quanto veículos. 


\section{Capítulo dois: A razão de ser deste estudo}

\subsection{Objetivos e justificativas}

A maioria das soluções adotadas no projeto e dimensionamento de tabuleiros de pontes de madeira utilizam arranjos estruturais cujo comportamento equivale ao de uma placa ortótropa. Este é o caso dos tabuleiros formados por postes de Eucalipto Citriodora solidarizados com aneis e dos tabuleiros de madeira laminada protendida.

Tais soluções já tiveram seu comportamento estrutural largamente estudado, existindo à disposição dos técnicos muitos processos construtivos levando em conta as condições de execução das pontes para as quais se destinam.

A possibilidade de viabilizar tabuleiros de pontes de madeira cujo arranjo estrutural possua comportamento equivalente ao de uma placa isótropa, e que permita um dimensionamento rápido e prático, bem como o desenvolvimento de processos construtivos eficientes e de fácil execução, levou à proposta de um tabuleiro formado por duas camadas compostas por peças de seção retangular, ortogonais entre si e a 45Errol Indicador não definido. em relação às bordas do tabuleiro, onde as peças de uma camada são solidarizadas às peças da outra pontualmente.

Pretende-se observar seu comportamento estrutural através de uma avaliação indireta da variação de sua rigidez à flexão com o aumento da quantidade de pontos de ligação. 
Serão examinados modelos pouco reduzidos de tabuleiro com o arranjo em questão, aqui chamado de "ortogonal", submetidos a ensaios de flexão sob ação de carregamentos variados e diferentes condições de vinculação dos apoios. Serão medidos os valores da superfície elástica em alguns pontos destes modelos de modo a permitir uma análise simplificada, porém criteriosa, primeiro da variação da rigidez com o acréscimo de pontos de ligação em um modelo utilizando pregos lisos de aço, em segundo lugar, a comparação entre o comportamento de um modelo pregado e outro utilizando cavilhas de madeira, e finalmente, do modelo de cálculo que melhor represente a configuração de pontos de solidarização mais eficiente, que aqui significa a capacidade de melhor absorver e transmitir esforços solicitantes, sendo examinada a possibilidade de comportamento de placa isótropa.

Tem-se a expectativa de que a conclusão deste trabalho lance luz sobre mais uma possibilidade de uso da madeira estrutural, estímulando o aprofundamento dos estudos de caracterização deste arranjo "ortogonal", bem como de processos construtivos apropriados à sua execução. 


\section{Capitulo três: Conhecimentos fundamentais}

\subsection{Propriedades físicas, de resistência e de elasticidade da madeira}

Enquanto material, a madeira pode ser definida como tipicamente porosa e descontínua, heterogênea e anisótropa. Estas características devem-se a muitos elementos que a formam e às estruturas internas não igualmente ordenadas que possui.

Além disso, a madeira pode ser considerada um material elasto-frágil, sendo seu comportamento na maioria das solicitações dividido em um intervalo de comportamento elástico-linear e um pequeno intervalo plástico, até alcançar a ruptura frágil.

Sua caracterização exige o estudo de diversas propriedades pelo menos ao longo de suas duas direções naturais de crescimento: axial - ou paralela às fibras - e transversal, nas direções dos raios medulares e das tangentes a seus anéis de crescimento. Estes estudos devem envolver tanto a estrutura microscópica da madeira quanto sua macroestrutura, e são referência obrigatória para quaisquer projetos envolvendo seu uso como material estrutural. Compreendem basicamente a umidade e a densidade, as resistências à tração, compressão e cisalhamento, paralelas e transversais à direção de crescimento das fibras da madeira, seu comportamento à flexão, torção e outros tipos de solicitação, estáticas e dinâmicas, bem como a relação entre elas e sua variação na espécie e entre espécies diferentes. 
No LaMEM, estes estudos tiveram início a partir de 1969 com Hellmeister, dando continuidade a estudos anteriormente iniciados no IPT.

Primariamente, as propriedades que mais importam no projeto $\mathrm{e}$ dimensionamento de pontes de madeira são: umidade e densidade, resistências à tração, compressão e cisalhamento, paralelos às fibras, as quais serão examinadas a seguir.

A variação da umidade na madeira pode implicar no desenvolvimento de condições favoráveis ao aparecimento de agentes deterioradores do material, tais como fungos apodrecedores e insetos xilófagos. A umidade da madeira varia com a temperatura e a umidade presente no ar atmosférico. Os primeiros estudos a respeito da umidade na madeira demonstraram este fato.

KOLLMANN (1951) apud HELLMEISTER (1973) propôs diagrama no qual é apresentada a variação da densidade aparente da madeira em função de sua umidade (Figura 3.1). Por meio de análise experimental, HELLMEISTER (1973) evidenciou a validade deste diagrama para as madeiras brasileiras.

Apresentou, ainda, informações segundo as quais a presença de água livre nos poros da madeira não altera sua resistência ou dimensões, porém a diminuição da água de impregnação faz com que ocorram variações significativas nas dimensões, chegando a causar o surgimento de fissuras, fendas e alteração nas propriedades de resistência e elasticidade.

Dentre as propriedades físicas necessárias à caracterização de madeiras, a densidade aparente é a mais importante, relacionada diretamente às propriedades de resistência e de elasticidade do material.

Tratando-se basicamente da relação entre a quantidade de massa e sua unidade de volume, a densidade aparente, juntamente com a umidade, influencia os valores da resistência da madeira. 


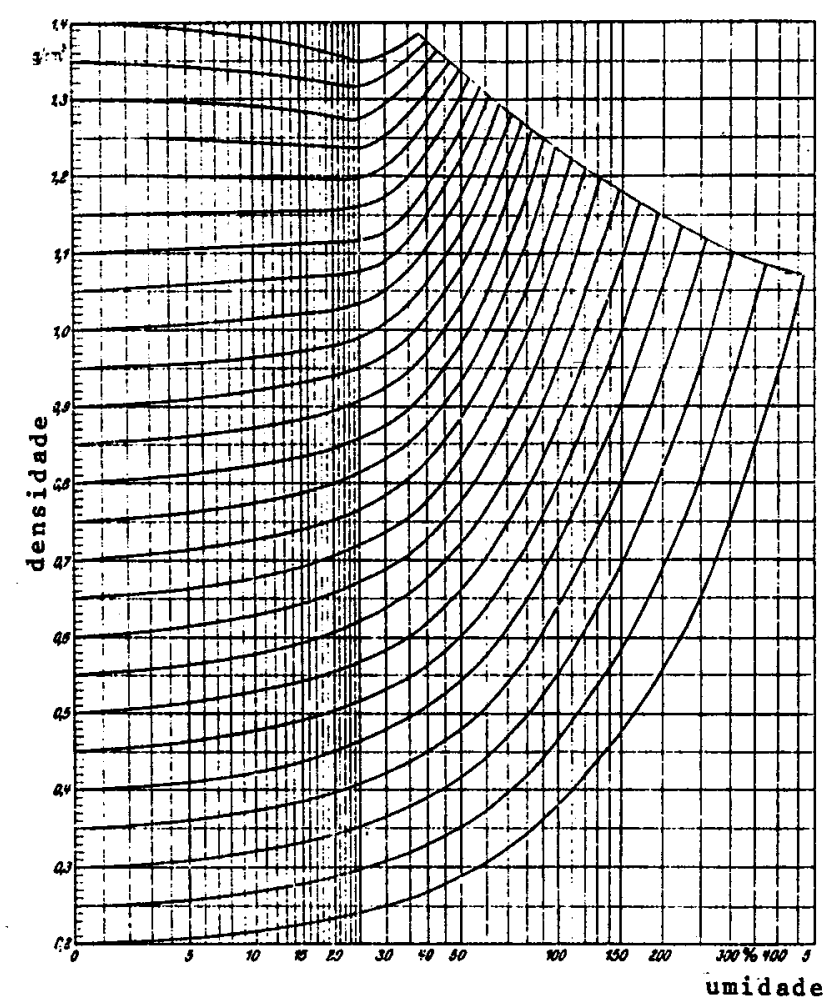

Figura 3.1: Diagrama Umidade da madeira vs Densidade. (KOLLMANN apud HELLMEISTER, 1973).

PIGOZZO (1982), MENDES (1984) E TANAAMI (1986) apresentaram estudos das variações das resistências à compressão, cisalhamento e tração paralelas às fibras, respectivamente, evidenciando dependência em relação à umidade e à densidade (Figura 3.2). Dos diagramas apresentados em seus trabalhos, observa-se que as resistências variam de $50 \%$ a $100 \%$ na compressão paralela e cisalhamento, e $20 \%$ a $50 \%$ na tração paralela para variações na umidade da madeira entre $10 \%$ e $30 \%$.

Como as pontes de madeira geralmente são executadas em locais onde a umidade do ar, e da madeira por consequência, está sujeita a grandes variações ao longo do tempo, torna-se de fundamental importância a compreensão destas propriedades para a previsão de seu comportamento, bem como para escolher a melhor técnica para sua manutenção. Além disso, a escolha de espécies com maior densidade pode garantir maior resistência às peças de madeira. 


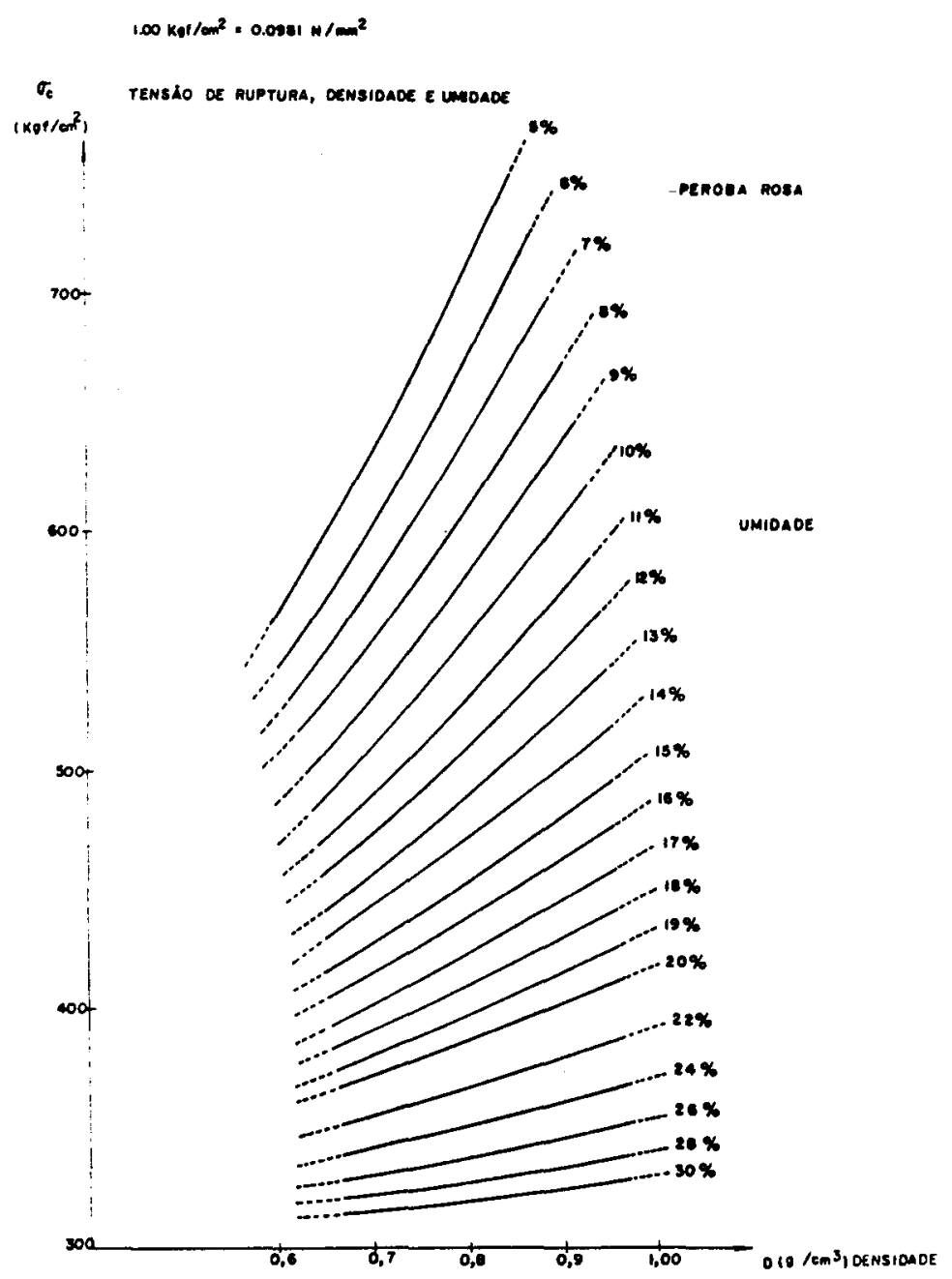

Figura 3.2: Diagrama de variação da resistência à compressão paralela às fibras com a umidade e a densidade. (PIGOZZO, 1982).

Em grande parte das estruturas de madeira os elementos que as compõem estão submetidos a esforços de tração e compressão paralelos às fibras. Seja na ocorrência de esforços axiais, seja nas solicitações de flexão, o conhecimento destas duas propriedades é fundamental ao uso de madeira estrutural.

CHAHUD (1985) apresentou informações que confirmaram a idéia de a madeira apresentar maior capacidade de resistência quando submetida a esforços de tração paralela às fibras. 


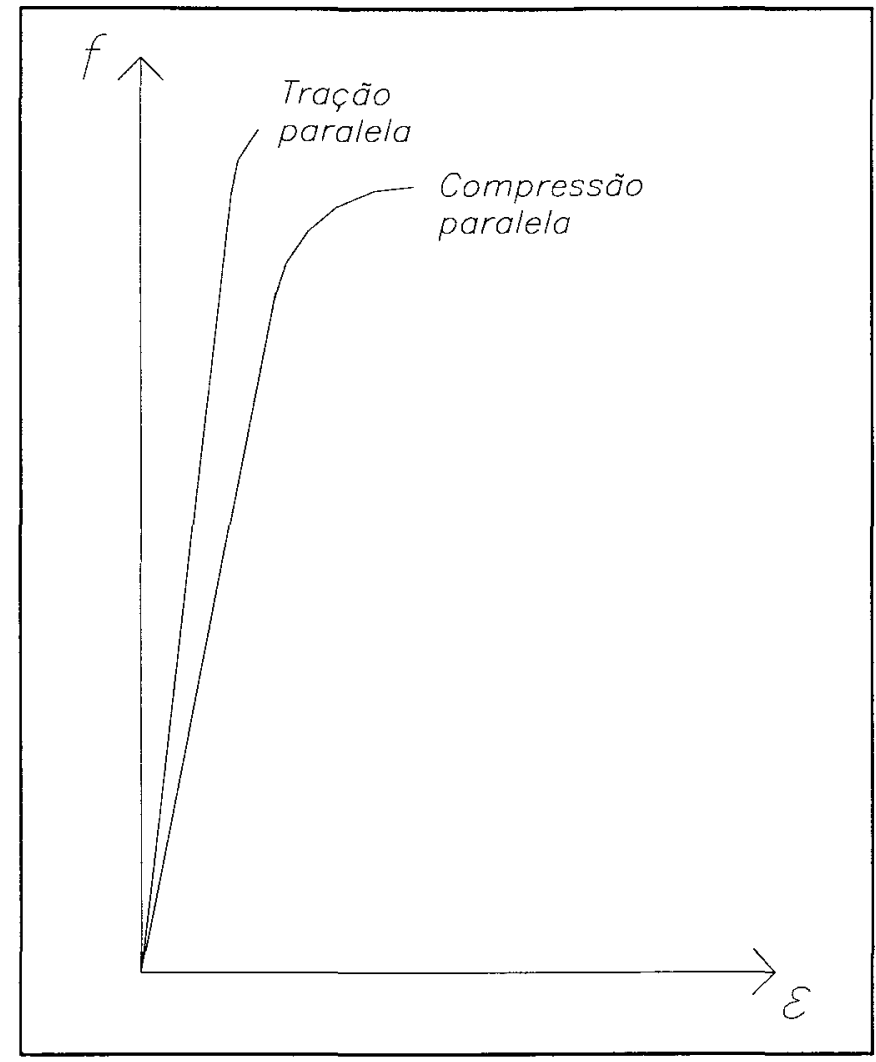

Figura 3.3: Comportamento típico da madeira submetida à tração $e$ compressão paralelas às fibras.

Observando um típico diagrama tensão vs deformação de um corpo de prova submetido à tração paralela às fibras, pode-se notar a ocorrência de um intervalo de escoamento plástico muito restrito, com ruptura frágil quase imediatamente após longo intervalo de comportamento elástico-linear (Figura 3.3).

No caso da compressão paralela às fibras, o intervalo de escoamento plástico é mais longo, após o qual ocorre a ruptura, sendo a tensão de ruptura inferior à tensão de ruptura à tração paralela às fibras.

O LaMEM tem adotado metodologia na qual a determinação dos valores das tensões de ruptura na compressão paralelas às fibras é feita a partir de ensaios em corpos de prova ligeiramente diferentes daqueles indicados pelo MB-26, e as tensões de ruptura na tração paralela às fibras em corpos de prova semelhantes aos adotados pela DIN 52188 (1979). 
A NBR-7190 indica a adoção de $15 \%$ do valor da tensão de ruptura na flexão para a tensão admissível à tração paralela às fibras.

O fenômeno da flexão em peças de madeira é assunto bastante extenso e não perfeitamente descrito. Dentro do intervalo de comportamento elástico-linear, a flexão em peças de madeira pode ser prevista pela Resistência dos Materiais. Porém a distribuição de tensões varia grandemente após ultrapassado o limite de proporcionalidade. O cisalhamento na flexão é ainda mais imprevisível, variando sensivelmente com o tipo e a posição do carregamento, sua intensidade e a proximidade da seção considerada em relação aos apoios.

PINTO (1983) estudando a flexão em peças de madeira apresentou modelos de distribuição teórica das tensões na flexão que refletem as fases de solicitação à tração e compressão paralelas em fibras opostas ao longo de uma mesma seção. Tais modelos são elasto-plásticos para a compressão e elasto-frágeis para a tração, caracterizando assim o comportamento da madeira submetida à flexão como um misto destes dois comportamentos (Figura 3.4). Mostra ainda que o cisalhamento na flexão não segue a previsão da Resistência dos Materiais (Figura 3.5), afastando-se rapidamente da previsão teórica à medida em que a seção considerada aproxima-se das regiões de carregamento ou das regiões dos apoios, não havendo ainda modelos teóricos que consigam prever o seu desenvolvimento.

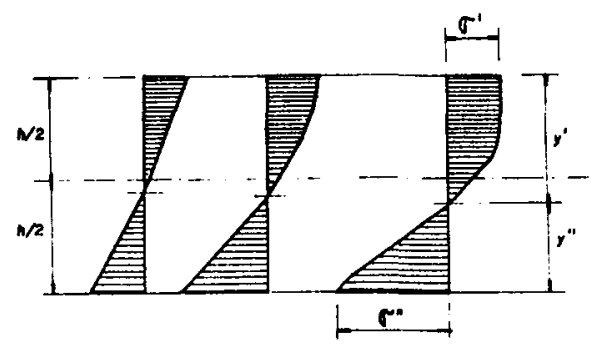

Figura 3.4: Distribuição das tensões de tração e compressão paralelas às fibras na madeira submetida à flexão. (BAUMANN apud KOLLMANN, 1951). 


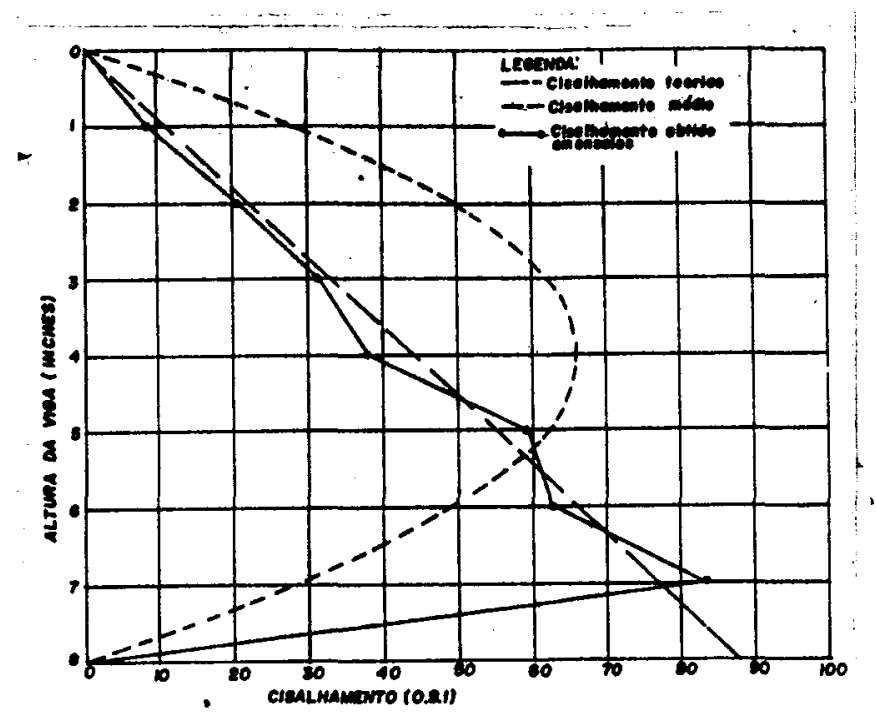

Figura 3.5: Distribuição das tensões de cisalhamento na madeira submetida à flexão. (COWAN apud PINTO, 1983).

Estas propriedades e suas relações de interdependência são as mais fundamentais para o projeto e dimensionamento de pontes de madeira.

\subsection{Ligações em peças estruturais de madeira}

As peças de madeira serrada comumente disponíveis no mercado possuem, independente de sua seção transversal, comprimentos máximos da ordem de 4 a $6 \mathrm{~m}$.

Nas estruturas de madeira simples, onde os vãos envolvidos não ultrapassem estas dimensões e onde as vinculações adotadas sejam simplesmente apoiadas (ou mesmo contínuas, mas com pequenos vãos), pode-se pensar na utilização de encaixes sem a necessidade do uso de ligações utilizando outros materiais na composição da estrutura.

Porém, não se pode pensar no projeto de estruturas de madeira maiores e mais complexas sem admitir o uso de elementos de ligação, até mesmo lançando mão de outros materiais que não a madeira. 
As ligações estruturais de peças de madeira tem o objetivo de, ao permitir a composição de duas ou mais peças, desde as mais simples até as tecnologicamente mais complexas, garantir a continuidade da estrutura, a transferência de esforços solicitantes, a superação das limitações nos vãos, e a promoção de soluções estruturais mais eficientes. Porém, mesmo as ligações melhor projetadas e executadas dificilmente conseguem atingir $100 \%$ de eficiência, entendida como a capacidade de a ligação transmitir as tensões, resultando em esforços nos elementos estruturais que se aproximem o máximo possível da previsão teórica. Não existem ainda modelos que descrevam com exatidão o comportamento das ligações.

Desse modo, o dimensionamento de ligações estruturais em peças de madeira deve ser baseado principalmente em resultados experimentais, os quais ainda são bastantes escassos.

\subsubsection{Uso de pregos}

CARRASCO (1983), em estudo sobre ligações pregadas, afirmou serem a espécie de madeira, o prego, e as condições de uso os principais fatores que afetam a eficiência destas ligações.

A espécie de madeira utilizada, com suas características físicas e mecânicas próprias, influencia o desempenho das ligações pregadas, havendo uma melhor distribuição de tensões na transferência dos esforços dos pregos para a madeira em espécies de maior densidade que em outras de densidade mais baixa, e também uma menor tendência ao fendilhamento em espécies de madeira mais macias ao contrário de espécies de maior dureza.

A utilização de pregos com diâmetros menores aumenta a tendência ao fendilhamento nas peças de madeira das ligações, a profundidade da penetração afeta a transferência de esforços entre as partes ligadas, e menores espaçamentos entres os 
pregos de uma mesma ligação pode induzir direções preferenciais de fendilhamento na madeira das ligações.

CARRASCO (1983) apresentou expressões e disposições construtivas fixadas por normas de diversos países, as quais foram examinadas frente a resultados de ensaios de 47 corpos de prova executados em Peroba Rosa, com dimensões variadas e utilizando pregos de vários tipos.

Seus resultados permitiram avaliar a adequabilidade daquelas expressões e disposições construtivas, bem como a elaboração de tabelas para o dimensionamento de ligações pregadas, obtendo a partir de regressão uma expressão para a carga admissível no prego.

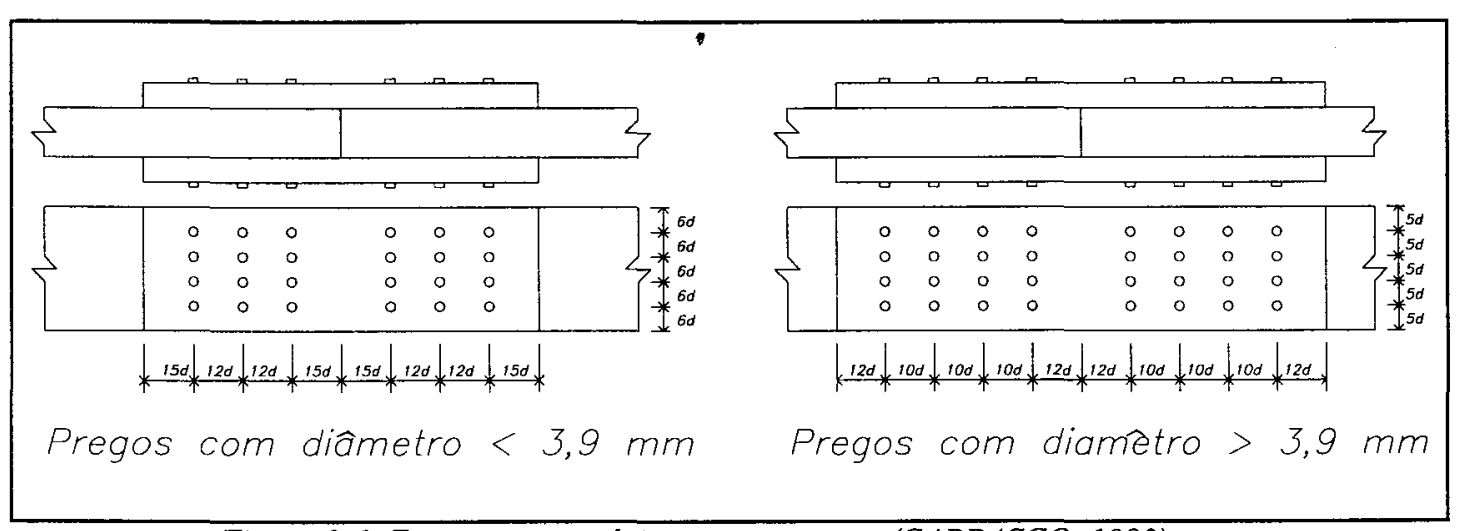

Figura 3.6: Espaçamento mínimo entre pregos. (CARRASCO, 1983).

FUSCO \& ALMEIDA (1989) apresentaram uma descrição do comportamento das ligações pregadas visando a aplicação do conceito de Estados Limites a estas ligações.

Seus ensaios demonstraram ser a ruptura destas ligações uma ruptura plástica, caracterizada basicamente pelo surgimento de deformações excessivas, antes da ruína propriamente dita. 
O dimensionamento de ligações é usualmente feito considerando o comportamento do prego como rígido, e o da madeira e da ligação, sob as cargas de projeto, dentro do intervalo de comportamento elástico linear, antes de atingir o seu limite de proporcionalidade, considerado igual ao da madeira utilizada sob a ação de compressão paralela às fibras.

ALMEIDA \& FUSCO (1992) apresentaram proposta de dimensionamento das ligações pregadas e parafusadas baseado no Método dos Estados Limites, visando ajuste da NBR 7190 neste sentido, onde concluíram ser ainda necessárias calibrações das cargas limites destas ligações por meio de ensaios em corpos de prova.

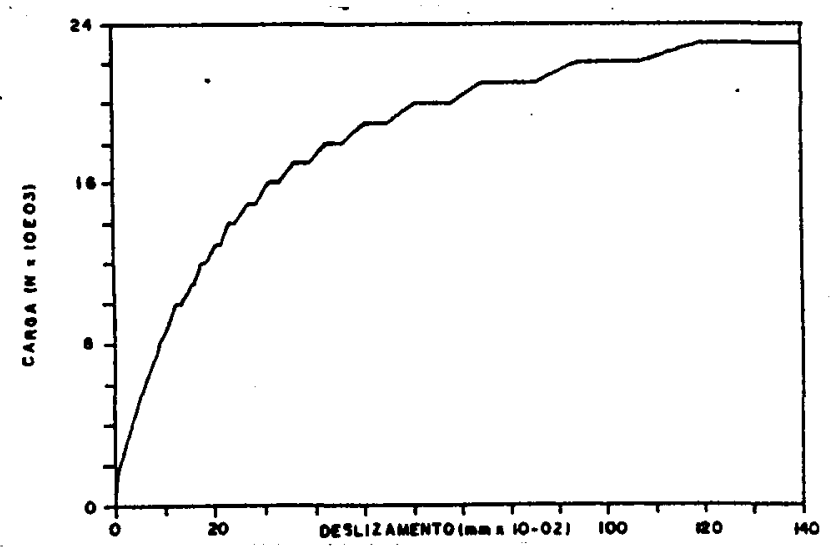

Figura 3.7: Comportamento de ligações pregadas. (FUSCO \& ALMEIDA, 1989).

\subsubsection{Uso de cavilhas}

PIEDADE (1972) ensaiou corpos de prova de ligações cavilhadas de Peroba Rosa e Pinho do Paraná à compressão paralela e compressão normal às fibras. As cavilhas utilizadas eram de Eucalipto Citriodora. 542 corpos de prova foram ensaiados com uma única cavilha, e 144 com mais de uma cavilha ou tarugo. Os 
resultados dos ensaios de ligações com mais de uma cavilha evidenciaram perda de resistência com o aumento da quantidade de cavilhas. Sugeriu expressões para obter a carga admissível das ligações com uma ou mais cavilhas.

GESUALDO (1982) apresentou estudo experimental de ligação de peças de madeira por meio de cavilhas partidas. Na preparação dos componentes dos corpos de prova, bem como sua montagem, foram adotadas soluções graciosamente simples e práticas. Em seu estudo, foram analizados os comportamentos destas ligações sob a ação de esforços de tração e compressão paralela às fibras, e flexão, nos quais a ruptura da ligação ocorreu invariavelmente nas cavilhas, demonstrando poder ser este elemento considerado rígido, ou seja, com a ruptura ocorrendo apenas na peça ligada, somente se seu diâmetro for suficientemente grande e sua densidade maior que o da madeira utilizada nas peças ligadas, de modo que a ruptura não se dê por flexão do conector.

\subsubsection{Pregos vs cavilhas - comportamento comparativo}

As ligações por meio de cavilhas, quanto à deformabilidade, apresentam desempenho estrutural inferior frente a ligações pregadas. Porém, a situação se inverte quando se trata de considerar o fator durabilidade e resistência à ação de ambiente agressivo.

A grande deficiência da ligação pregada está no uso de pregos lisos, pois sob a ação de carregamentos dinâmicos, principalmente na flexão, existe uma tendência a ocorrer um afrouxamento do prego no furo e consequente arrancamento.

Esta dificuldade pode ser reduzida pela adoção de pregos com ranhuras, roscas ou mossas que aumentem o atrito entre a madeira e o prego. Se por um lado o uso de cavilhas aumenta a durabilidade e, por que não?, a beleza das ligações estruturais, por 
outro apresenta dificuldades frente ao fenômeno de retração diferenciada entre a madeira das cavilhas e a madeira das peças ligadas.

É aconselhável o uso de cavilhas com densidade maior que a densidade da madeira utilizada nas peças ligadas. As madeiras mais densas tendem a possuir coeficientes de retratibilidade menores, e consequente estabilidade dimensional maior que as madeiras menos densas.

Este problema se coloca como da maior importância nas ligações com cavilhas, levando a um aumento no diâmetro dos furos que contêm as cavilhas e uma redução em seu desempenho estrutural. Este fenômeno ainda não fọi suficientemente estudado.

Há, ainda, o problema das deformações das ligações estruturais. GESUALDO (1987) apresentou estudo experimental onde comparou o desempenho de modelos estruturais com ligações feitas por parafusos e através de cavilhas, onde constatou ser a rigidez dos modelos menor que a do modelo teórico, e menor a rigidez do modelo cavilhado frente ao modelo parafusado. É possível supor que esta comparação pode ser feita de forma análoga entre estruturas pregadas e estruturas cavilhadas, independente do sistema estrutural considerado (vigas, pórticos, arcos, placas, etc.), guardadas as diferenças.

Conclui-se então ser necessária a caracterização destes parâmetros em vários corpos de prova, com condições de carregamento, umidade, densidade e quantidade de ligações variadas, afim de se poder prever com maior exatidão o comportamento destas ligações e proceder seu dimensionamento com maior critério. 


\section{Capitulo quatro: Sobre pontes de madeira}

Nos Capítulos quatro e cinco buscou-se fundamentar a experimentação e a análise de dados a partir de trabalhos que abordassem aspectos do comportamento da madeira estrutural e de tabuleiros para pontes de madeira. Tal metodologia justificase diante da limitada disponibilidade de trabalhos diretamente relacionados ao tema desta Dissertação. Aproveita-se aqui a oportunidade de se resgatar um pouco da história do desenvolvimento da linha de pesquisa em pontes de madeira no SETLaMEM.

\subsection{Pontes: algumas definições}

Dentre as estruturas de maior importância para o desenvolvimento da humanidade ao longo da História, as pontes se apresentam entre as mais belas e complexas.

Desde um simples tronco de árvore colocado sobre um pequeno riacho, até os mais avançados sistemas de pontes múltiplas combinadas, sua função de unir locais sem ligação natural entre si ainda causa espanto e admiração, comovendo até as mentes mais despreparadas por sua beleza e complexidade, ou rudeza e simplicidade.

FREITAS (1978) define a ponte como "uma obra destinada a manter a continuidade de uma via de comunicação qualquer, através de um obstáculo natural ou artificial, com a característica de não interromper totalmente esse obstáculo". Estas vias de comunicação podem ser rodovias, ferrovias, vias de pedestres, etc., 
podendo ser citados como obstáculos naturais os rios, lagos, depressões, etc. e como obstáculos artificiais outras vias de comunicação, canais e lagos artificiais.

LEONHARDT \& MÖNNIG (1979) apresentaram as pontes como constituídas de duas partes básicas: a superestrutura e a infraestrutura. A primeira compreende a estrutura da ponte propriamente dita, a segunda refere-se a um conceito coletivo que compreende os encontros, os pilares, os apoios, etc.

Por sua vez, PFEIL (1983) apresenta as pontes como formadas por três partes básicas bem distintas: a superestrutura, a mesoestrutura e a infraestrutura.

Compõem a superestrutura das pontes, na ordem de recebimento e transferência de esforços, o tabuleiro, as transversinas, as longarinas, as vigas de rigidez transversais, e as vigas de rigidez longitudinais. Pode-se ainda incluir, no caso das pontes suspensas, os tirantes e cabos dos sistemas de suspensão, e, no caso das pontes protendidas, os cabos e as ancoragens do sistema de protensão.

A mesoestrutura é composta basicamente das torres de suspensão, aparelhos de apoio e pilares, enquanto a infraestrutura compreende os encontros, os blocos e sapatas de fundação, estacas, tubulões, e as peças de ligação destes elementos entre si e com a mesoestrutura.

A maior parte das pontes de madeira se enquadra dentro da segunda definição, sendo a infraestrutura mais comumente executada em concreto armado, e com menor frequência em madeira, e a superestrutura e a mesoestrutura em madeira, podendo esta última ser de perfis de aço ou de concreto armado.

A superestrutura tem a função de receber os carregamentos atuantes sobre a ponte, resistindo aos esforços solicitantes por eles produzidos, e transmiti-los à mesoestrutura. O tabuleiro recebe as cargas oriundas do tráfego sobre a ponte, e as transmite para as vigas de rigidez transversal e longitudinal através das transversinas e longarinas. As vigas de rigidez transversais transmitem suas cargas às vigas de 
rigidez longitudinais, que, por sua vez, as transmitirão à mesoestrutura, diretamente (pontes em viga, treliça), ou por meio de tirantes e cabos (no caso das pontes suspensas).

A mesoestrutura recebe os esforços transmitidos pela superestrutura, resistindo a eles e aos esforços oriundos de carregamentos atuantes diretamente sobre ela (vento, água em movimento, etc.), e transmite-os à infraestrutura.

A infraestrutura recebe os esforços transmitidos pela mesoestrutura, resiste a estes e aos esforços resultantes dos aterros de acesso, quando houver, e os transfere ao solo de modo a impedir que sejam transmitidos aos outros elementos formadores das pontes (tal é o caso dos encontros).

As pontes podem ser classificadas de várias maneiras. São citadas aqui as 4 de maior relevância: classificação quanto à finalidade, ao material, ao tipo estrutural, e ao vão.

Pontes podem ser de uso rodoviário, ferroviário, para pedestres (caso em que são denominadas passarelas), e mistas. Podem servir ao suporte de tubulações, canais de navegação, etc.

A classificação quanto ao material refere-se ao material predominante na composição da ponte, notadamente da superestrutura, podendo ser de madeira, pedra, concreto armado ou protendido, ou metálica.

Segundo o tipo estrutural, encontram-se pontes em viga simplesmente apoiada, viga contínua, pórtico, treliça, arco, tabuleiro laminado (pregado, colado, protendido, etc.) e suspensas, bem como pontes formadas pela composição destes tipos estruturais (Figura 4.1).

Quanto aos vãos, as pontes de madeira podem ser de pequenos, médios e grandes vãos, não havendo consenso quanto ao vão definido para cada classe. 


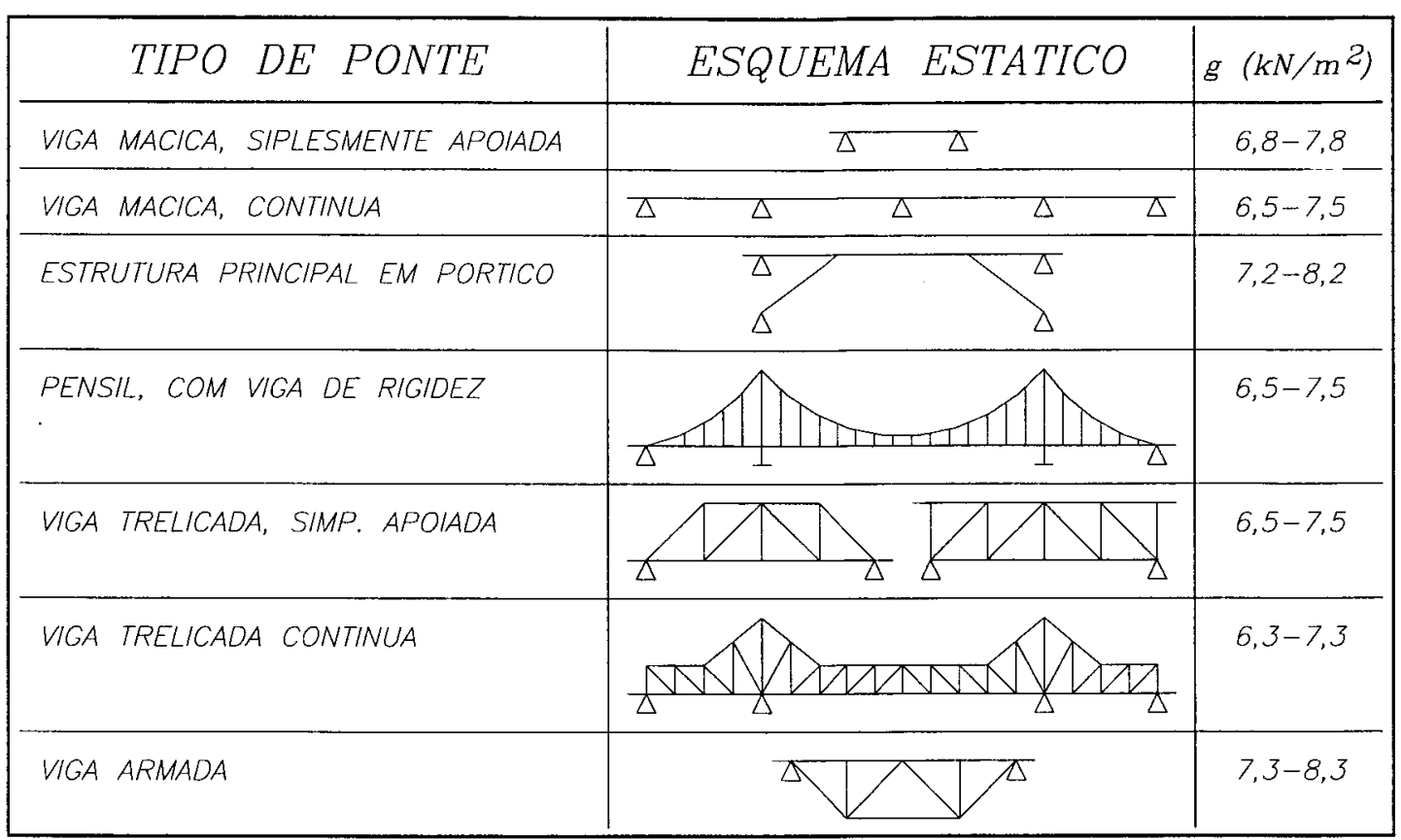

Figura 4.1: Alguns tipos estruturais de pontes de madeira.(LOGSDON, 1983).

A compreensão das várias classificações existentes para as pontes tem sua importância para o projetista no tocante às soluções adotadas nos projetos, onde, por exemplo, o vão livre determinará a escolha do sistema estrutural mais adequado e o processo construtivo necessário à sua execução.

\subsection{Pontes de madeira: trabalhos do SET-LaMEM}

O campo de aplicação das madeiras é muito amplo, variando desde o seu uso isolado até à combinação com outros materiais em estruturas e edificações em geral. Habitações, galpões, arcos, pórticos, silos, pontes, etc., a possibilidade de uso da madeira em construcão civil é imensa.

Já foi enfatizada a necessidade de se aprofundar e ampliar as pesquisas a respeito das madeiras e suas aplicações tecnológicas no Brasil. O conhecimento do material, por natureza poroso (descontínuo), heterogêneo e anisótropo, de ocorrência diversificada na natureza e com propriedades variáveis de uma espécie a outra, por si 
só justificaria a necessidade de pesquisas que visem sua caracterização e aplicação tecnológica.

No caso do estudo das pontes, o LaMEM muito tem contribuído no tocante à ampliação do uso da madeira em nosso País. Já no início da década de 1970 existem trabalhos dos cursos de graduação oferecidos pelo SET-LaMEM direcionados ao dimensionamento e detalhamento das pontes de madeira (ASSAN et al.,1970; BALLULA et al., 1970).

HELLMEISTER \& OLIVEIRA (1975) apresentaram memória de cálculo para uma ponte de madeira em pórtico, sobre o Ribeirão dos Porcos - SP, com tramo central, 2 tramos internos e 2 tramos extremos de $6 m, 4,5 m$ e $3 m$ de vão livre, respectivamente, utilizando postes de Eucalipto Citriodora.

HELLMEISTER, CALIL \& LAHR (1977) desenvolveram projeto para a construção de uma ponte pênsil de madeira sobre o Rio Tietê (Figura 4.2), composta de tabuleiro, vigas de rigidez e torres em postes de Eucalipto Citriodora. O cálculo e dimensionamento seguiu a Teoria Elástica para o cálculo de pontes pênseis, conforme apresentada em GRAVINA (1947).

Após a construção da ponte, foi realizada uma prova de carga na qual as flechas resultantes mostraram-se coerentes com o cálculo teórico.

A partir deste trabalho, tem sido desenvolvida no LaMEM toda uma linha de pesquisas a respeito de pontes de madeira.

Têm sido realizadas pesquisas a nível de iniciação cientifíca que geraram subsídios para outras mais amplas, como pode-se ver em SHIOGA (1978), DIAS (1982), BENINI (1988), GODOI (1988, 1989), MORAES (1990) e MONGES (1990), que deram origem a trabalhos de maior importância, ainda hoje em andamento no LaMEM. 
HELLMEISTER (1978) propôs o uso de postes de Eucalipto Citriodora para a composição de vigas e tabuleiros nos quais a conicidade natural dos postes é compensada dois a dois, e as peças são solidarizadas por meio de anéis metálicos partidos ao longo do comprimento, obtendo-se elementos compostos de elevada rigidez.

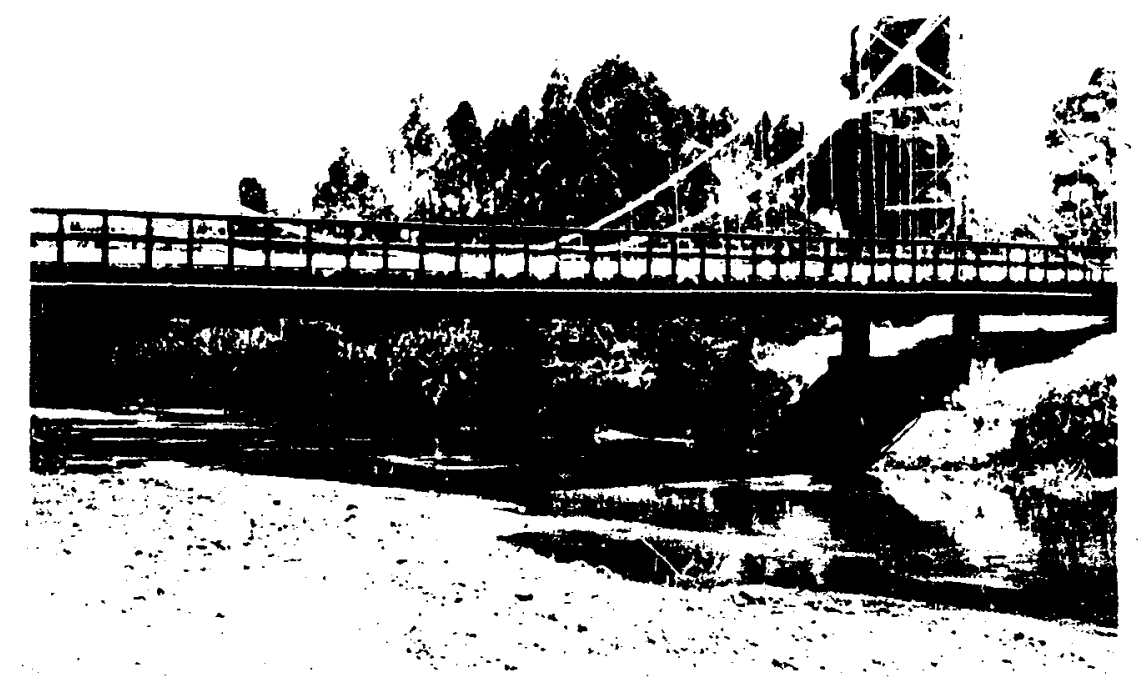

Figura 4.2: Ponte pênsil sobre o Rio Tietê, São Miguel Paulista - SP. (HELLMEISTER, CALIL \& LAHR, 1977).

SZÜCS (1979) propôs o uso de vigas treliçadas contínuas compostas por barras unidas através de ligações por anéis metálicos. Apresentou projeto detalhado de uma treliça continua composta por três tramos com $10 \mathrm{~m}, 20 \mathrm{~m}$ e $10 \mathrm{~m}$, respectivamente, aplicada ao projeto de uma ponte rodoviária Classe 36 da antiga NB-6.

HORTEGAL (1979) apresentou a aplicação de duas teorias consagradas para o cálculo de pontes pênseis: Teoria Elástica e Teoria dos Deslocamentos para o projeto de uma ponte pênsil Classe 36 composta por dois tramos extremos com $20 \mathrm{~m}$ e um central com $40 m$ de vão livre, cuja viga de rigidez e as torres foram propostas em madeira laminada e colada. Propôs e montou o ensaio de um modelo reduzido que foi levado a efeito por DIAS (1983), no qual foram medidas flechas na viga de rigidez a 
partir da aplicação de cargas concentradas e cargas distribuídas em diversos pontos. Os resultados deste ensaio apresentaram dispersão em relação à Teoria Elástica, demonstrando ter havido falhas nas condições de montagem do modelo.

LOGSDON (1982) desenvolveu belíssimo trabalho apresentando dados essenciais para o projeto e ante-projeto de pontes de madeira, a partir dos quais são exemplificados casos de pontes rodoviárias de madeira utilizando postes de Eucalipto Citriodora solidarizados por anéis metálicos em três tipos estruturais básicos: Viga simplesmente apoiada, viga contínua e pórtico.

DIAS (1987) apresentou trabalho experimental no qual foi avaliada a distribuição transversal de cargas em pontes de madeira. Os resultados mostraram-se satisfatórios em relação à previsão teórica, utilizando analogia de grelha e admitindo a continuidade das peças.

MATTHIESEN (1987), juntamente com uma ampla revisão bibliográfica, apresentou resultados de ensaios de modelos de placas maciças compostas por peças de madeira serrada e placas nervuradas compostas por postes de Eucalipto Citriodora, nas quais as peças foram solidarizadas por meio de anéis metálicos partidos.

NASCIMENTO (1993) realizou estudo no qual são apresentados aspectos concernentes à estrutura e construção de pontes pênseis de madeira, no qual é feita uma análise experimental de um tabuleiro de madeira laminada protendida composto por peças comerciais de seção $6 \times 16 \mathrm{~cm}^{2}$.

CALIL, LAHR \& DIAS (1993) publicaram trabalho no qual são apresentados aspectos do projeto e da construção de uma passarela pênsil sobre o Rio Piracicaba, na cidade de Piracicaba-SP, cujo tabuleiro é composto por duas camadas de peças de madeira serrada ortogonais entre si posicionadas a $45^{\circ}$ em relação ao eixo da ponte, sendo as transversinas e as vigas de rigidez em treliças compostas por peças de 
madeira serrada ligadas por meio de parafusos metálicos e as torres constituídas por perfís metálicos.

PRATA (1995) desenvolveu estudos entre os quais são apresentados vários sistemas construtivos e métodos de análise e dimensionamento de pontes de madeira. Enfatizou o estudo de pontes de madeira laminada protendida, tendo organizado informações permitindo a caracterização de parâmetros elásticos necessários ao projeto destas pontes, levando a efeito estudo experimental para uso da espécie Eucalipto Citriodora. São apresentadas, ainda, diretrizes de projeto destas pontes segundo métodos consagrados internacionalmente.

Todos estes trabalhos procuraram alertar para a necessidade de preceder a utilização da madeira por um tratamento preservativo e/ou impermeabilizante adequado que garanta ao material uma maior durabilidade e resistência a agentes agressivos.

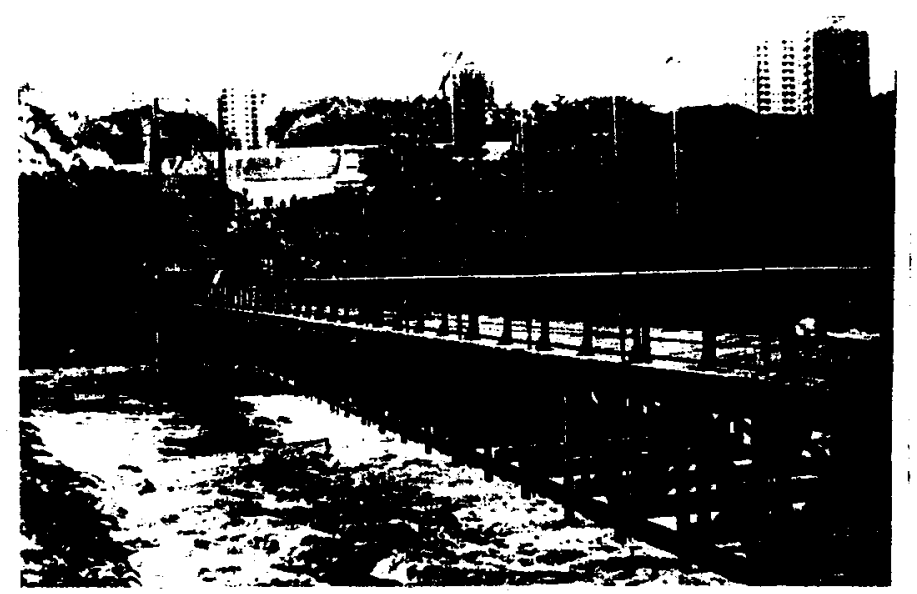

Figura 4.3: Passarela pênsil sobre o Rio Piracibaca, Piracicaba - SP. (CALIL, LAHR \&DIAS, 1993). 


\section{Capítulo cinco: Tabuleiros de pontes de madeira}

Tabuleiros de pontes, de uma forma geral, podem ser admitidos como placas retangulares, dado as ações de importância no seu estudo, como peso próprio, carga móvel de veículos e de pedestres, atuarem perpendicularmente à sua superfície e sua espessura sendo muito inferior às dimensões das bordas.

No caso dos tabuleiros de pontes de madeira, as configurações possíveis de serem adotadas são várias, utilizando tanto postes roliços como peças de madeira serrada facilmente encontrados no mercado.

\subsection{Arranjos ortótropos}

HELMEISTER (1978) propôs o uso de tabuleiros transversais formados por pequenos postes de Eucalipto Citriodora submetidos a tratamento preservativo. Apontou a necessidade de fixação adequada dos postes às vigas longitudinais, sugerindo o contraventamento entre as peças do tabuleiro pela utilização de tiras de aço de 4,7 $\mathrm{mm} \times 50,8 \mathrm{~mm}$ de seção transversal ao longo da direção longitudinal da ponte.

Concluiu que a regularização mais adequada à superfície de rolamento deveria ser feita pela adoção de uma camada de concreto magro sob outra de concreto asfáltico. Tal composição leva a uma melhor distribuição das cargas sobre a pista de rolamento e aumento da rigidez do tabuleiro. 


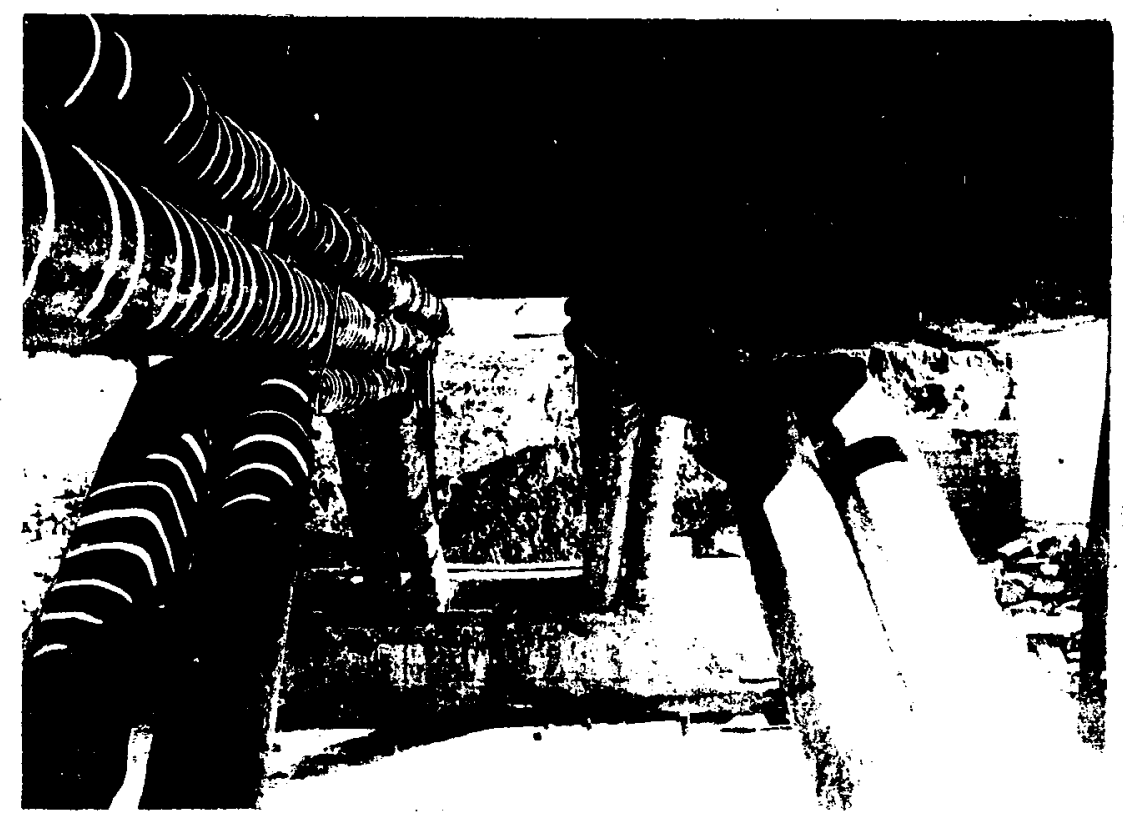

Figura 5.1: Tabuleiro de postes de Eucalipto Citriodora. (HELLMEISTER, 1983).

LOGSDON (1982) apresentou o dimensionamento de tabuleiros de pequenos postes de Eucalipto Citriodora, seguindo as idéias apresentadas por HELLMEISTER (1983). No seu cálculo foi admitido que o comportamento do tabuleiro é uma composição do comportamento de várias vigas formadas por dois postes colocados lado a lado, tendo sido este número determinado a partir de indicações da NBR 7190, item 15.

DIAS (1987), ao contrário do estipulado pela NBR 7190, sobre a repartição transversal de cargas entre várias vigas proporcionada pelas peças dos tabuleiros nas pontes de madeira, propôs a aplicação de analogia de grêlha à análise teórica da distribuição destas cargas, admitindo a continuidade das peças do tabuleiro. Nesta analogia, as longarinas da grelha são as vigas principais da ponte e as transversinas obtidas a partir do tabuleiro considerado como contínuo. 
Esta proposta foi confrontada a ensaios com um modelo com 4 vigas principais de postes de Eucalipto Citriodora sobre os quais apoiava-se o tabuleiro, também formado pela composição de postes de Eucalipto Citriodora, solidarizados entre si por meio de fitas de aço de $4,7 \mathrm{~mm} \times 50,8 \mathrm{~mm}$ de seção transversal (HELLMEISTER, 1978), tendo esta solidarização sido feita sobre a linha das vigas principais.

Os ensaios constituíram de flexão do conjunto sob a ação de cargas concentradas, simulando a ação de uma roda e um eixo da NBR 7188, onde foram medidas flechas e deformações, havendo "ótima concordância entre os resultados teóricos e experimentais".

MATTHIESEN (1987) apresentou estudo no qual avaliou o desempenho de modelos de 3 tipos de tabuleiros de pontes de madeira: placas maciças de madeira, tabuleiros compostos por vigas de madeira serrada, e tabuleiros constituídos por postes de Eucalipto Citriodora, na escala 1:4, estes últimos tendo suas peças componentes solidarizadas através do uso de anéis metálicos partidos.

Nos primeiros ensaios, utilizou tábuas de madeira serrada, simulando o comportamento de hipotéticas pontes de tabuleiro maciço de madeira, com dimensões $20 m \times 9,6 m \times 0,85 m$, biapoiadas, sob a ação de carga concentrada, a partir de dois modelos reduzidos de $60 \mathrm{~cm} \times 28,8 \mathrm{~cm} \times 2,5 \mathrm{~cm}$ e $100 \mathrm{~cm} \times 20 \mathrm{~cm} \times 4$ $\mathrm{cm}$, nas escalas $1: 33,33$ e $1: 20$, respectivamente.

Dando sequência a este experimento, foram construídos modelos de tabuleiros compostos por vigas de Peroba Rosa com dimensões $500 \mathrm{~cm} \times 16 \mathrm{~cm} \times 6 \mathrm{~cm}$, de modo a representar, na escala $1: 4,1 / 2$ e 1 faixa de tráfego de uma ponte com comprimento de $20 \mathrm{~m}$ e espessura de $0,64 \mathrm{~m}$.

Estes modelos foram ensaiados em condições de solidarização e carregamento variadas. Primeiro foram ensaiados modelos representativos de uma faixa de tráfego 
compostos por 10 vigas solidarizadas com barras de aço espaçadas de $100 \mathrm{~cm}$. Após ensaiado o modelo, o espaçamento entre as barras foi reduzido para $50 \mathrm{~cm}$ e a sequência de ensaios repetida.

Em seguida, as barras foram substituídas por anéis metálicos partidos, tendo sido as barras do modelo anterior utilizadas construtivamente para unir as peças, sem colaborar para um aumento da rigidez do tabuleiro. Estes três modelos foram submetidos à ação de cargas concentradas em vários pontos da direção de tráfego, tendo sido variadas ainda as condições de apoio.

Após estes ensaios, foram acrescentadas 9 vigas ao último modelo ensaiado, de modo a representar uma faixa de tráfego. Sobre este novo modelo foi aplicada uma composição de cargas concentradas em vários pontos da direção de tráfego, simulando um eixo do trem-tipo classe 36 da antiga NB-6.

Ensaiou também modelos de tabuleiros na escala 1:4, com dimensões $500 \mathrm{~cm} x$ $98 \mathrm{~cm}$ e formados por postes de $\phi$ médio $=14 \mathrm{~cm}$ solidarizados por meio de anéis metálicos partidos. Um dos modelos tinha seção transversal simples e outro seção transversal nervurada. Ambos foram ensaiados sob ação de carga concentrada variável ao longo da seção e da direção de tráfego da ponte.

Em todos os pontos foram medidas as flechas e determinadas as linhas elásticas, sendo que os modelos de placa maciça, tabuleiro composto por 19 vigas, e tabuleiro nervurado de postes de Eucalipto Citriodora foram carregados até alcançar a ruptura.

Dos resultados obtidos observou que os modelos de pontes de tabuleiro maciço de madeira "apresentaram comportamento comparável com o de placas ortotrópicas", e o resultado dos ensaios dos modelos de tabuleiros constituídos por vigas serradas e por postes de Eucalipto Citriodora, de seção simples ou nervurada, solidarizados por anéis metálicos partidos "evidenciou a viabilidade de seu 
comportamento tipo placa ortotrópica", adequado para a constituição de uma ponte de madeira.

NASCIMENTO (1993) ensaiou modelo de tabuleiro de madeira protendida com dimensões $1,60 m \times 2,40 m$ composto por lâminas de seção $6 \mathrm{~cm} \times 11 \mathrm{~cm}$. Para promover a protensão transversal foram utilizadas barras de aço comum, obtendo assim uma placa de madeira de $11 \mathrm{~cm}$ de espessura.

As peças utilizadas na montagem do modelo foram escolhidas a partir de 37 vigas disponíveis no LaMEM, submetidas à classificação não destrutiva das peças, optando-se por aquelas que apresentaram módulo de elasticidade longitudinal

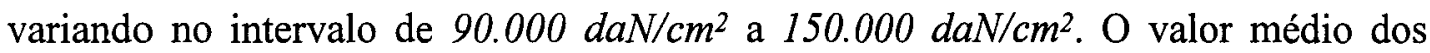
módulos de elasticidade das peças foi igual a $123.098 \mathrm{daN} / \mathrm{cm}^{2}$, e o desvio padrão igual a $22.670 \mathrm{daN} / \mathrm{cm}^{2}$.

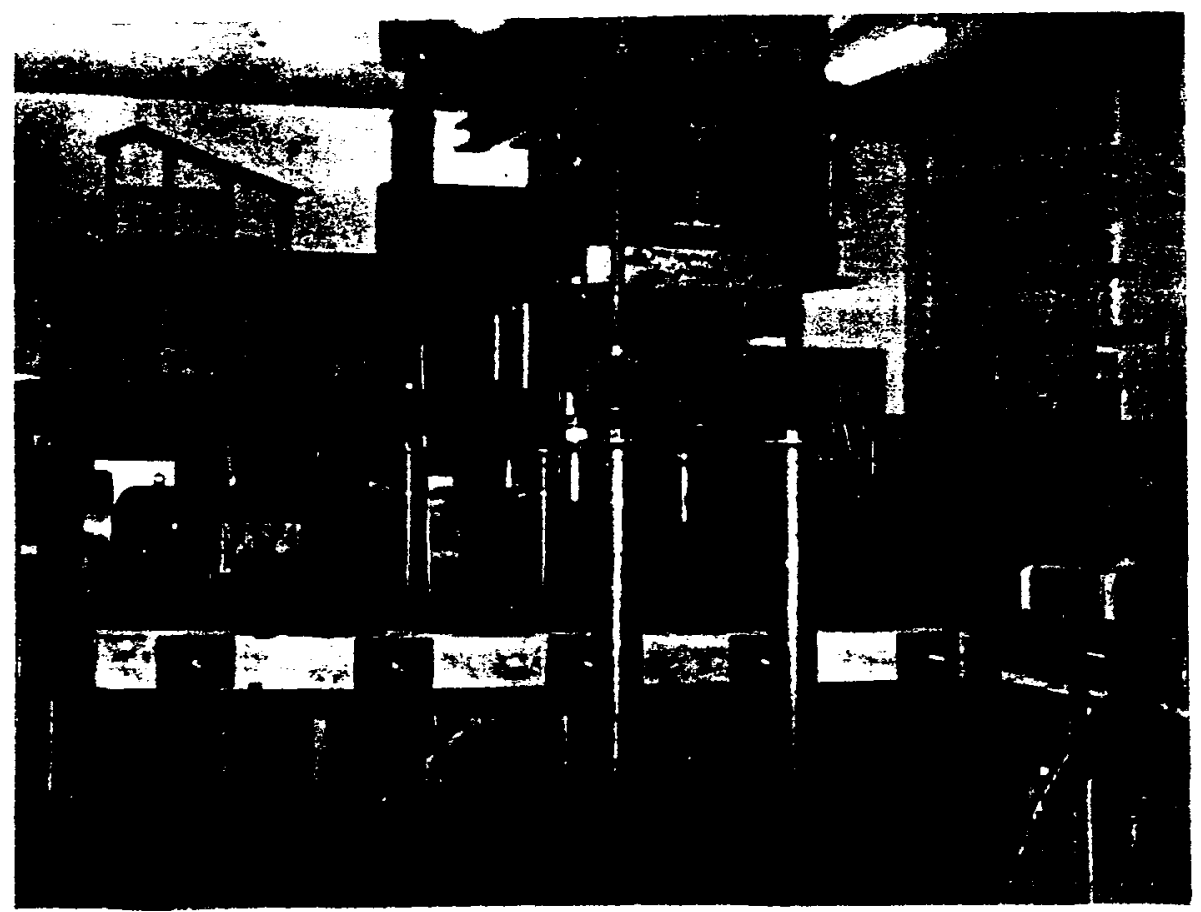

Figura 5.2: Modelo de tabuleiro de madeira laminada protendida. (NASCIMENTO, 1993). 
Sob a ação de carregamentos variáveis, foram medidas flechas e deformações em vários pontos do tabuleiro, sendo ao final alcançada a ruptura sob a ação de carga concentrada na região central do tabuleiro, ruptura esta caracterizada pelo início da ruptura da peça central do tabuleiro.

Concluiu que a aplicação manual da protensão contribuiu significativamente para dificultar a análise de tensões de tração nas barras, em função de problemas na instalação de extensômetros elétricos, admitindo a redução destes problemas pela substituição dos extensômetros por células de carga, permitindo inclusive avaliar perdas de protensão nas barras ao longo do tempo. Apesar destes inconvenientes, "o efeito da protensão foi significativo para o comportamento de placa", e assim sendo, "as expectativas iniciais de comportamento de placa ortotrópica foram confirmadas na experimentação, dado o desempenho do modelo utilizado".

PRATA (1995), visando caracterizar o comportamento à torção de um tabuleiro de madeira laminada protendida utilizando madeiras de reflorestamento nacionais (Eucalipto Citriodora), ensaiou dois modelos em escala real formados a partir de peças de seção transversal nominal $5 \mathrm{~cm} \times 22 \mathrm{~cm}$, seguindo metodologia desenvolvida no Forest Products Laboratory.

Caracterizando o comportamento do sistema de protensão nas peças de madeira, utilizou amostra de 60 unid. de Eucalipto Citriodora com dimensões nominais de $5 \mathrm{~cm} \times 22 \mathrm{~cm} \times 22 \mathrm{~cm}$ "para se detectar a flutuação da força de protensão com o tempo, estando o material confinado e apoiado no solo". Foi utilizada uma barra lisa de aço de fabricação mecânica, tracionada com uso de um cilindro de reação de capacidade $50 \mathrm{kN}$, comprimindo as peças através de placas de ancoragem nas extremidades, sendo as forças nas extremidades lidas através de células de carga vazadas. A mesma sequência de ensaio foi repetida, desta vez utilizando uma barra de aço especial para protensão. 
As peças utilizadas na montagem dos modelos foram classificadas por meio de um ensaio de flexão simples, a maior dimensão da seção transversal disposta horizontalmente e o vão ensaiado igual a seu comprimento menos $10 \mathrm{~cm}$, estando todas as peças pré-furadas, permitindo assim uma aplicação direta dos resultados na aplicação final e sua posição na placa. Ensaiou os dois modelos à torção, seguindo equacionamento apresentado em RIBEIRO (1986), cujos resultados fornecem os parâmetros de comportamento de placa ortótropa (espessa), os quais podem ser utilizados em dimensionamentos. Ensaios semelhantes com a espécie Douglas Fir foram levados à efeito no Forest Products Laboratory e na Queen's University, com o nível de tensão de confinamento nas peças quatro vezes inferior ao utilizado para as peças de Eucalipto Citriodora.

De suas conclusões temos que "... até que se desenvolva uma Norma Técnica nacional, este procedimento (apresentado no estudo) é o recomendado. Além disso, recomenda-se obedecer os procedimentos de protensão e retensionamento indicados pela Especificação TB 622 ... até que se levante experimentalmente (em campo) o comportamento estrutural em serviço das pontes de Eucalipto citriodora laminadas protendidas".
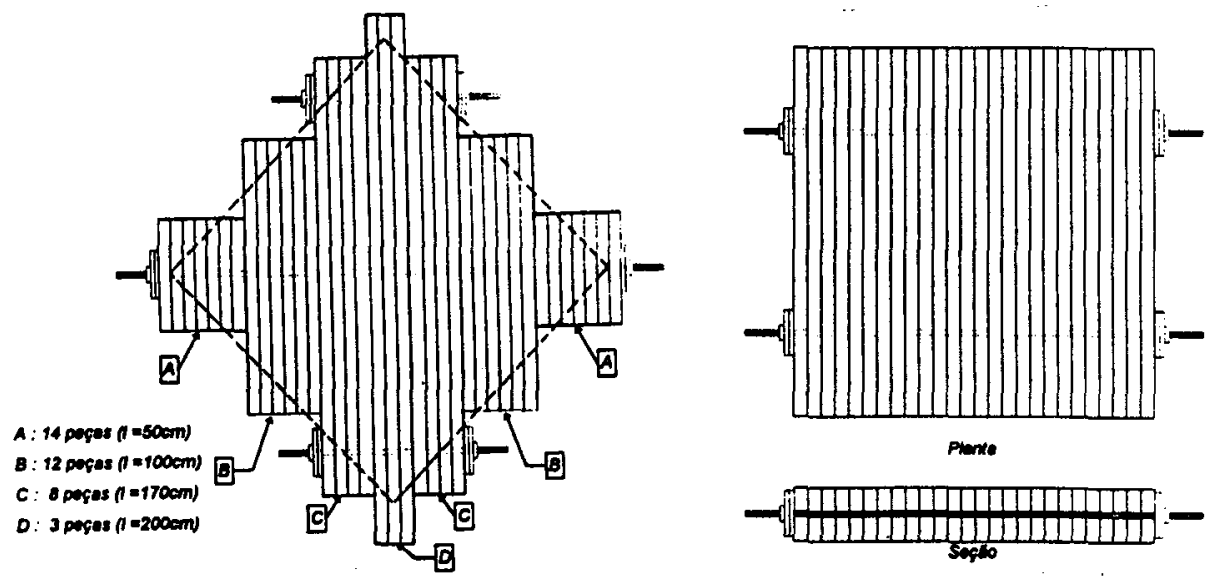

Figura 5.3: Modelo de tabuleiro de madeira laminada protendida. (PRATA, 1995). 


\subsection{Arranjos isótropos}

O fato da madeira se apresentar como um material anisótropo não impede o comportamento ortotrópo dos tabuleiros das pontes de madeira, o qual é conseguido pelo arranjo estrutural adotado, resultando em uma ortotropia de forma, como se viu nos trabalhos anteriormente citados, onde a rigidez em uma direção (a dos eixos das peças que o compõem) é muito superior à rigidez na direção perpendicular a esta. Este é o caso dos tabuleiros compostos por postes ou por peças retangulares posicionadas segundo a direção de tráfego da ponte, ou perpendicular a ela, independente de serem solidarizados por fitas de aço, anéis metálicos, barras de aço comum ou de protensão.

Deste modo, o desenvolvimento de esquemas estruturais que pudessem garantir aos tabuleiros de pontes de madeira um comportamento "isótropo" contribuiria para um melhor aproveitamento do material e consequente melhoria de seu desempenho. Neste sentido, estão apresentadas aqui algumas idéias de tabuleiros compostos por duas camadas de peças retangulares dispostas lado a lado, onde uma camada se posiciona perpendicularmente às peças da outra camada, solidarizadas entre si em pontos discretos, os cruzamentos das peças das duas camadas, de modo a formar um arranjo do tipo grelha ou placa "isotrópa".

\subsubsection{Vigas de alma cheia}

$\mathrm{O}$ arranjo estrutural considerado neste estudo evolui a partir de outro semelhante utilizado na execução de vigas de alma cheia, onde as almas são compostas por duas camadas de ripas, com as peças de uma camada colocadas perpendicularmente em relação às da outra, e solidarizadas entre si por meio de pregos. 
LASKUS \& SCHÖDER (1955) apresentaram o cálculo teórico de vigas de madeira de seções transversais em I, duplo I e caixão, nas quais as mesas eram compostas de duas ou mais peças de madeira dispostas na direção do eixo da viga, e as almas compostas por uma ou mais camadas de peças inclinadas em relação a este eixo de um ângulo variando entre $30^{\circ}$ e $40^{\circ}$. As mesas e as almas eram solidarizadas por meio de pregos, havendo enrigecedores para resistir à força cortante espaçados de uma distância não superior a um valor pré-estabelecido. A partir deste modelo, apresentaram o projeto de uma ponte com vigas de seção I cuja alma era composta por duas camadas de peças posicionadas a $45^{\circ}$ em relação ao eixo da viga, solidarizadas às mesas e entre si, na região da linha neutra, por meio de par de pregos.

Também foi apresentado o projeto de uma ponte rodoviária em arco lamelar com vigas de seção I semelhantes às do projeto anteriormente mencionado, porém com a solidarização entre a alma e as mesas tendo sido promovida por uma dezena de pregos, e entre as peças da alma por meio de 2 pares de pregos. Este mesmo projeto já apresentava o tabuleiro composto por duas camadas de peças colocadas a $60^{\circ}$ com a direção de tráfego da ponte.

S.M.B. ALMEIDA (1989), estudou as vigas de madeira com alma cheia, denominando-as vigas de madeira com alma em treliça. Em seu estudo, abordou o dimensionamento realizado segundo analogia de treliça, as peças das mesas constituindo os banzos da treliça, e as peças da alma suas diagonais, com inclinação de $45^{\circ}$ em relação ao eixo da viga. Com esta abordagem, prosseguiu estudo experimental "com o objetivo de analisar o comportamento estrutural das vigas de madeira com alma em treliça e comprovar a validadade do método de cálculo proposto". Foram ensaiados 4 modelos de vigas simplesmente apoiadas com vãos de 2,5 m, executadas com madeira da espécie Jatobá Amarelo. 

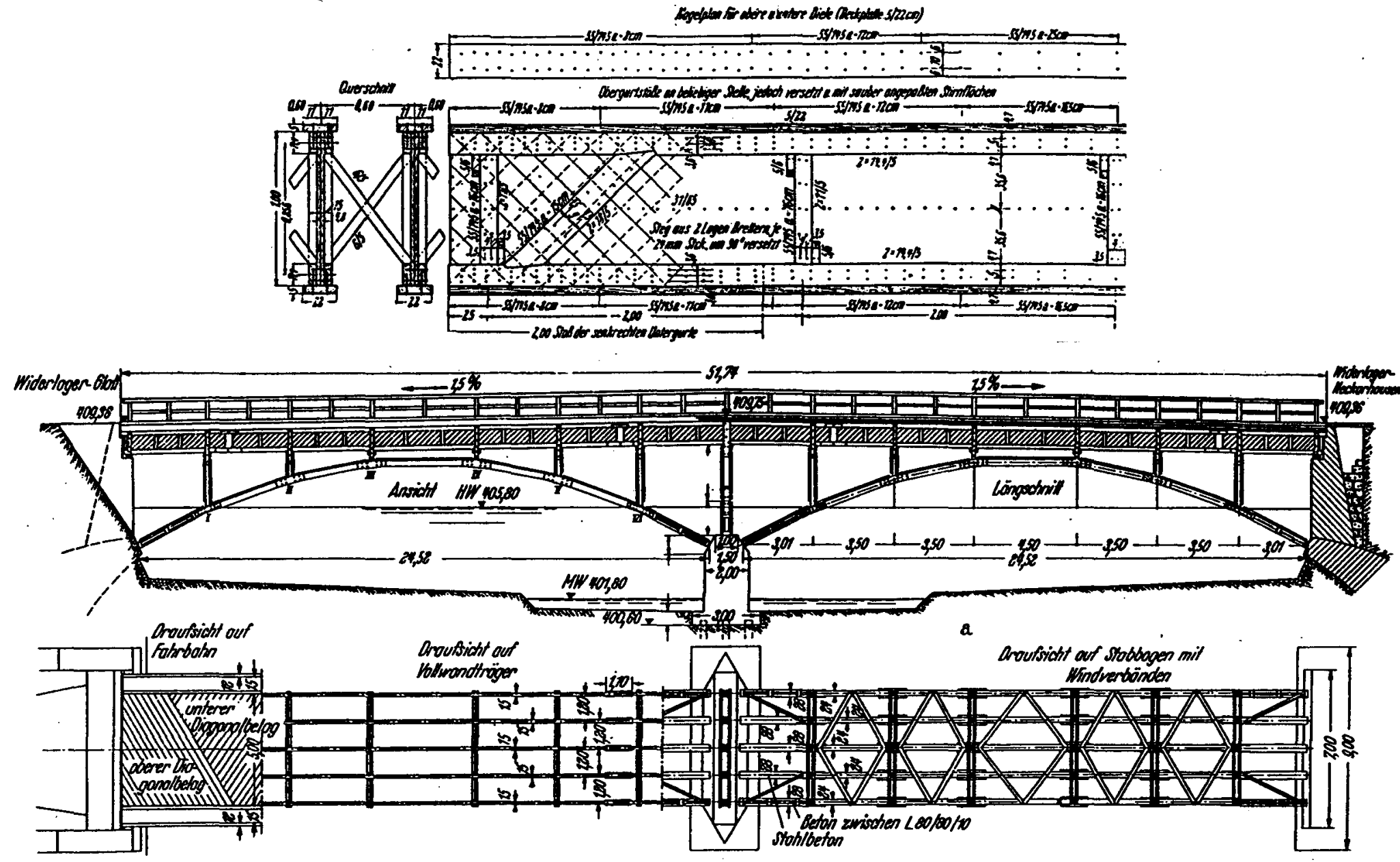

Figura 5.4: Viga de alma cheia e sua aplicação ao projeto de uma ponte de madeira em arco lamelar. observar a idéia do tabuleiro formado por duas camadas compostas por peças $a 60^{\circ}$ com o eixo da ponte. LASKUS \& SCHÖDER (1955). 
As vigas foram ensaiadas na escala $1: 4$, com seção transversal de uma alma e abas simples, uma alma e abas duplas, e duas almas e abas duplas, todas com altura de $30 \mathrm{~cm}$. As peças constituintes das almas foram solidarizadas às abas por meio de 3 e 5 pregos, e entre si por meio de um par de pregos na região da linha neutra.

A viga de uma alma e abas simples foram instrumentadas de modo a obter-se leituras de deformações nos banzos e diagonais, e flechas ao longo do vão da viga, bem como de seus valores residuais após a descarga. A seguir foi submetida a um carregamento concentrado no meio do vão, com duas descargas sucessivas, até alcançar a ruptura ao final do terceiro carregamento.

$\mathrm{Na}$ montagem dos ensaios das vigas de uma alma e abas duplas, e duas almas e abas duplas, foram utilizados enrijecedores em função de no ensaio anterior ter havido flexão localizada na aba comprimida. A instrumentação realizada e a sequência de carregamento utilizado foi semelhante ao ensaio do primeiro modelo, não sendo porém levadas à ruptura.

\subsubsection{Tabuleiros ortogonais}

S.M.B. ALMEIDA (1989), dando sequência ao estudo das vigas de alma cheia, analisou tabuleiros de pontes com arranjo "constituído por duas camadas ortogonais de lâminas superpostas", com as camadas compostas por "tábuas justapostas formando um ângulo de $45^{\circ}$ com o eixo longitudinal da ponte", e em cada cruzamento as peças das duas camadas solidarizadas entre si por meio de pregos.

A partir das expressões fornecidas pela teoria das placas elásticas isótropas, examinou experimentalmente dois modelos de placas, uma quadrada com $1,0 \mathrm{~m}$ de lado, simplesmente apoiada nos quatro lados, e outra retangular com dimensões 2,50 $m \times 0,70 m$, simplesmente apoiada ao longo dos dois lados mais longos e livre nos 
outros dois, admitindo as hipóteses de "placa de madeira isotrópica com coeficiente de Poisson nulo".

Ambas foram executadas com peças de Jatobá Amarelo, tendo sido as camadas da primeira solidarizadas por meio de 2 pares de pregos inclinados, e as camadas da segunda por um único prego vertical.

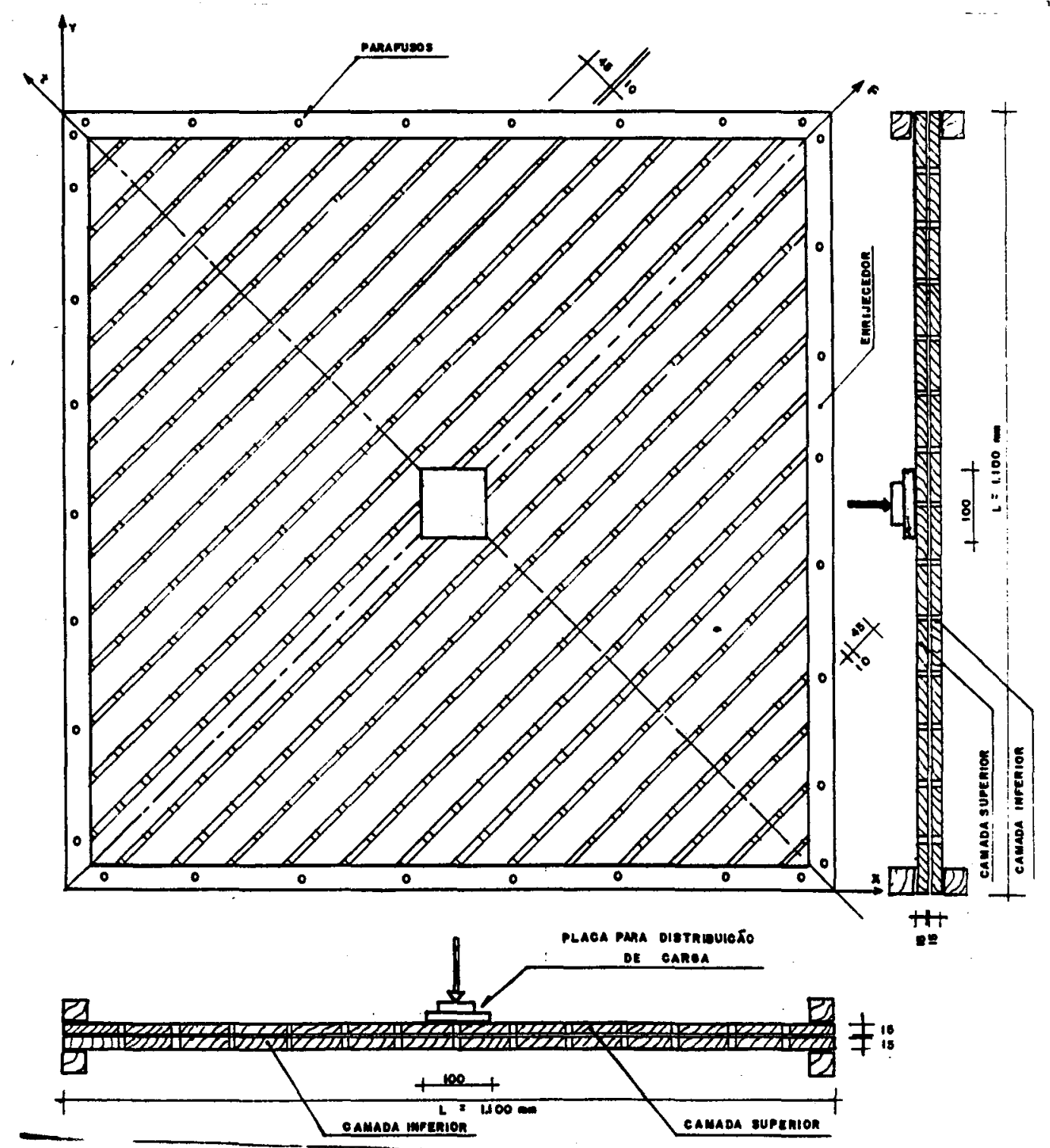

Figura 5.5: Modelo de tabuleiro isótropo de madeira (Modelo II). S.M.B. ALMEIDA (1989). 
O primeiro modelo foi instrumentado de modo a se obter leituras de deformações e flechas em vários pontos da placa. Foi submetido à ação de carregamento concentrado e descarregado três vezes, tendo sido levado à ruptura ao final da $4^{\text {a }}$ sequencia de carregamento, ruptura esta determinada anteriormente por meio da teoria das charneiras plásticas.

O segundo modelo foi identicamente instrumentado, apoiado em dois lados sobre as vigas de duas almas e abas compostas anteriormente ensaiadas, e deixado livre nos outros dois lados, tendo sido submetido a identico carregamento concentrado. A partir dos resultados obtidos, concluiu que o comportamento destes arranjos estruturais de placas podem ser previstos a partir da teoria de placas elásticas, de modo semelhante ao de uma placa maciça isótropa de madeira, com espessura igual à espessura de uma das camadas e com coeficiente de Poisson nulo.

Baseado neste estudo, P.A.O. ALMEIDA (1990) apresentou o projeto de uma ponte de madeira sobre o Rio Piracicaba, Iperó - SP, com 3,60 m de largura e 28,20 $m$ de vão livre, com 2 longarinas apoiadas em encontros de concreto armado, contraventadas longitudinalmente com uso de 11 transversinas, todas formadas por vigas de alma cheia formadas por peças de $6 \mathrm{~cm} \times 16 \mathrm{~cm}$ (mesas) e $3 \times 16 \mathrm{~cm}$ (almas), estas inclinadas à $45^{\circ}$ em relação ao eixo da viga, e tabuleiro formado por duas camadas compostas por peças de $6 \mathrm{~cm} \times 16 \mathrm{~cm}$ posicionadas a $45^{\circ}$ em relação ao eixo da ponte, todas as peças são da espécie Maçaranduba (Manilkara huberi).

As longarinas possuem enrijecedores nas seções sobre os apoios e nas seções de travamento com transversinas, bem como ao longo de todo seu comprimento na região da linha neutra, as transversinas das regiões de apoio sendo mais rígidas que as intermediárias. As transversinas são enrijecidas nas seções de apoio com as longarinas e em seções intermediárias. O tabuleiro é apoiado sobre as transversinas, sobre longarinas secundárias e sobre as abas internas dos enrijecedores ao longo da 
linha neutra, sendo a ligação entre estes e o tabuleiro promovida por peças suplementares.

Esta composição garante classificar a ponte como uma ponte de viga com tabuleiro intermediário. As ligações entre as peças componentes das vigas, e a solidarização entre as peças componentes das duas camadas que formam o tabuleiro, são promovidas através de pregos de aço de bitola ABNT $72 \times 170$ e $54 \times 110$, respectivamente.

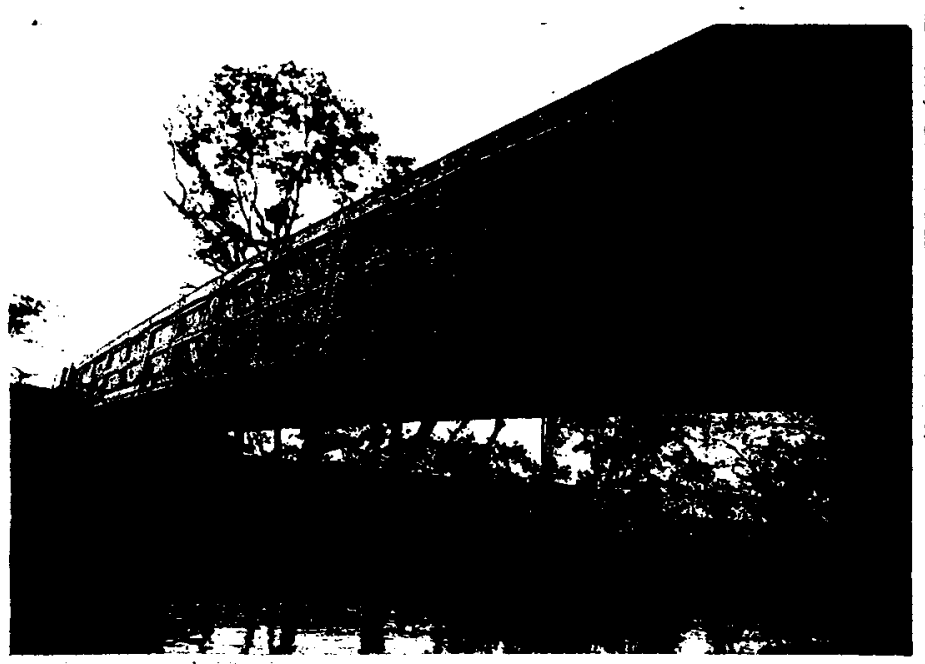

Figura 5.6: Ponte sobre o Rio Sorocaba, Iperó - SP. VASCONCELLOS (1993).

As ligações entre transversinas e longarinas são promovidas por cantoneiras metálicas parafusadas nos enrijecedores de extremidade nas transversinas e na lateral das longarinas através de parafusos de porcas ajustados.

No dimensionamento do tabuleiro admitiu as hipóteses confirmadas no estudo de S.M.B. ALMEIDA (1989), quais sejam as de que o tabuleiro comporta-se como placa elástica com coeficiente de Poisson nulo, e de que "... o número de pregos não 
afeta significativamente o comportamento da placa", sendo utilizado dois pregos em cada cruzamento das peças componentes das duas camadas.

Além disso, considerando a continuidade do tabuleiro sobre as transversinas, admitiu que "a área de influência do carregamento fosse determinada pelos critérios usuais referentes às placas de concreto armado", o que pareceu razoável diantes das investigações realizadas por ALMEIDA (1989).

Após executada, a ponte foi submetida à prova de carga com uso de caminhão com características semelhantes ao trem-tipo utilizado no dimensionamento.

Dos resultados obtidos para as flechas lidas, salientou: "... verifica-se que o arranjo adotado para as longarinas permite a colaboração da alma na sua rigidez. Observa-se que o mesmo não foi verificado para vigas de pequeno porte com reduzido número de peças nas abas e nos enrigecedores".

Este resultado parece indicar que tanto o comportamento das vigas como o do tabuleiro confirma as hipóteses de comportamento isótropo para ambos os arranjos.

CALIL, LAHR \& DIAS (1993) apresentaram projeto e aspectos da execução de uma passarela pensil sobre o Rio Piracicaba - SP, na qual o tabuleiro adotado possuia o arranjo de duas camadas ortogonais de peças de madeira posicionadas a $45^{\circ}$ com o eixo da passarela, solidarizadas entre si por meio de pregos, apenas na linha de apoio sobre as vigas de rigidez transversal.

Pretende-se neste trabalho avaliar o comportamento de tabuleiros de madeira com a configuração estrutural adotada por ALMEIDA (1989), ALMEIDA (1990) e CALIL, LAHR \& DIAS (1993), variando o tipo e a quantidade de pontos de solidarização entre as peças das duas camadas, bem como as vinculações dos apoios e o carregamento. 


\section{Capitulo seis: Parte experimental}

\subsection{Objetivos}

Nesta experimentação buscou-se obter dados que permitissem:

- Observar o comportamento sob flexão, de um tabuleiro com arranjo estrutural formado por duas camadas compostas de peças de seção retangular, ortogonais entre si e colocadas a $45^{\circ}$ em relação à direção de tráfego.

- Avaliar a variação da rigidez do arranjo com o aumento da quantidade de pontos de ligação entre as peças componentes das duas camadas.

- Comparar o desempenho entre tabuleiros ligados por pregos e através de cavilhas de madeira.

- Comparar os resultados dos ensaios com os obtidos por meio de análise numérica com auxílio do programa SAP90.

$\mathrm{O}$ arranjo poderá ser adequado para a execução de tabuleiros a partir de módulos retangulares com dimensões da ordem de $3,0 \mathrm{~m}$ a 3,5 $\mathrm{m}$ de lados.

Considerando-se a escolha dos pontos de carregamento e de leitura de flechas, optou-se pelo uso de modelos pouco reduzidos, com dimensões laterais de $100 \mathrm{~cm} x$ $100 \mathrm{~cm}$ formados por duas camadas de $2 \mathrm{~cm}$ de espessura.

Estes modelos representaram módulos de tabuleiros com dimensões laterais de $300 \mathrm{~cm} \times 300 \mathrm{~cm}$ formados por duas camadas de $6 \mathrm{~cm}$ de espessura na escala 1:3. 


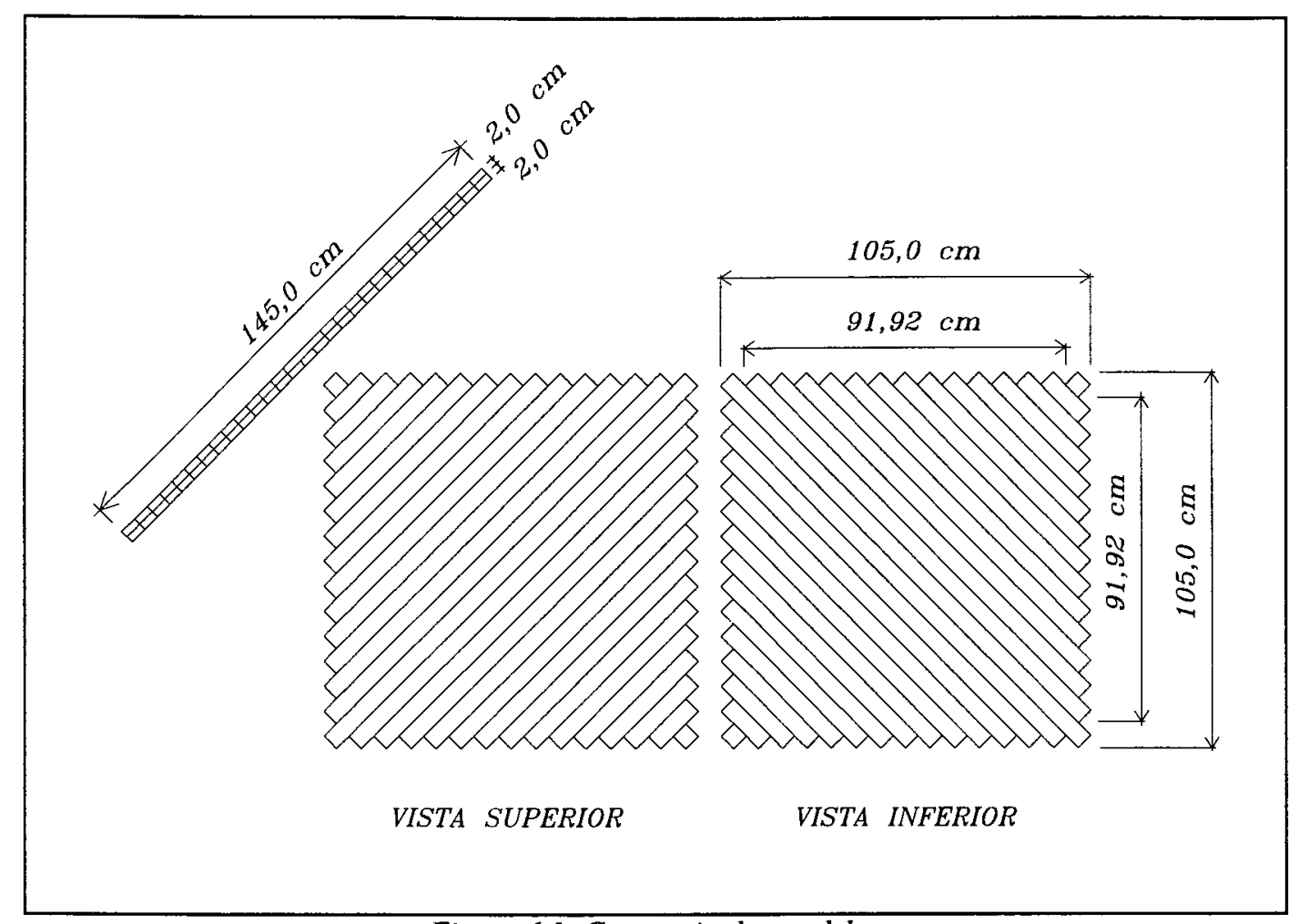

Figura 6.1: Geometria dos modelos.

\subsection{Descrição dos modelos}

Foram ensaiados dois modelos pouco reduzidos do módulo com o arranjo proposto. As dimensões nominais dos modelos eram de $100 \mathrm{~cm} \times 100 \mathrm{~cm} \mathrm{x} 4 \mathrm{~cm}$, representando módulos com dimensões de $300 \mathrm{~cm} \times 300 \mathrm{~cm} \times 12 \mathrm{~cm}$, na escala 1:3.

Cada modelo era formado por duas camadas de espessura $2 \mathrm{~cm}$, compostas por sarrafos de Peroba Rosa de seção transversal nominal de $2 \mathrm{~cm} \times 5 \mathrm{~cm}$. A solidarização entre as peças das duas camadas foi obtida por meio de ligações pontuais nos cruzamentos das peças utilizando pregos lisos de aço de $\phi=5 \mathrm{~mm}$ ou cavilhas de Ipê de $\phi=9 \mathrm{~mm}$.

\subsubsection{Materiais componentes dos modelos}

Na construção dos modelos foram utilizados: sarrafos de Peroba Rosa na composição das camadas e pregos, cavilhas de madeira e cola Cascofen na ligação 
dos pontos de cruzamento entre as peças das duas camadas. As características dos materiais utilizados são descritas a seguir.

\subsubsection{Sarrafos de peroba rosa}

Os sarrafos utilizados na construção dos modelos possuiam dimensões de $2 \mathrm{~cm}$ $x 5 \mathrm{~cm} \times 175 \mathrm{~cm}$. O módulo de elasticidade longitudinal dos sarrafos foi determinado através de ensaios de flexão simples, nos quais cada sarrafo foi considerado como viga simplesmente apoiada, submetida a carregamento concentrado no meio do vão.

Inicialmente, foram determinadas as seções transversais para cada peça através da leitura dos valores da largura e da espessura na metade do comprimento com o uso de um paquímetro, os quais foram admitidos como constantes ao longo de toda a peça.

A peça ensaiada foi simplesmente apoiada sobre duas mesas metálicas fixadas à viga de reação do LaMEM de modo a obter um vão livre de $150 \mathrm{~cm}$, constante em todos os ensaios. A seguir, aplicou-se uma carga concentrada de 3,930 daN sobre o meio do vão, lendo-se o valor da flecha correspondente.

Com uma régua fixada à peça por meio de um pequeno prego, a flecha devida ao carregamento padrão foi determinada pela leitura da posição de um barbante em relação à régua antes e após a deformação da peça, sendo seu valor igual à diferença entre essas duas leituras, com uma sensibilidade de $0,1 \mathrm{~cm}$.

A flecha máxima em uma viga prismática de seção retangular $b \times d$ constante, simplesmente apoiada, submetida à flexão por uma carga concentrada no meio do vão é dada pela Resistência dos Materiais através da expressão:

$$
f=\frac{P L^{3}}{48 E I}+\frac{c P L}{G A}
$$




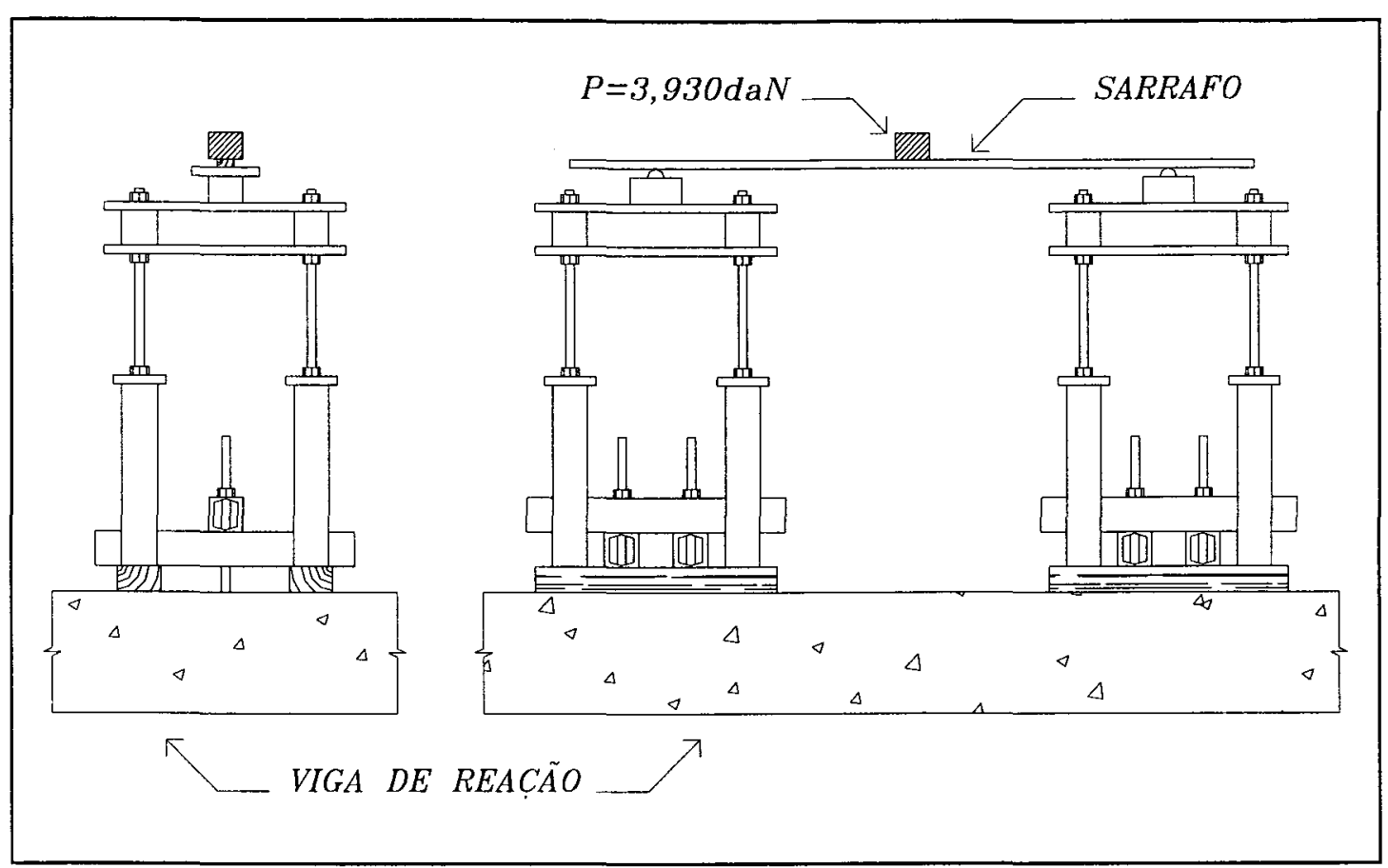

Figura 6.2: Montagem dos ensaios de flexão dos sarrafos de Peroba Rosa.

onde: $f=$ Flecha máxima.

$P=$ Valor da carga concentrada.

$L=$ Vão livre.

$b=$ Largura.

$d=$ Altura

$A=b d=$ Área.

$I=\frac{b d^{3}}{12}=$ Momento de inércia.

$c=$ Coeficiente de forma

$E=$ Módulo de elasticidade longitudinal.

$G=$ Módulo de elasticidade transversal.

A primeira parcela da expressão (6.1) refere-se à flecha causada pelos momentos fletores, a segunda parcela à flecha causada pelos esforços cortantes. 
LAHR (1983) cita equacionamento para o problema da flexão em vigas de madeira de seção retangular no qual a flecha máxima é dada pela expressão:

$$
f=\frac{P L^{3}}{48 E I}+\frac{3 P L}{10 G A}
$$

a qual, para vigas nas quais a relação vão / altura seja superior a 21 , pode ser simplificada para:

$$
f=\frac{P L^{3}}{48 E I}
$$

e, então,

$$
E=\frac{P L^{3}}{48 f I}
$$

Daí, tem-se:

$$
E=\frac{3,930 \cdot 150,0^{3}}{48 f I} \quad E=\frac{2,7633 \cdot 10^{5}}{f I}
$$

A partir da expressão (6.5) e dos resultados dos ensaios de flexão dos sarrafos, construi-se o Tabela 6.1.

\begin{tabular}{cccccc} 
& $b(\mathrm{~cm})$ & $\boldsymbol{d}(\mathrm{cm})$ & $f(\mathrm{~cm})$ & $I\left(\mathrm{~cm}^{4}\right)$ & $E\left(\mathrm{daN} / \mathrm{cm}^{2}\right)$ \\
\hline $\boldsymbol{X}_{\boldsymbol{m} \text { médio }}$ & 2,011 & 4,996 & 0,63 & 3,40 & 135.076 \\
$\boldsymbol{S}_{\boldsymbol{X}}$ & 0,052 & 0,331 & 0,11 & 0,36 & 29.616 \\
$\boldsymbol{X}_{\boldsymbol{k}_{5 \%}}$ & 1,926 & 4,452 & 0,45 & 2,81 & 86.357 \\
$\boldsymbol{X}_{\boldsymbol{k}_{95 \%}}$ & 2,096 & 5,539 & 0,80 & 3,99 & 183.795 \\
\hline \multicolumn{2}{r}{ Tabela 6.1: Resultados dos ensaios de flexão dos sarrafos de Peroba Rosa. }
\end{tabular}

\subsubsection{Pregos lisos de aço e cavilhas de Ipê}

No dimensionamento de ligações por pregos de aço, ou com cavilhas de madeira, o valor da carga admissivel causadora de cisalhamento no elemento de 
ligação é obtido a partir de seu diâmetro e da resistência à compressão paralela às fibras da espécie de madeira utilizada nas peças a serem ligadas.

Assim, neste estudo os ensaios de caracterização realizados com os sarrafos foram não-destrutivos, ou seja, as relações carga vs deformação foram mantidas abaixo do limite de elasticidade do material. As ligações entre as peças componentes das duas camadas que formam um modelo foram admitidas como rígidas.

Isto é razoável dentro dos objetivos propostos para a metodologia de ensaio, quais sejam os de considerar os modelos solicitados dentro do intervalo de comportamento elástico-linear, e a função dos elementos de ligação sendo a de transmitir esforços entre as peças componentes das duas camadas que os formam. Em função disto, não foram realizados ensaios específicos para caracterizar o comportamento dos pregos e das cavilhas.

\subsubsection{Montagem dos modelos}

A execução das ligações, quer por pregos ou através de cavilhas, foi sempre precedida por uma pré-furação de aproximadamente $0,9 \phi$. As ligações foram posicionadas perpendicularmente à superfície do modelo, com as cavilhas tendo sido preliminarmente embebidas em cola Cascofen antes da sua introdução nos furos.

A principal diferença entre ligações por pregos e através de cavilhas adotadas foi o fato de que os pregos atravessavam as peças da camada superior do modelo e penetravam até $2 / 3$ da espessura das peças da camada inferior, enquanto as cavilhas atravessavam as peças de ambas as camadas. Inicialmente a quantidade de pregos utilizada foi suficiente para garantir apenas a solidarização das peças ao longo de 4 linhas externas, consideradas como as bordas do modelo ensaiado. 


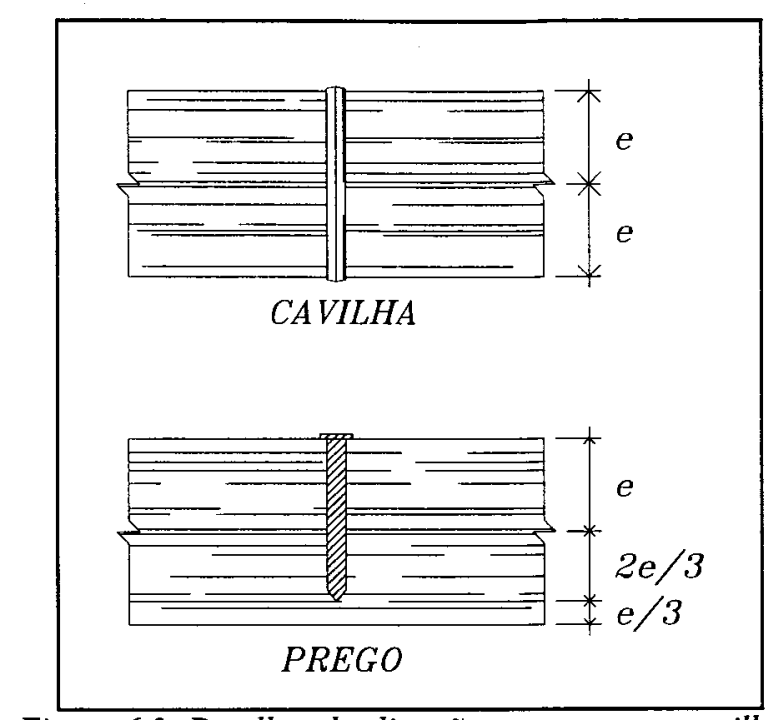

Figura 6.3: Detalhes das ligações por pregos e cavilhas.

Após a realização de cada sequência de ensaios, foi acrescentada maior quantidade de pregos, de modo que ao final haviam sido ensaiados um total de 3 diferentes configurações de pregação em um mesmo modelo.

Com o objetivo de se obter um maior número de dados comparativos, foi ensaiado um segundo modelo com as mesmas características do primeiro, seguindo as mesmas sequências de ensaios e mudanças na configuração das pregações adotadas.

Após a realização de todos os ensaios previstos para os modelos pregados, a última configuração de pregos utilizada no primeiro modelo foi substituída por idêntica configuração formada utilizando cavilhas de Ipê embebidas em cola Cascofen, sendo este novo modelo submetido à mesma sequência de ensaios que os modelos pregados.

\subsection{Ensaios de flexão}

O objetivo dos ensaios de flexão dos modelos foi avaliar a variação da rigidez de um modelo com o acréscimo da quantidade de pontos de ligação, bem como comparar, na configuração III, o comportamento dos modelos pregado e cavilhado. 


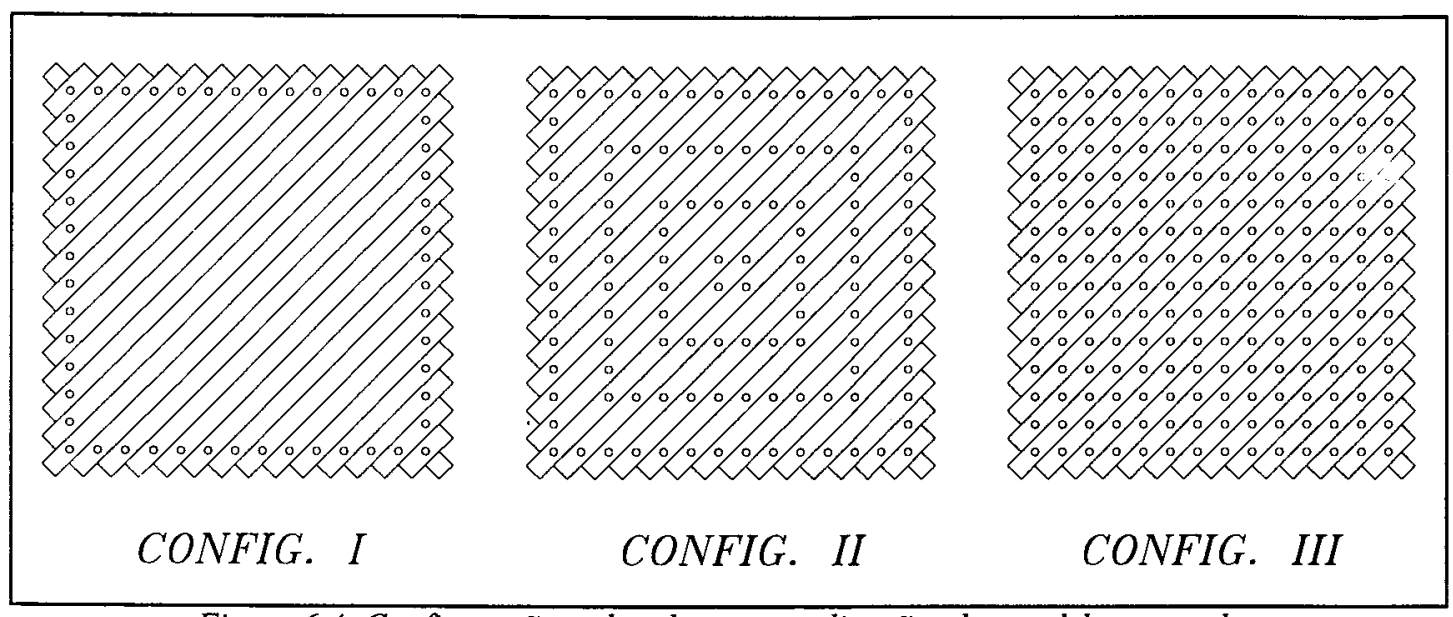

Figura 6.4: Configurações adotadas para as ligações dos modelos pregados.

A expectativa inicial de comportamento para os modelos pregados era que a rigidez aumentasse com o acréscimo de pontos de ligação, permitindo assim a idéia de uma quantidade limite de pontos de ligação a partir da qual não haveria ganho considerável de rigidez, e que o modelo pregado apresentasse uma performance inferior ao modelo cavilhado.

Os ensaios foram realizados sobre a viga de reação do LaMEM, com o modelo tendo sido apoiado sobre um quadro-gabarito. Este, por sua vez, foi colocado sobre vigas metálicas apoiadas sobre mesas metálicas fixadas à viga de reação. A aplicação das cargas foi feita com auxílio de um pistão hidráulico de capacidade $100 \mathrm{kN}$. A leitura da carga aplicada foi realizada através de um anel dinamométrico de capacidade $20 \mathrm{kN}$ e constante de leitura de carga $C=1,828 \mathrm{daN} / \mathrm{div}$.

O modelo foi ensaiado em duas condições de apoio diferentes: apoio simples ao longo de 4 lados, na primeira condição, e apoio simples em dois lados opostos, com os outros dois lados livres, na segunda condição. Estas duas condições são indicadas como Vínculo 1 e Vinculo 2, respectivamente.

Estas condições de apoio simulam duas possíveis situações em pontes: tabuleiro apoiado sobre duas vigas de rigidez longitudinais e duas vigas de rigidez transversais, e tabuleiro apoiado apenas sobre duas vigas de rigidez longitudinais. 

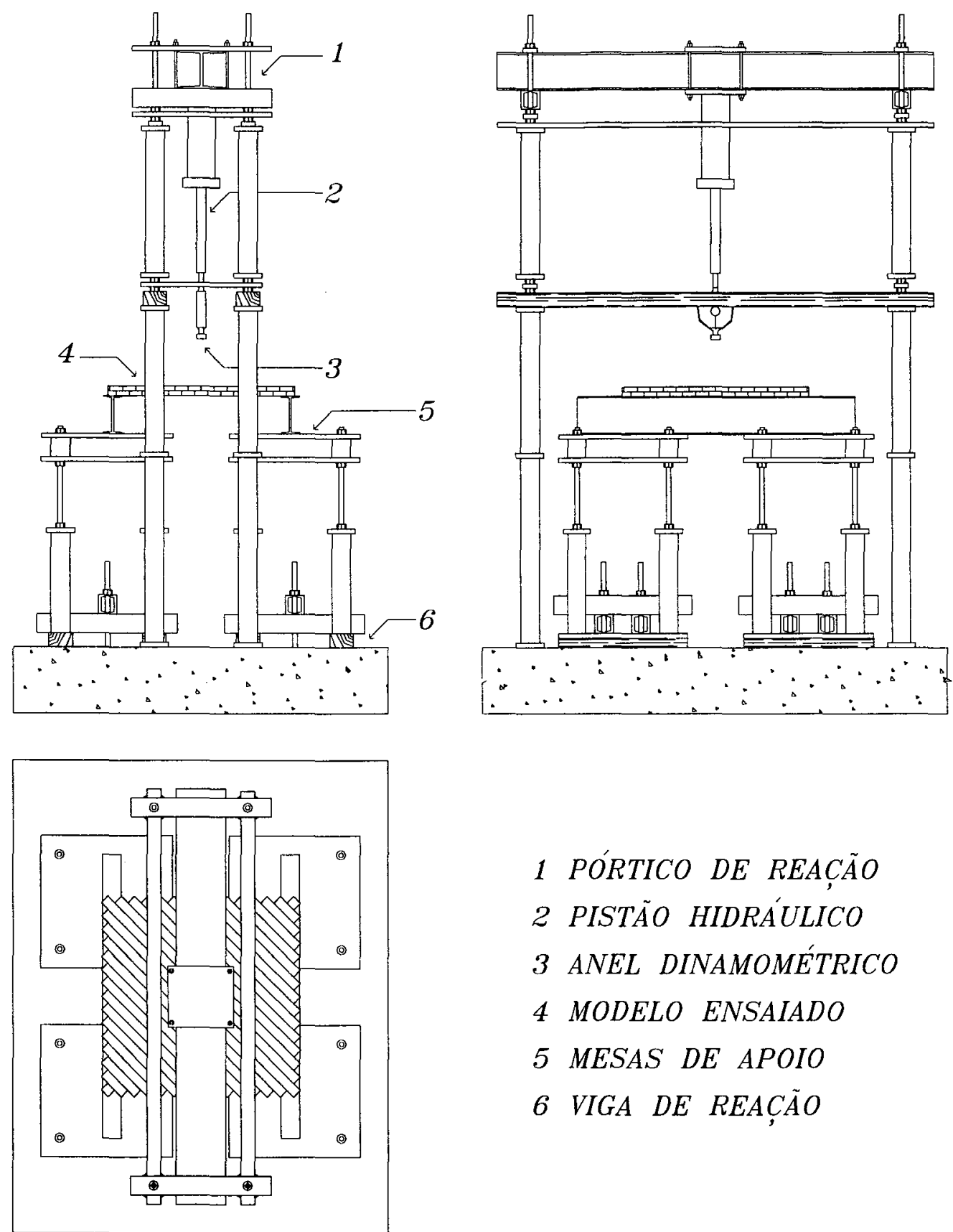

1 PÓRTICO DE REAÇÃO

2 PISTÃO HIDRÁULICO

3 ANEL DINAMOMÉTRICO

4 MODELO ENSAIADO

5 MESAS DE APOIO

6 VIGA DE REAÇAOO

Figura 6.5: Montagem dos ensaios de flexão dos modelos.

Na primeira condição, o tabuleiro colabora de forma secundária para aumentar a rigidez à torção da ponte. Na segunda condição ele é o principal responsável pela resistência aos esforços laterais e de torção. 

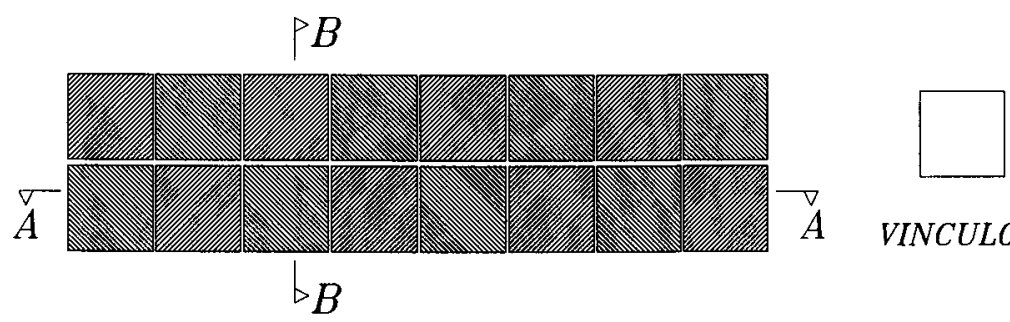

VINCULO 1
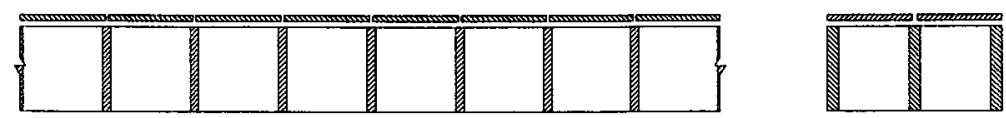

CORTE $A-A$

CORTE $B-B$

CONDIÇÃO DE APOIO 1

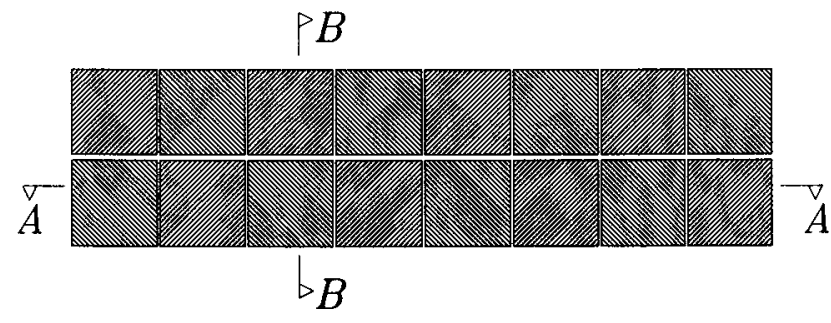

VINCULO 2
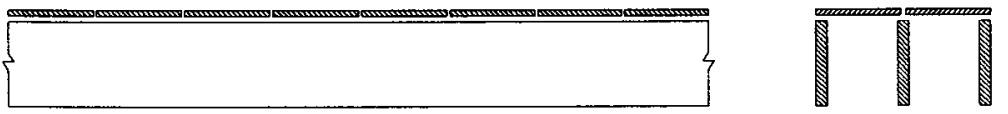

CORTE $A-A$

CORTE $B-B$

CONDIÇÃO DE APOIO 2

Figura 6.6: Condições de apoio adotadas nos ensaios de flexão dos modelos.

As leituras dos valores da superfície elástica do modelo deformado realizou-se por meio de relógios comparadores de sensibilidade $10^{-2} \mathrm{~mm}$, tomadas no ponto central, para a condição 1 , e nos pontos central e metade do vão nas bordas, para a condição 2. Em cada condição de apoio foram aplicados 3 carregamentos distintos, sendo 1 simétrico e 2 bissimétricos. Estes carregamentos procuraram simular três condições de uso comum em pontes: uma roda de um caminhão de médio porte atuando no centro, as quatro rodas de um pequeno automóvel atuando a $1 / 4$ das 
bordas, e um trem de rodas de um caminhão de grande porte atuando ao longo da linha central do tabuleiro.

A estes três carregamentos denominamos pontual, 4 pontos e linear excêntrico, respectivamente. Durante os carregamentos foram tomados pares $P v s w$, sendo $P$ a carga lida no anel dinamométrico e $w$ o valor da superfície elástica no ponto considerado, cada fase dos ensaios tendo sido repetida 2 vezes.

Admite-se aqui que o comportamento do arranjo equivale ao de uma placa isótropa de madeira com espessura $d$ e coeficiente de Poisson $v$, (lembrar que ALMEIDA, 1989 admitiu $d=e$ e $v=0$, onde $e$ é a espessura de uma camada), os quais pretende-se estimar com uso de análise numérica.

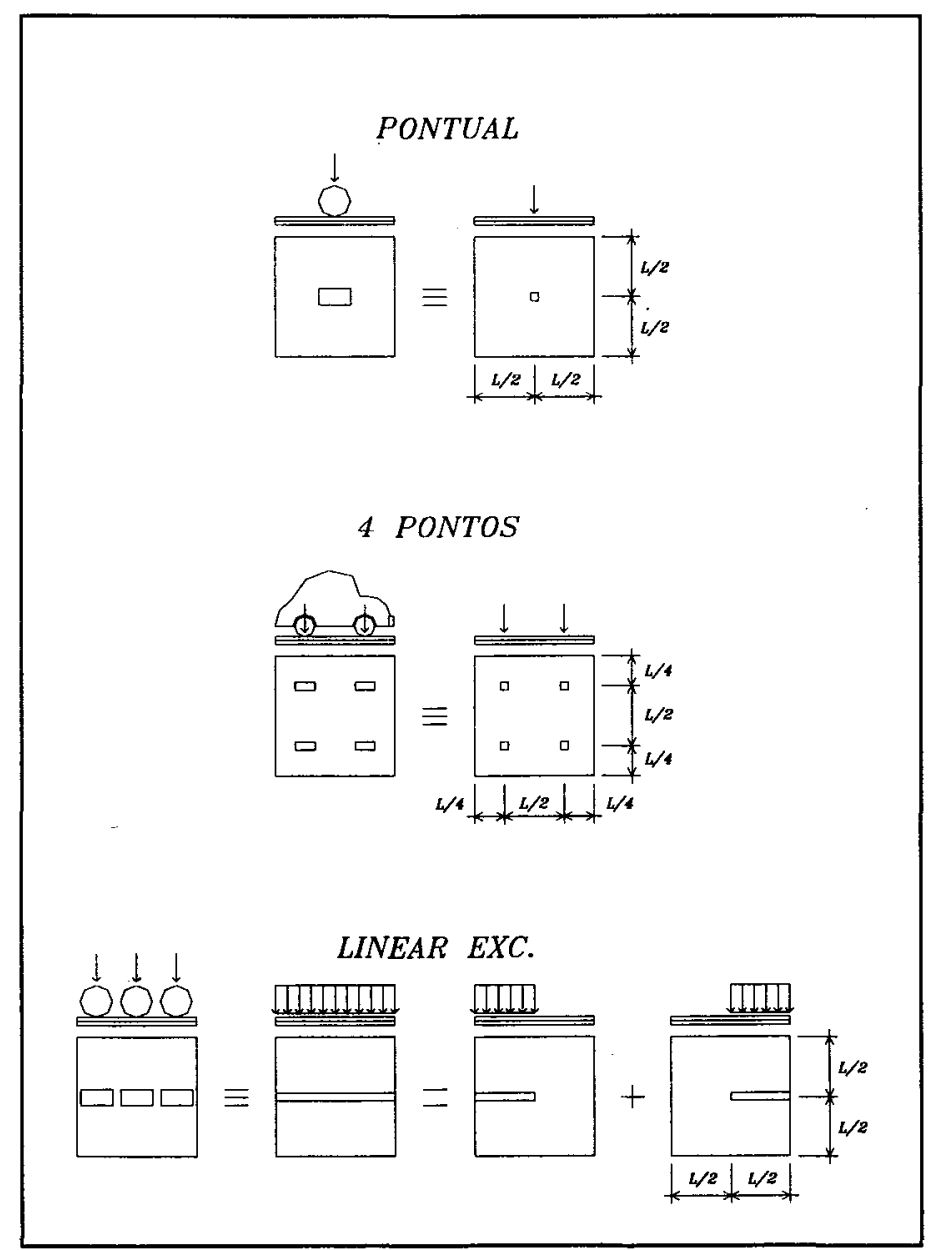

Figura 6.7: Padrões de carregamentos aplicados durante os ensaios. 
A Teoria das placas delgadas isótropas permite modelar o problema da flexão de uma placa quadrada submetida a um carregamento qualquer através de equaçñes na forma:

$$
w(x, y)=\frac{P}{D} \cdot \phi(a, \xi, \eta, u, v) \cdot f(x, y)
$$

onde: $w(x, y)=$ Função que define a superfície elástica da placa deformada.

$P=$ Carga total atuante sobre a placa.

$\phi(a, \xi, \eta, u, v)=$ Constante que depende das dimensões da placa $(a)$, da posição do centro da área carregada $(\xi, \eta)$, e das dimensões da área de carregamento $(u, v)$.

$D=\frac{E d^{3}}{12\left(1-v^{2}\right)}=$ Rigidez da placa

$f(x, y)=$ Função que depende das condições de vínculo da placa.

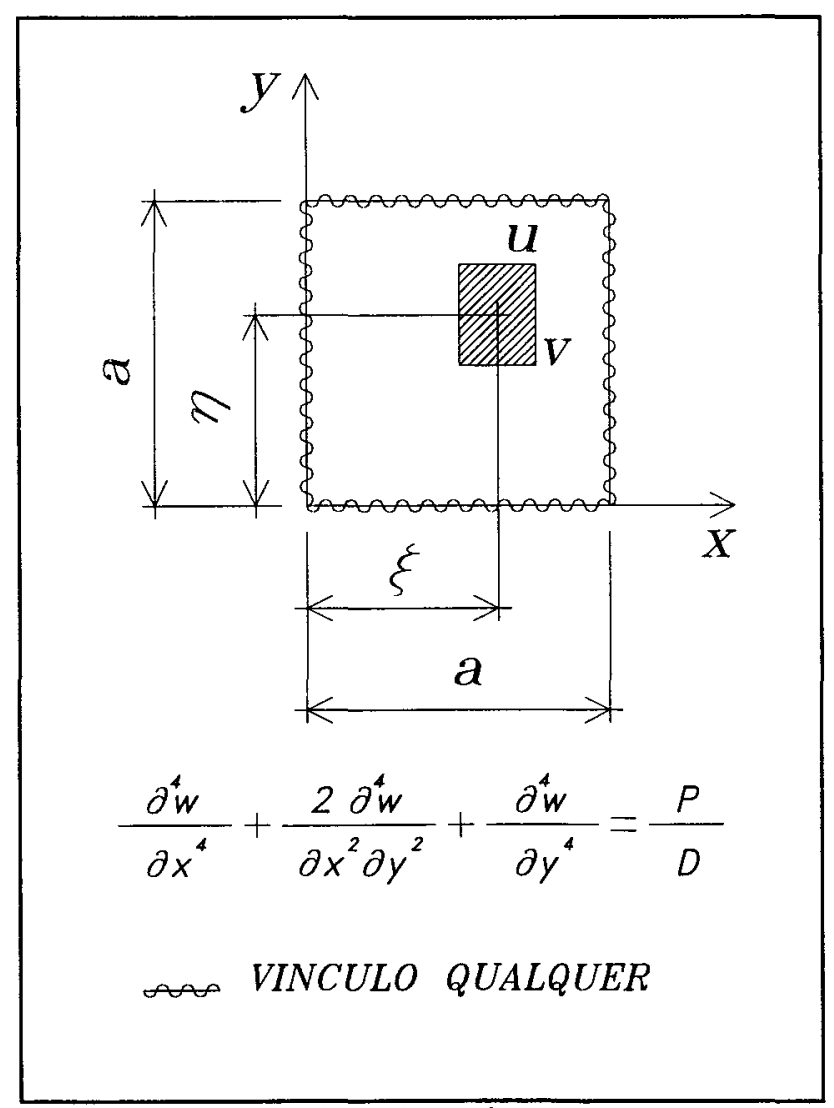

Figura 6.8: Placa quadrada submetida a carregamento em região retangular, e equação diferencial das placas elásticas. 
Não é objetivo deste trabalho tratar do modelamento matemático do problema da flexão do arranjo considerado, mas obter uma avaliação de sua rigidez. Vemos pela forma da expressão da rigidez $D$ não ser possivel uma avaliação direta pela simples substituição das variáveis $E, d$ e $v$, pois não dispõe-se de seus valores. Assim, uma parte da discussão fará a avaliação indireta de seu valor, e outra a estimativa de suas propriedades mecânicas por análise numérica realizada com o programa SAP90.

Deste modo, a partir do conjunto dos dados obtidos foi determinado um coeficiente $k$ que relaciona a carga aplicada pelo pistão com o valor da superfície elástica no ponto considerado, na seguinte forma:

$$
\begin{aligned}
& P=k \cdot w \\
& k=\frac{\sum_{\substack{i=1,6 \\
j=1,3}} P_{i} \cdot w_{i j}}{\sum_{\substack{i=1,6 \\
j=1,3}} w_{i j}^{2}}
\end{aligned}
$$

onde: $\mathrm{i}=$ Número de incrementos de carga aplicados.

$\mathrm{j}=$ Número de repetições do carregamento.

O valor de $k$ será utilizado como parâmetro de avaliação indireta da rigidez do modelo considerado, e será obtido por meio de regressão com uso do Método dos mínimos quadrados expressão (6.8), apresentado nos Anexos.

\begin{tabular}{cccc}
\hline$P($ daN $)$ & $w_{1}(\mathrm{~mm} / 100)$ & $w_{2}(\mathrm{~mm} / \mathrm{l00})$ & $w_{3}(\mathrm{~mm} / \mathrm{l00})$ \\
\hline$P_{1}$ & $w_{11}$ & $w_{21}$ & $w_{31}$ \\
$P_{2}$ & $w_{12}$ & $w_{22}$ & $w_{32}$ \\
$P_{3}$ & $w_{13}$ & $w_{23}$ & $w_{33}$ \\
$P_{4}$ & $w_{14}$ & $w_{24}$ & $w_{34}$ \\
$P_{5}$ & $w_{15}$ & $w_{25}$ & $w_{35}$ \\
$P_{6}$ & $w_{16}$ & $w_{26}$ & $w_{36}$
\end{tabular}

Tabela 6.2: Pares de leitura $P$ vs $w$ obtidos nos ensaios de flexão dos modelos. 


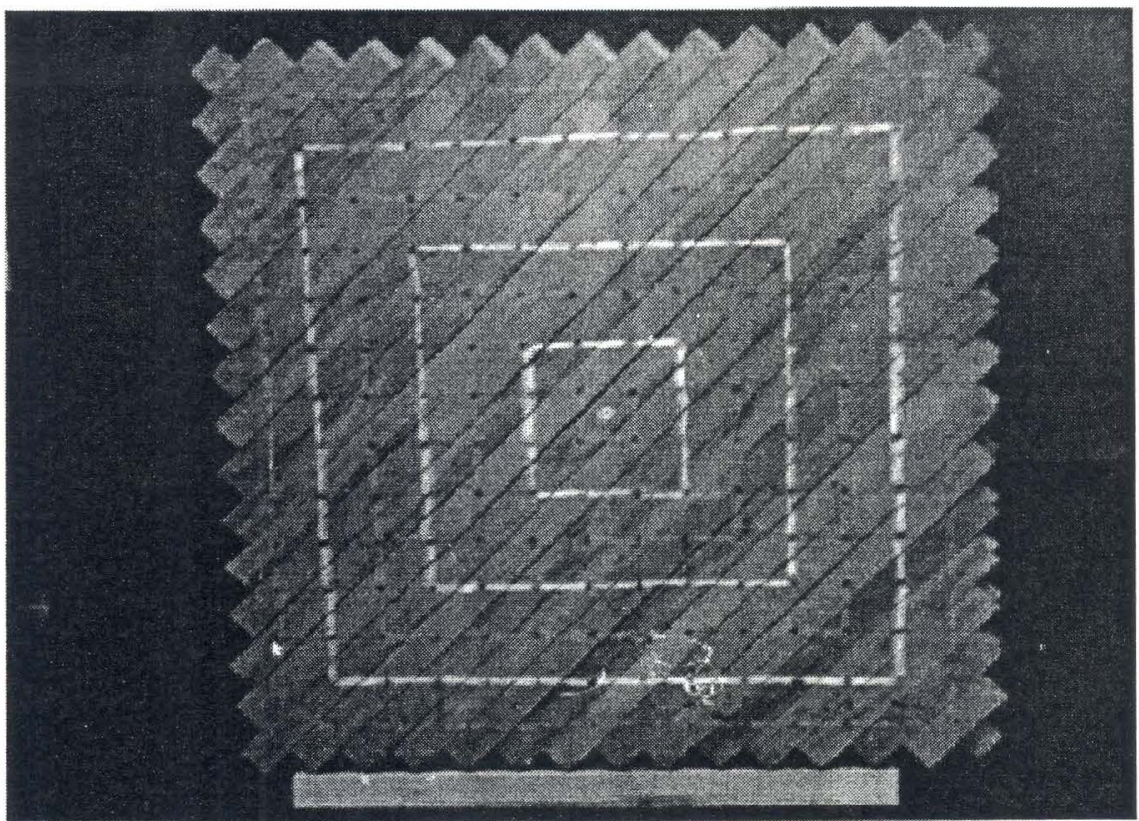

Figura 6.9: Modelo solidarizado por pregos.

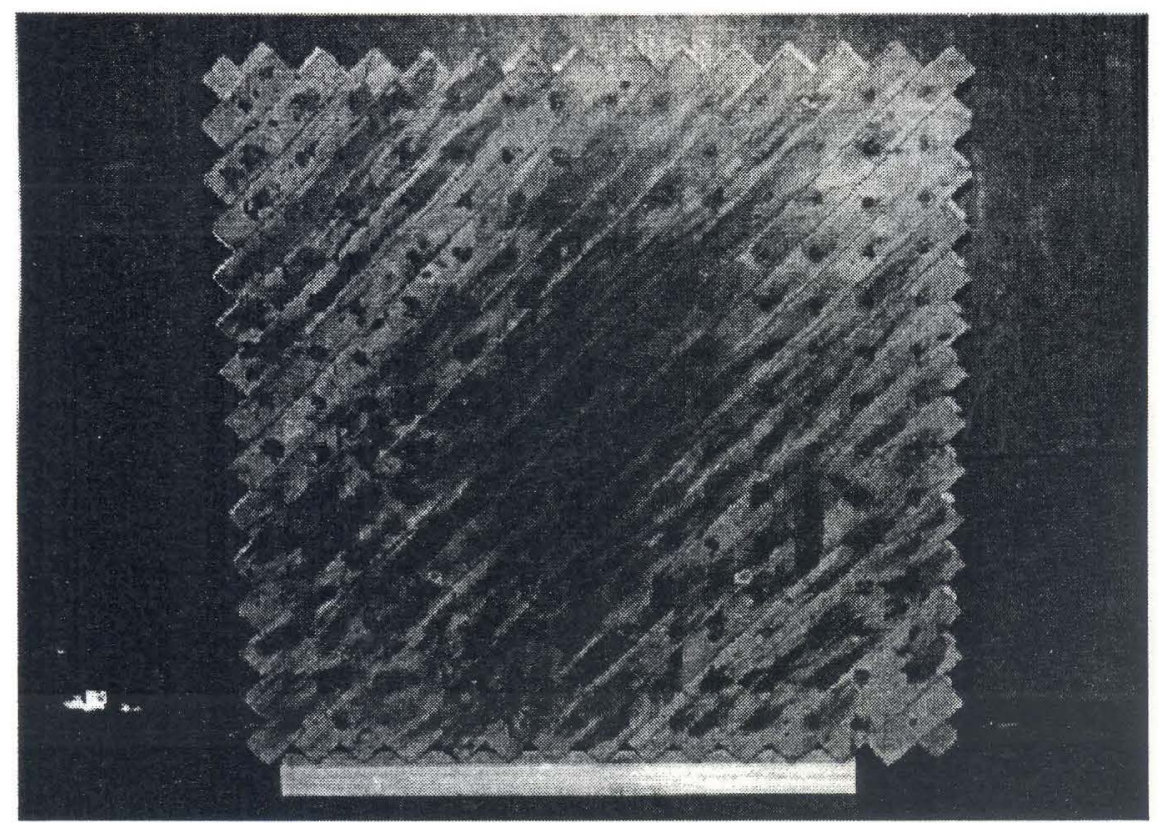

Figura 6.10: Modelo solidarizado com cavilhas. 


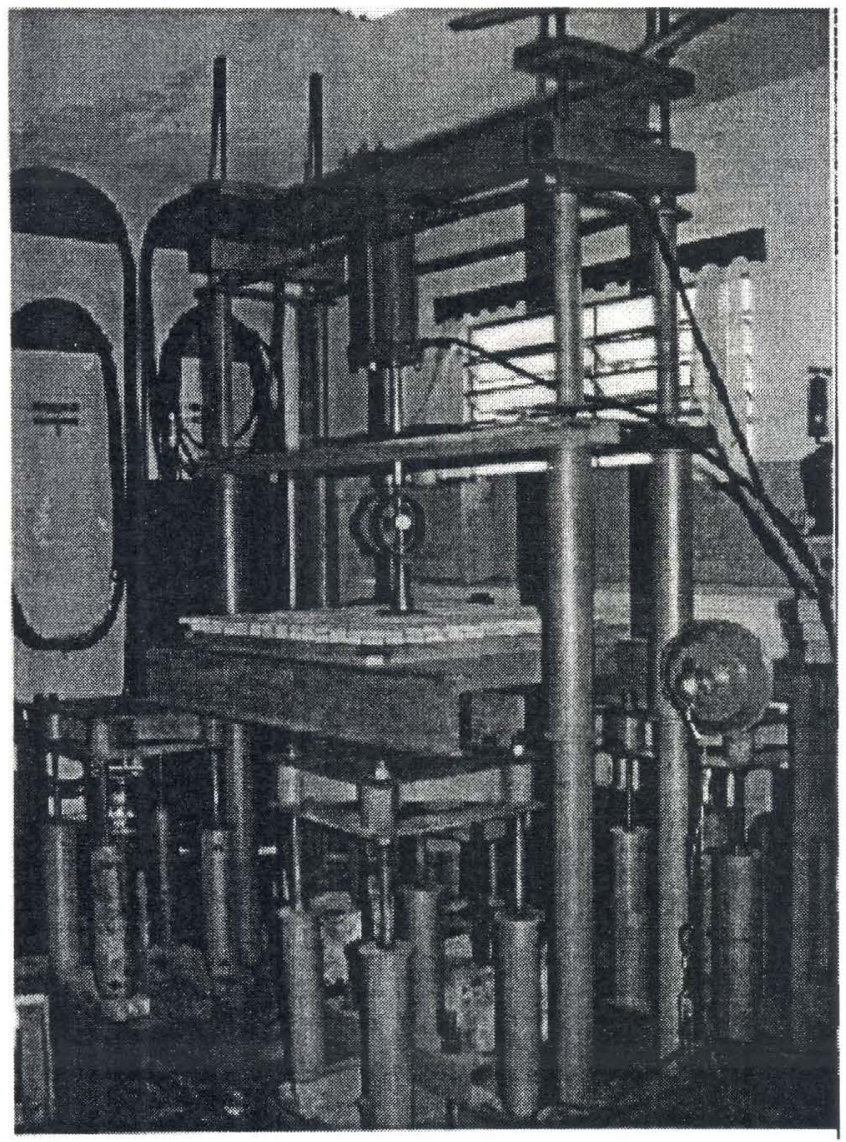

Figura 6.11: Carregamento pontual.

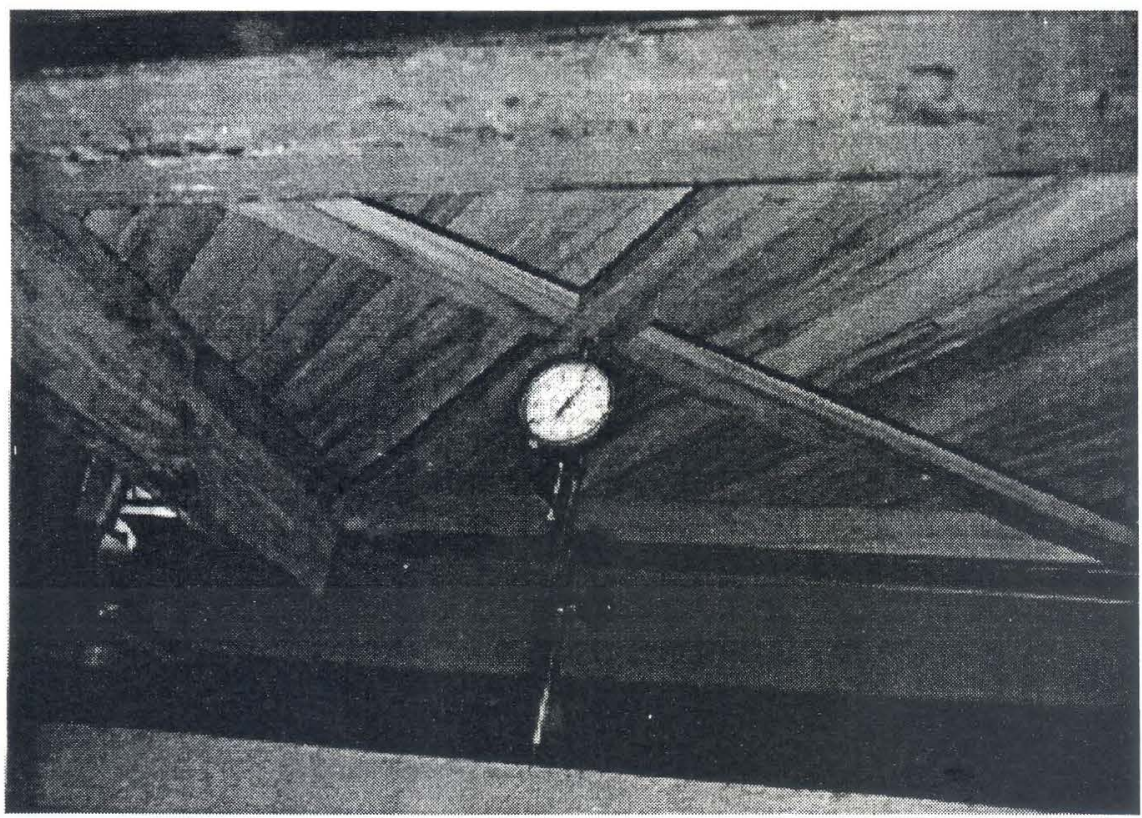

Figura 6.12: Vinculo 1. 


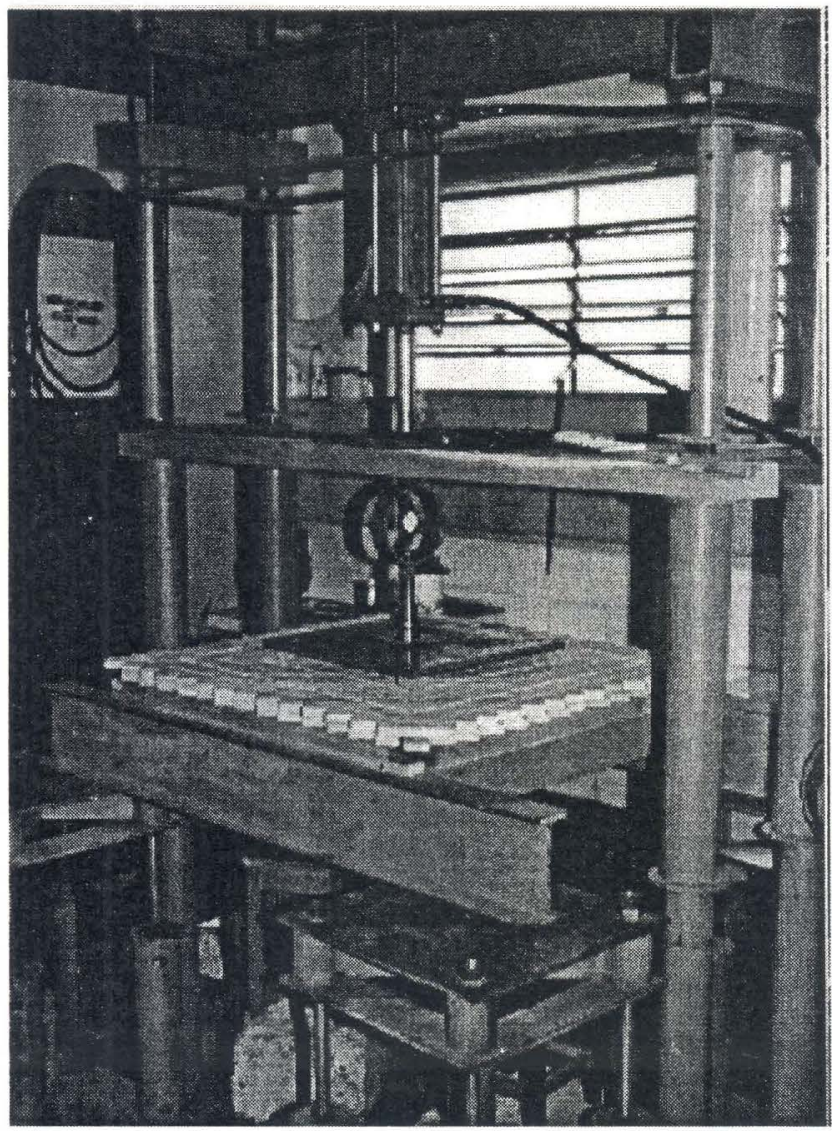

Figura 6.13: Carregamento 4 pontos.

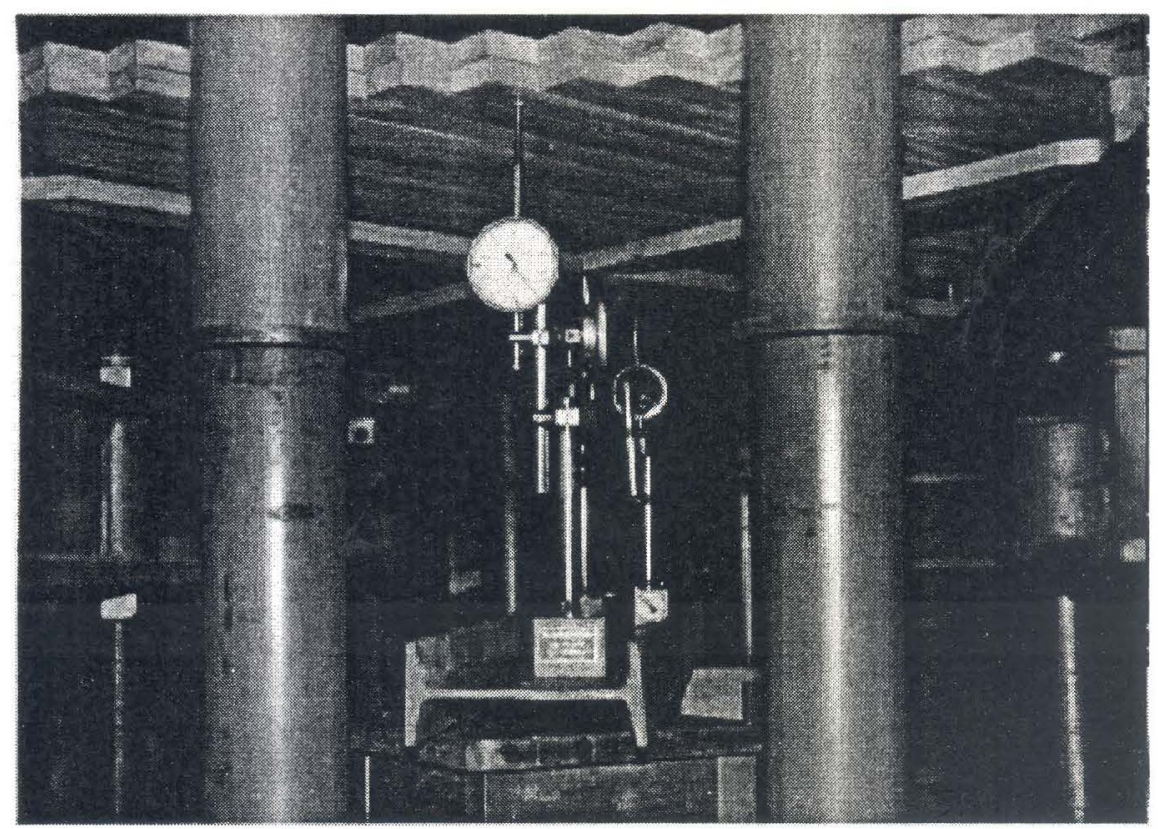

Figura 6.14: Vínculo 2. 


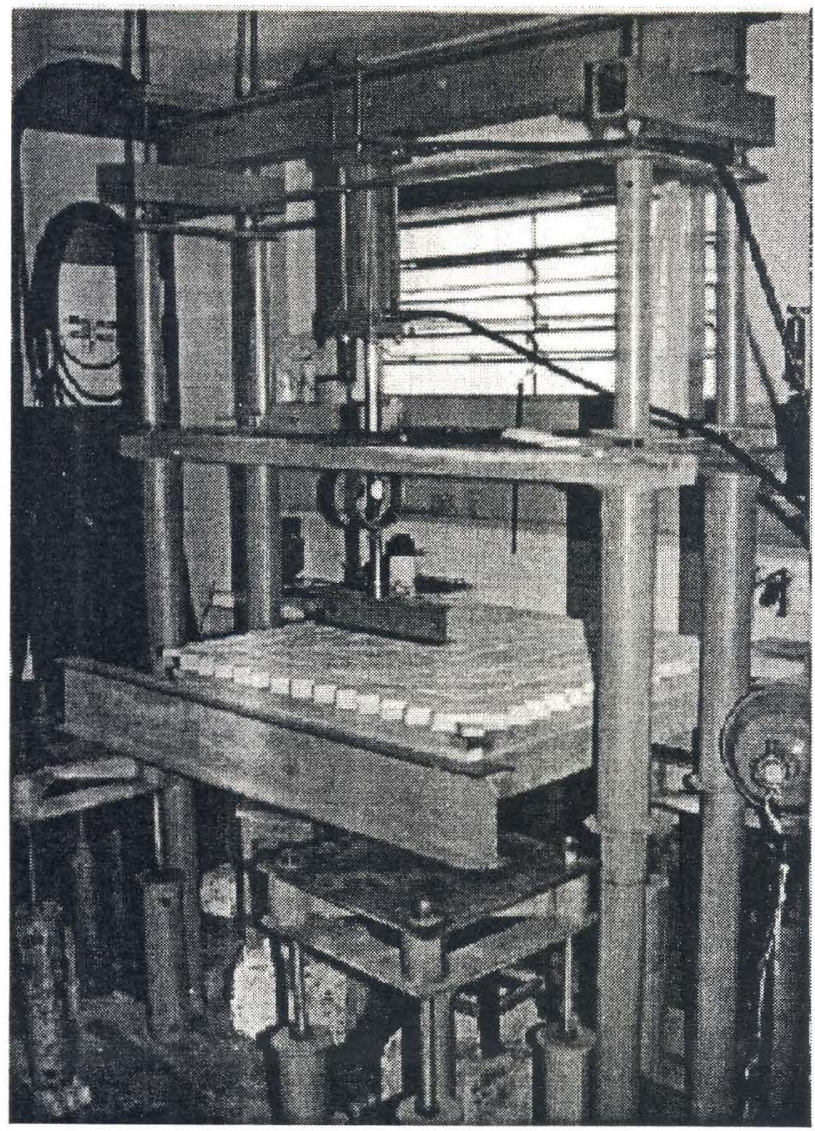

Figura 6.15: Carregamento Linear excêntrico. 


\section{Capitulo sete: Análise dos resultados}

Neste capítulo são apresentados os resultados dos ensaios de flexão dos modelos. Para facilitar a discussão, são colocados sob a forma de quadros e gráficos que mostram o aumento da "rigidez" k com o acréscimo de pontos de solidarização. Os resultados na sua forma integral são apresentados nos Anexos.

\subsection{Variação da "rigidez" $k$ do modelo pregado com o acréscimo de pontos de} ligação

Pelos gráficos pode-se observar uma grande variação nos valores obtidos para a "rigidez" em cada condição de vínculo e carregamento. Examinando-se estas condições de vínculo, sendo a "rigidez" $\mathrm{k}$ uma relação entre o valor da carga total aplicada sobre a superfície do modelo e o valor da consequente superfície elástica formada, no ponto considerado $(k=P / w)$, é justificável a diferença entre as curvas referentes aos carregamentos Pontual, 4 pontos e Linear excêntrico.

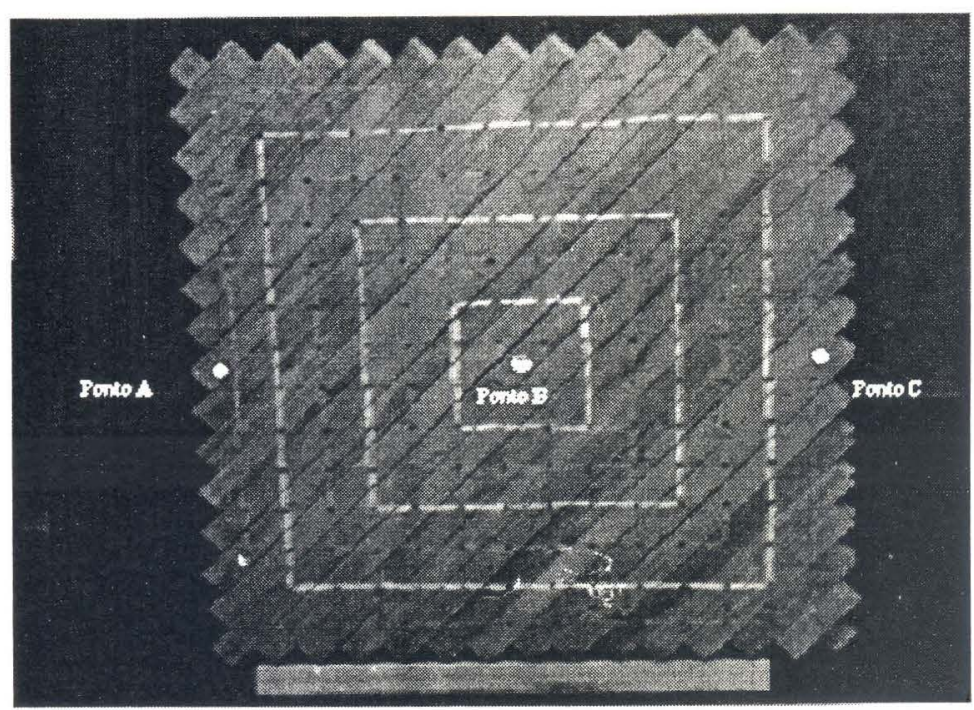

Figura 7.1: Esquema de locação dos pontos de medida de deslocamentos. 
MODELO IA

MODELO IB

\begin{tabular}{|c|c|c|c|c|c|c|c|c|c|}
\hline & & VINC. I & & VÍNC. 2 & & VINC. I & & VÍNC. 2 & \\
\hline Carga & Solidar. & $B$ & $\vec{A}$ & $B$ & $C$ & $B$ & $A$ & $B$ & $C$ \\
\hline \multirow{3}{*}{ Pontual } & $I$ & 0,1591 & 0,1612 & 0,1812 & 0,2092 & 0,3636 & 0,1714 & 0,1295 & 0,2364 \\
\hline & $I I$ & 0,4393 & 0,1777 & 0,1658 & 0,1586 & 0,3496 & 0,1327 & 0,1512 & 0,1361 \\
\hline & III & 0,4177 & 0,1881 & 0,2024 & 0,1794 & 0,3873 & 0,1713 & 0,1782 & 0,1395 \\
\hline \multirow{3}{*}{4 pontos } & $I$ & 0,4622 & 0,2627 & 0,3116 & 0,2567 & 1,1296 & 0,2441 & 0,2528 & 0,2654 \\
\hline & II & 0,9923 & 0,2850 & 0,2150 & 0,2240 & 0,7551 & 0,2256 & 0,2731 & 0,2114 \\
\hline & III & 0,8969 & 0,2817 & 0,3412 & 0,2759 & 0,8182 & 0,2266 & 0,1798 & 0,1311 \\
\hline \multirow{3}{*}{ Lin. exc. } & $I$ & 0,6840 & 0,1455 & 0,2580 & 0,2884 & 2,9876 & 0,0824 & 0,1713 & 0,2038 \\
\hline & II & 0,8884 & 0,1947 & 0,1175 & $0,185 I$ & 0,5381 & 0,1078 & 0,1657 & 0,1538 \\
\hline & III & 0,7340 & 0,1391 & 0,2076 & 0,1988 & 0,7139 & 0,1189 & 0,1837 & 0,1583 \\
\hline
\end{tabular}

Tabela 7.1: "Rigidez" $k$ dos modelos pregados (100 daN/mm).

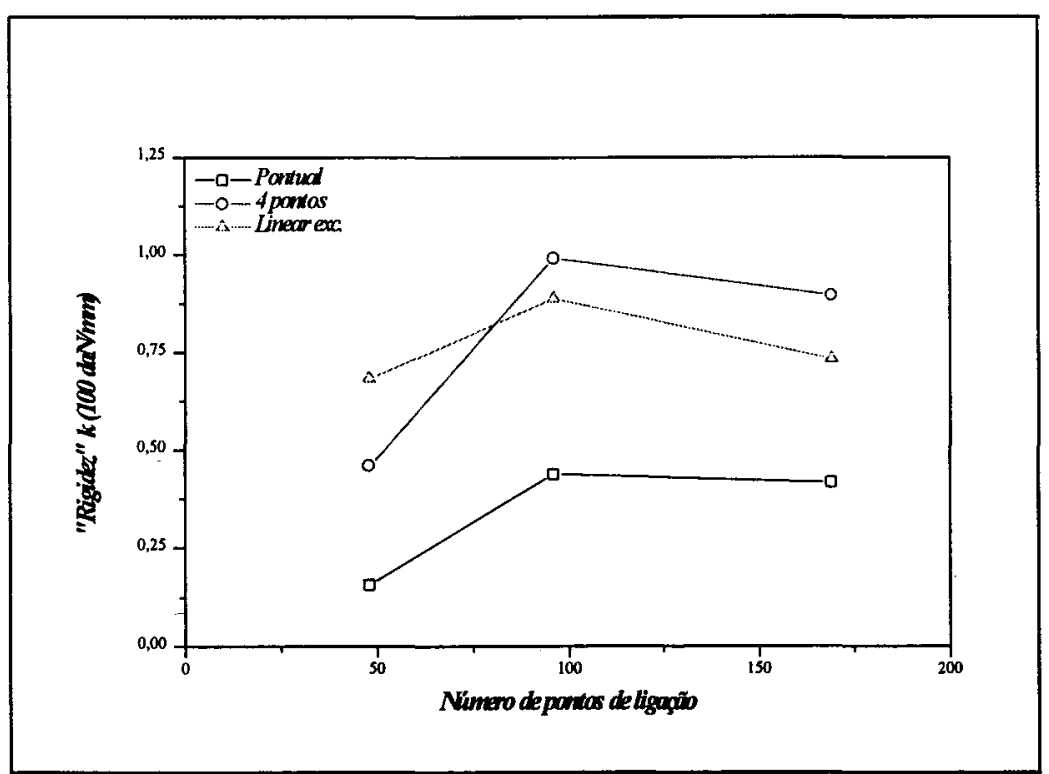

Figura 7.2: Modelo 1A, vínculo 1, flecha em B. 


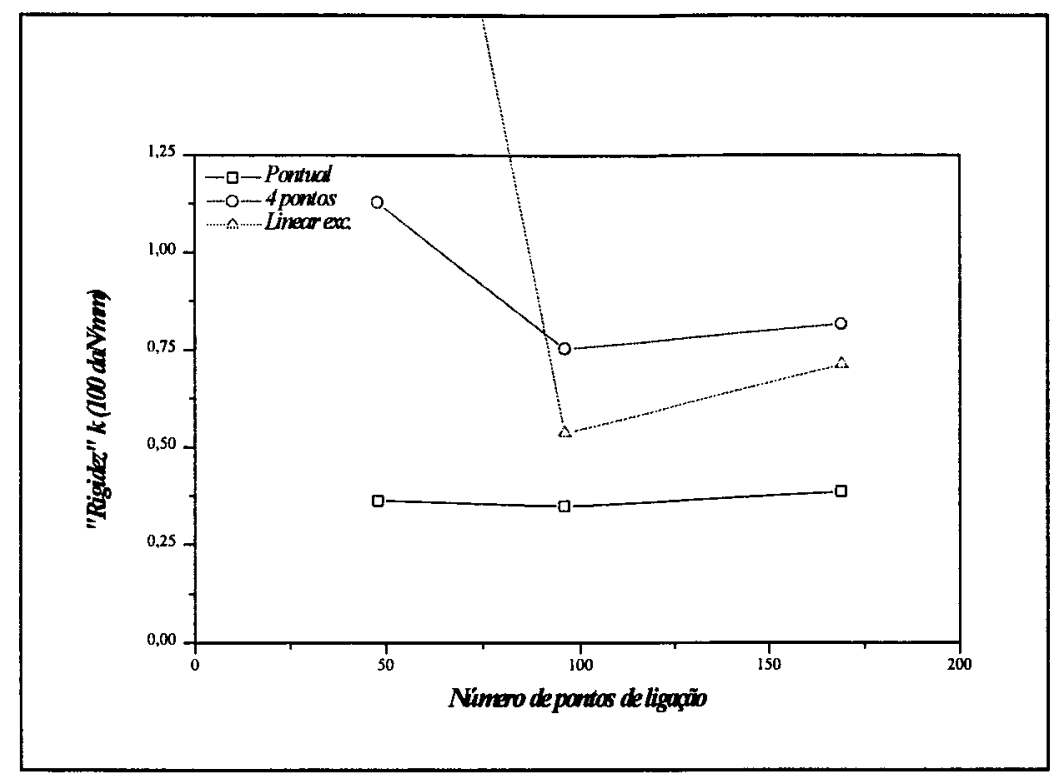

Figura 7.3: Modelo 1B, vínculo 1, flecha em $B$.

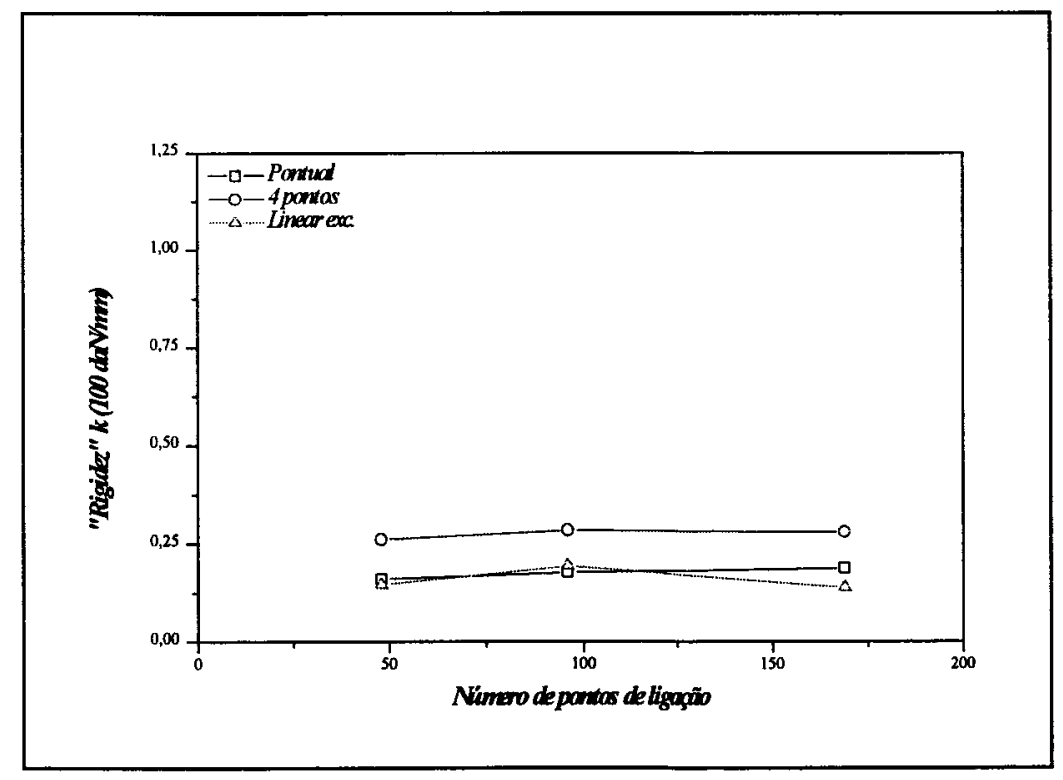

Figura 7.4: Modelo 1A, vinculo 2, flecha em A. 


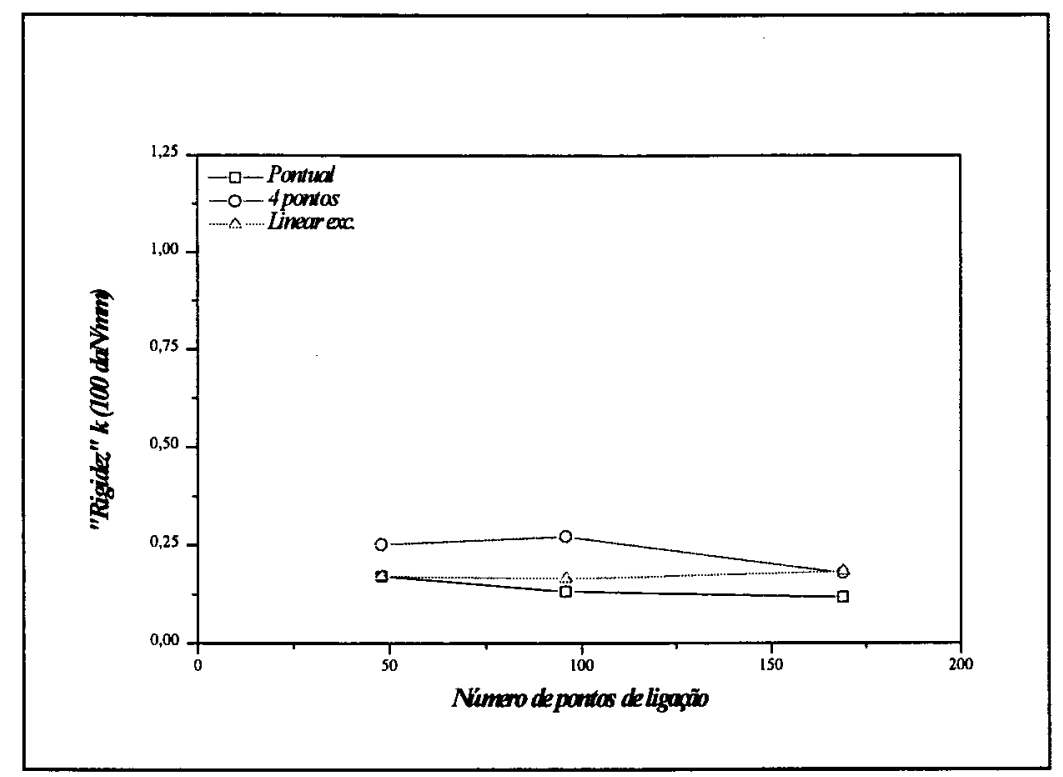

Figura 7.5: Modelo 1B, vínculo 2, flecha em $A$.

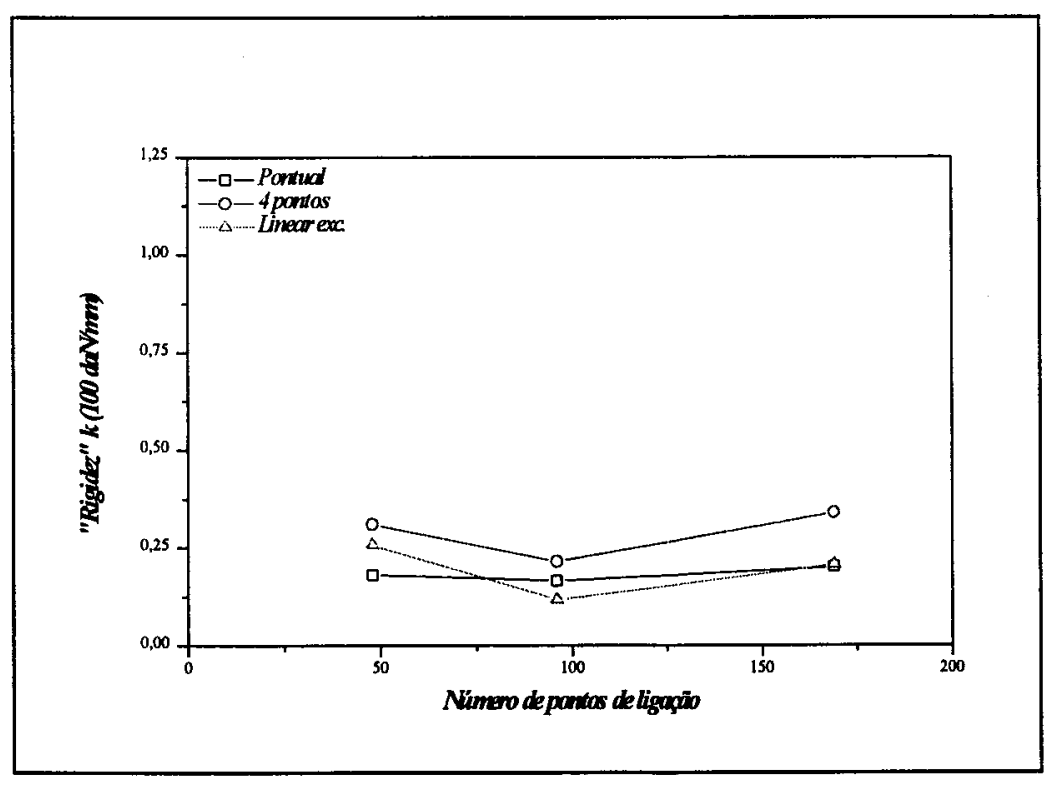

Figura 7.6: Modelo 1A, vínculo 2, flecha em B. 


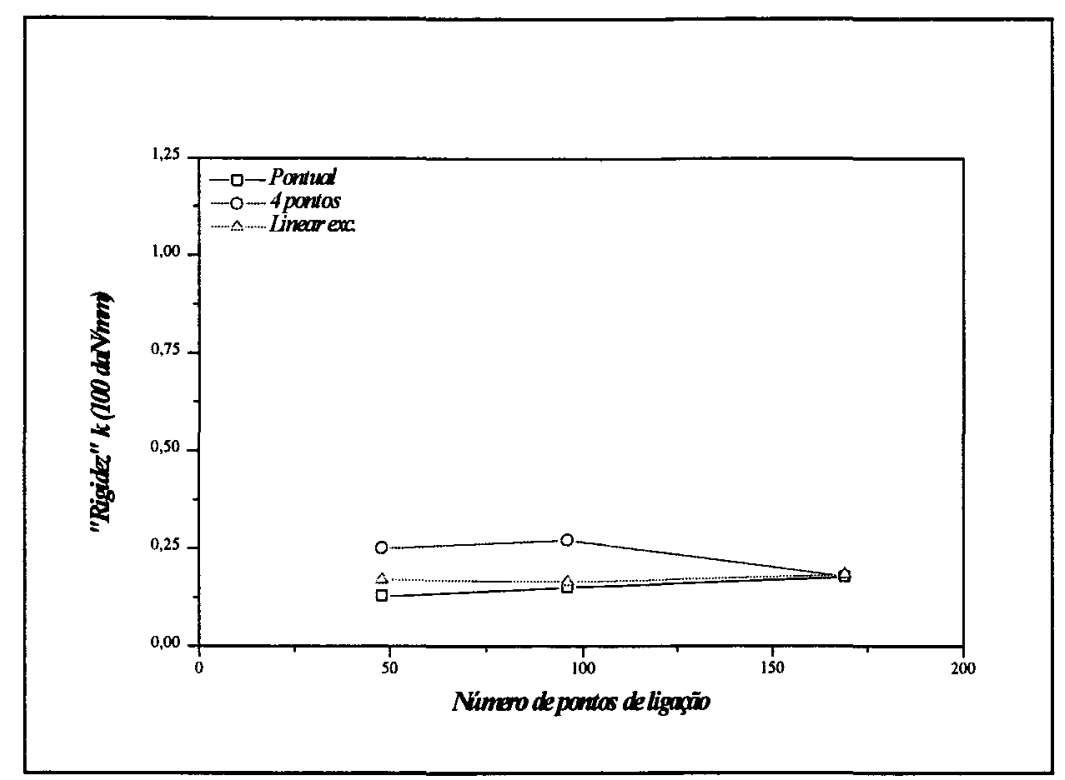

Figura 7.7: Modelo IB, vínculo 2, flecha em B.

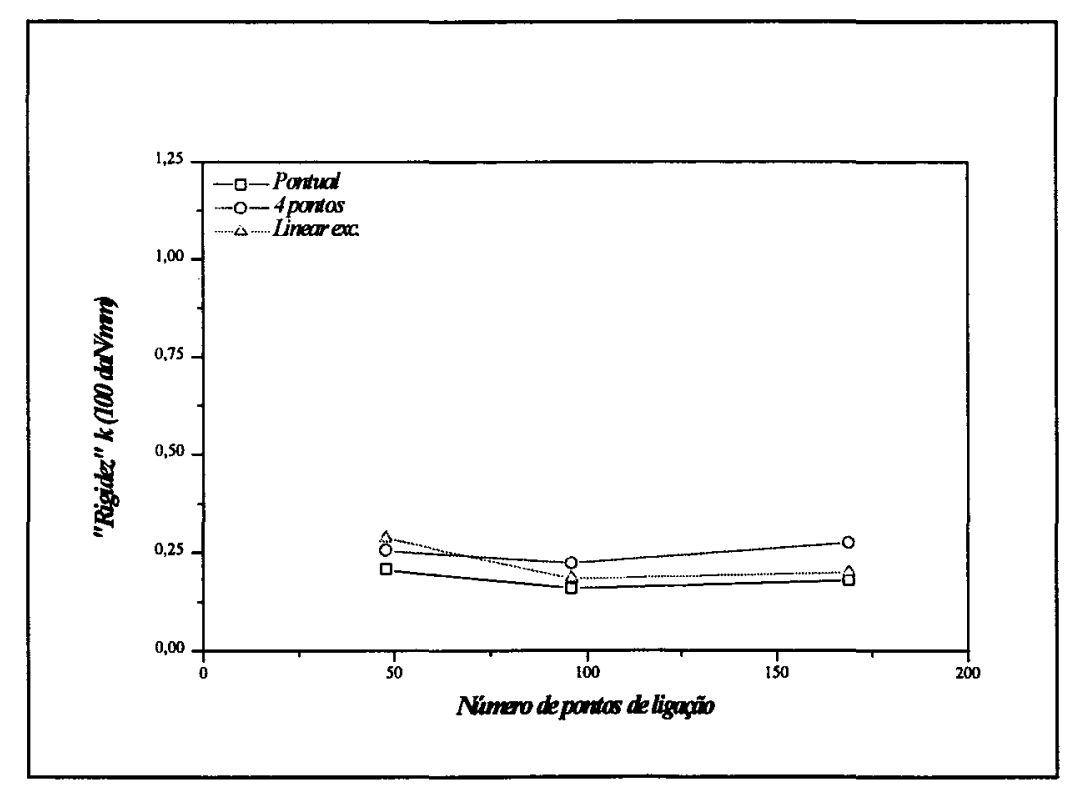

Figura 7.8: Modelo 1A, vinculo 2, flecha em $C$. 


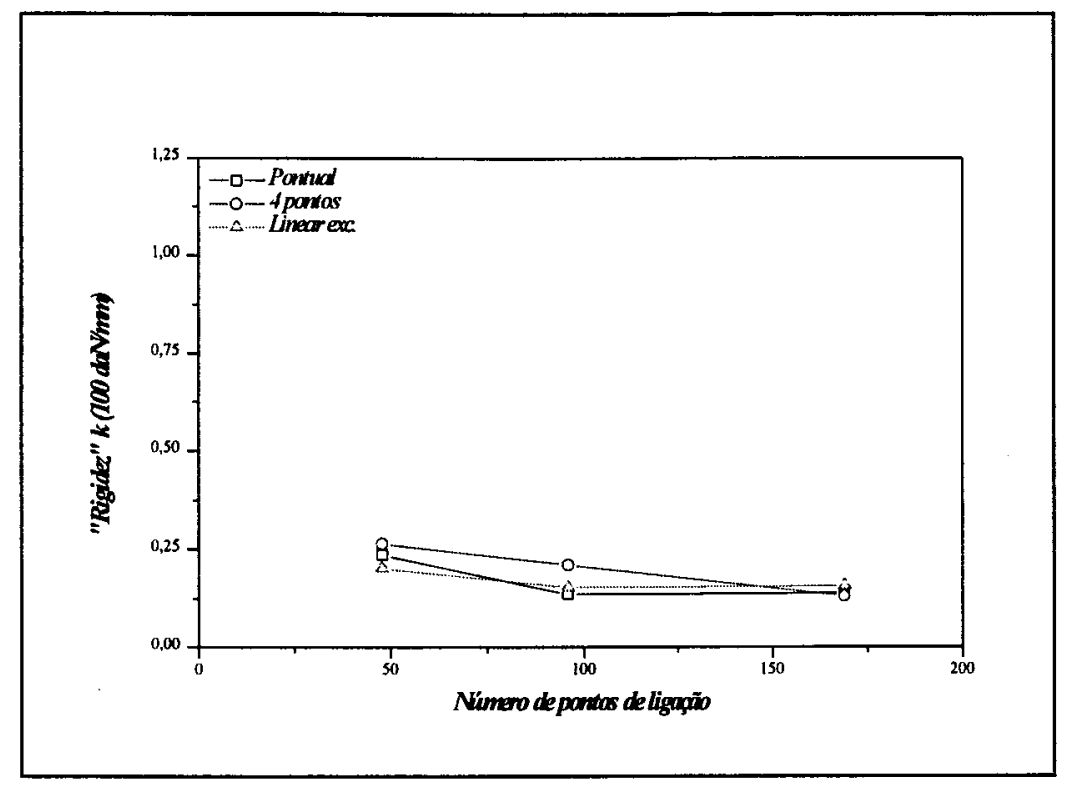

Figura 7.9: Modelo 1B, vínculo 1, flecha em C.

Fazendo-se uma analogia com comportamento de uma viga simplesmente apoiada, de vão igual a $L$, a qual, quando submetida a uma carga concentrada $P$ no meio do vão, forma uma linha elástica com flecha máxima no meio do vão igual a:

$$
f l=\frac{1}{48} \cdot \frac{P L^{3}}{E I}
$$

Se a carga concentrada $P$ for substituída por uma carga uniformemente distribuída $p=P / L$, tem-se:

$$
f_{2}=\frac{5}{384} \cdot \frac{p L^{4}}{E I}=\frac{5}{384} \cdot \frac{p L \cdot L^{3}}{E I}
$$

dai,

$$
f_{2}=\frac{5}{384} \cdot \frac{P L^{3}}{E I}
$$

Desse modo, organizando-se estas expressões: 


$$
\frac{f_{2}}{f_{1}}=\frac{\frac{5}{384} \cdot \frac{P L^{3}}{E I}}{\frac{1}{48} \cdot \frac{P L^{3}}{E I}}=\frac{5}{384} \cdot \frac{48}{1}=\frac{240}{384}=0,625
$$

e, então

$$
f_{2}=0,625 \cdot f_{1}
$$

Ou, seja, para uma mesma carga total atuante $P$, há diferentes relações entre esta e a flecha obtida (neste caso, pode-se dizer: $k=P / f$, e $k_{l}=0,625 k_{2}$ ).

No caso das vínculações pode ser feito raciocínio semelhante. Observando, serem as flechas, no caso da condição de vínculo 2 , superiores àquelas obtidas na condição 1 , é de se esperar valores de $k_{V 2}$ inferiores aos de $k_{V 1}$.

Estes fatos explicam as diferenças entre os gráficos, nas vinculações correspondentes, e justificam a proposta inicial de uma análise simplificada, qualitativa, da variação da rigidez do modelo com o aumento do número de pontos de solidarização entre as peças.

Feitas estas considerações, observa-se a partir dos gráficos haver uma tendência no comportamento do modelo $1 \mathrm{~A}$, cuja rigidez (aqui avaliada indiretamente por meio do parâmetro $k$ ), aumenta gradativamente com o acréscimo de pontos de ligação, no caso da vinculação 1, segundo uma curva hiperbólica que tende assintóticamente para um valor máximo (Figura 7.10).

Para a vinculação 2, esta tendência não está tão clara, indicando ter havido influência no tipo de vinculação adotada, na qual o modelo parece ter comportamento mais próximo de uma viga que de uma placa, dado terem sido muito baixos os níveis de carregamento utilizados.

Para o modelo 1B, não é possível concluir sobre os gráficos obtidos, indicando ter havido falhas na montagem do modelo. 


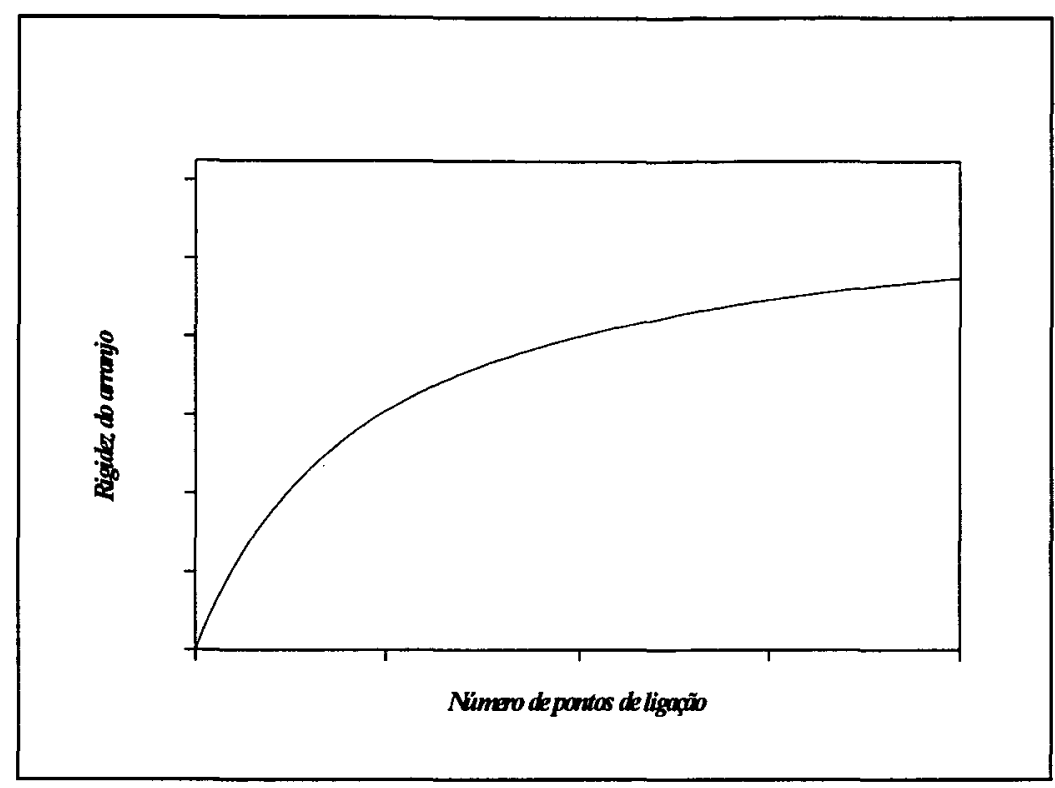

Figura 7.10: Variação hiperbólica da rigidez do arranjo com o número de pontos ligados.

No caso do modelo $1 \mathrm{~A}$, observa-se pequeno ganho de rigidez na passagem da configuração de ligação $I I$ para $I I$, o que permite considerar a configuração $I I$ como sendo a ótima, não havendo vantagem relativa em se aumentar a quantidade de pontos de ligação. Ao invés de aumentar o número de pontos de ligação, deve-se adotar pares de pontos de ligação, como utilizado no estudo de ALMEIDA (1989), garantindo assim uma melhor mobilização de momentos volventes no arranjo.

\subsection{Comportamento comparativo entre arranjos solidarizados por pregos e com cavilhas}

A partir dos valores da "rigidez" $k$ dos modelos pregado e cavilhado apresentados na Tabela 5, observa-se haver dois comportamentos distintos em função da condição de vínculo considerada.

Quando sujeito à condição 1, apoio simples ao longo dos quatro lados, o arranjo cavilhado parece apresentar rigidez ligeiramente maior que o arranjo pregado. Isso se deve à presença da cola, dificultando rotações das peças em torno da cavilha, 
enquanto no arranjo pregado este movimento é praticamente desimpedido, devido à superfície lisa dos pregos utilizados, os quais não podem absorver esforços torçores no plano médio do arranjo, ao contrário das cavilhas embebidas em cola, as quais pela maior solidarização gerada entre as peças das duas camadas que o formam, conseguem mobilizar uma parcela de resistência a estes esforços.

Quando se considera a condição de vínculo 2, apoio simples ao longo de duas bordas opostas e outras duas bordas livres, ocorre uma alteração no comportamento dos arranjos, com o cavilhado apresentando rigidez inferior à do pregado, com uma diferença da ordem de $10 \%$ a $30 \%$.

\begin{tabular}{ccccccc}
\hline Carga & Preg. 1A & Cav. & $\Delta *$ & Preg. $1 A$ & Cav. & $\Delta$ \\
\hline Pontual & 0,4177 & 0,4510 & $8 \%$ & 0,1881 & 0,1296 & $-31 \%$ \\
4 pontos & 0,8969 & 0,9241 & $3 \%$ & 0,2817 & 0,2157 & $-23 \%$ \\
Lin. exc. & 0,7340 & 0,6510 & $-11 \%$ & 0,1391 & 0,0809 & $-42 \%$ \\
\hline Pontual & 0,2024 & 0,2164 & $7 \%$ & 0,1794 & 0,1608 & $-10 \%$ \\
4 pontos & 0,3412 & 0,3106 & $-9 \%$ & 0,2759 & 0,2171 & $-21 \%$ \\
Lin. exc. & 0,2076 & 0,1839 & $-11 \%$ & 0,1988 & 0,1962 & $-1 \%$ \\
\hline
\end{tabular}

Tabela 7.2: Relações entre os valores obtidos para a "rigidez" $k$ dos modelos pregado e cavilhado, $n a$ configuração III.

Isto se dá em função da aparente preponderância de esforços de flexão frente aos de torção no arranjo, demonstrando assim um comportamento inferior da ligação cavilhada em relação à pregada, para esta vinculação, confirmando a analogia

${ }^{*} \Delta=100 .\left(k_{c a v}-k_{\text {preg }}\right) / k_{\text {preg. }}$ 
admitida em relação às observações de GESUALDO (1987). Porém é necessário serem feitos mais exames quanto ao comportamento destas ligações no arranjo ortogonal.

\subsection{Análise numérica do arranjo pregado, configuração II}

Admitindo a configuração II como ótima para o modelo 1A, fez-se o exame de modelos numéricos de placa isótropa, com o objetivo de determinar qual a placa isótropa equivalente a esta configuração, utilizando os resultados obtidos nos ensaios para a condição de vínculo 1, mais indicada para o uso em pontes de madeira.

Fixando-se inicialmente o módulo de elasticidade da placa como igual à média dos módulos obtidos nos ensaios de flexão dos sarrafos de Peroba Rosa utilizados na confecção dos modelos, foram examinadas 4 diferentes espessuras, $10 \mathrm{~mm}, 20 \mathrm{~mm}, 30$ $m m$ e $40 \mathrm{~mm}$, sendo esta última a espessura do modelo real ensaiado. Para construção dos modelos numéricos, foi admitido um intervalo para o valor do coeficiente de Poisson, $v$, situado entre $0,0<v<0,33$.

Desse modo, tem-se as Tabela 6 e 7:

\begin{tabular}{cccc}
\hline \multicolumn{4}{c}{$v=0$} \\
\hline$d$ & Pontual & 4 Pontos & Lin exc. \\
\hline Modelo & 0,4393 & 0,9923 & 0,8884 \\
\hline 10 & 0,1205 & 0,1986 & 0,1912 \\
20 & 0,9278 & 1,5886 & 1,5293 \\
30 & 3,2520 & 5,3619 & 5,3821 \\
40 & 7,7101 & 12,7065 & 12,2399 \\
\hline
\end{tabular}

\begin{tabular}{cccc}
\hline \multicolumn{4}{c}{$v=0,33$} \\
\hline$d$ & Pontual & 4 Pontos & Lin. exc. \\
\hline Modelo & 0,4393 & 0,9923 & 0,8884 \\
\hline 10 & 0,1354 & 0,2233 & 0,2150 \\
20 & 1,0835 & 1,7864 & 1,7928 \\
30 & 3,6563 & 6,0277 & 6,0496 \\
40 & 8,6655 & 14,2857 & 14,3472 \\
\hline
\end{tabular}

Tabelas 7.3 e 7.4: "Rigidez" $k$ do Modelo pregado $1 \mathrm{~A}$ em comparação com modelos numéricos de placa isótropa. 
Das Tabelas 6 e 7 observa-se que a espessura da placa equivalente situa-se no intervalo $10 \mathrm{~mm}<d<20 \mathrm{~mm}$ para qualquer dos coeficientes de Poisson examinados. Isto mostra ser razoável a hipótese do intervalo entre 0 e 0,33 para o valor do coeficiente de Poisson.

Para se ter uma idéia mais precisa a respeito do valor da espessura da placa equivalente, é necessário lembrar que a rigidez da placa aumenta com o cubo de sua espessura, também se verificando ao se tratar da "rigidez" k. Deste modo pode-se admitir a seguinte relação:

$$
k_{i}=k_{j} \cdot\left(\frac{d_{i}}{d_{j}}\right)^{3} \text { e, então, } d_{i}=d_{j} \cdot\left(\frac{k_{i}}{k_{j}}\right)^{1 / 3}
$$

Admitindo $d j=10 \mathrm{~mm}$ :

\begin{tabular}{ccccccc}
\hline \multicolumn{4}{c}{$v=0$} & \multicolumn{4}{c}{$v=0,33$} \\
\hline$d$ & Pontual & 4 Pontos & Lin exc. & Pontual & 4 Pontos & Lin. exc. \\
\hline$k i$ & 0,4393 & 0,9923 & 0,8884 & 0,4393 & 0,9923 & 0,8884 \\
$k j$ & 0,1205 & 0,1986 & 0,1912 & 0,1354 & 0,2233 & 0,2150 \\
$k i$ & 15,3 & 17,1 & 16,6 & 14,8 & 16,4 & 16,1 \\
\hline
\end{tabular}

Tabela 7.5: Valores obtidos para a espessura da placa equivalente.

Observa-se que a espessura da placa equivalente é da ordem de $40 \%$ do espessura do modelo real, considerando o intervalo de $37 \%$ a $43 \%$, não havendo condições de se realizar uma estimativa mais precisa do valor do coeficiente de Poisson. 


\subsection{Estimativa da capacidade de carga para para um tabuleiro ortogonal solidarizado por meio de pregos com a configuração II}

Em seu estudo, S.M.B. ALMEIDA (1989) estima a carga de ruptura dos modelos ensaiados admitindo a aplicação da Teoria das Charneiras Plásticas, tendo sido os resultados suficientemente próximos à previsão realizada.

Admita-se que a mesma aplicação possa ser feita, ao nível de ilustração, para uma estimativa de carga de ruptura para o arranjo estudado neste trabalho. Suponhase o uso do arranjo ortogonal para a execução de um tabuleiro de ponte de madeira apoiado sobre vigas de rigidez longitudinais e transversinas rígidas (pensando na aplicação em uma ponte pênsil, por exemplo), utilizando módulos quadrados de dimensões da ordem de $3 m$ a $4 m$.

Sejam as dimensões laterais do módulo considerado iguais a 3,5 $m \times 3,5 \mathrm{~m}$, construído a partir de peças de seção retangular de seção $6 \mathrm{~cm} \times 16 \mathrm{~cm}$, da espécie Eucalipto Citriodora.

As peças constituirão duas camadas de $6 \mathrm{~cm}$ de espessura, solidarizadas por pregos lisos de aço utilizando linhas de ligação semelhantes às apresentadas na configuração $I I$ deste estudo.

Supondo o módulo simplesmente apoiado nas quatro bordas, e sujeito à ação de uma roda de caminhão de porte médio atuando no centro, qual a máxima capacidade de carga, considerando as linhas de ruptura?

A Teoria das Charneiras Plásticas fornece para este problema o seguinte equacionamento para a carga de ruptura

$$
P_{\text {rup }}=8 m_{\text {rup }}
$$

onde: $m_{\text {rup }}$ é o momento de ruptura determinado para o material, e tem dimensões de momento por unidade de comprimento. 
Considere-se uma viga de seção retangular de largura unitária. A tensão de ruptura é dada pela Resistência dos Materiais através da expressão:

$$
\text { rup }=\frac{M_{\text {rup }}}{W}=\frac{M_{\text {rup }}}{b d^{2} / \dot{\sigma}}=\frac{6 M_{\text {rup }}}{b d^{2}}=\frac{6 m_{\text {rup }}}{d^{2}}
$$

daí,

$$
m_{\text {rup }}=\frac{\sigma_{\text {rup }} \cdot d^{2}}{6}
$$

onde: $m_{\text {rup }}=M_{\text {rup }} / b$

Logo, tem-se:

$$
\operatorname{Prup}=\frac{8}{6} \sigma_{r u p} \cdot d^{2}
$$

Para o Eucalipto Citriodora, a tensão de ruptura é da ordem de 1000 a 1200 $\mathrm{daN} / \mathrm{cm}^{2}$. Admitindo que a espessura da placa equivalente seja $40 \%$ da espessura do tabuleiro, tem-se:

$$
\begin{aligned}
& P_{r u p}=\frac{8}{6} 1000 \cdot(0,4 \cdot 12)^{2}=30.720 \mathrm{daN} \\
& P_{\text {adm }}=0,2 \cdot P_{\text {rup }}=0,2 \cdot 30.720=6.144 \mathrm{daN}
\end{aligned}
$$

Estes valores indicam que o tabuleiro ortogonal é viável nas dimensões apresentadas, em termos de resistência, ao uso em pontes de classe 30 . Porém, esta estimativa deve ser considerada grosseira, sendo necessários outros estudos afim de se poder realizar esta estimativa com segurança. 


\section{Capítulo oito: Considerações finais}

\subsection{Conclusões do estudo}

Da análise realizada com os dados dos ensaios, pode-se admitir as seguintes conclusões:

- A rigidez do tabuleiro de madeira com arranjo ortogonal aumenta hiperbólicamente com o acréscimo de pontos de solidarização entre as peças das camadas que o compõem, tendendo assintóticamente a um máximo.

- A configuração de solidarização II pode ser admitida como sendo ótima. Aumentos no número de pontos de solidarização a partir dela não são acompanhados de significativo ganho de rigidez. O uso de uma configuração com maior número de ligações pontuais pode ser substituído pela configuração II utilizando dois pontos de ligação.

- O modelo cavilhado tem rigidez ligeiramente inferior em relação ao modelo pregado, devendo vir a ser melhor caracterizado este comportamento relativo.

- Pode-se admitir, como modelo matemático para avaliação da rigidez à flexão do modelo 1A, na configuração $I I$, o comportamento de uma placa isótropa com espessura equivalente da ordem de $40 \%$ da espessura real, nada podendo ser dito em relação ao coeficiente de Poisson.

- O arranjo é suficientemente resistente para uso em pontes secundárias, havendo indicação de capacidade de carga admissível da ordem de $50 \mathrm{kN}$ a $60 \mathrm{kN}$, 
para um módulo de $300 \mathrm{~cm} \times 300 \mathrm{~cm}$ formado por duas camadas de peças de seção 6 $x 16 \mathrm{~cm} 2$, para a espécie Eucalipto Citriodora.

\subsection{Críticas e sugestões para continuidade do estudo do arranjo ortogonal}

A metodologia empregada neste estudo não foi suficientemente rigorosa para permitir uma quantificação dos parâmetros de rigidez do arranjo considerado como placa isótropa. Em função disso algumas colocações devem ser feitas.

Em uma fase posterior de continuação deste estudo, devem ser tomados maiores cuidados quanto à obtenção e caracterização dos materiais. $\mathrm{O}$ uso de pregos lisos de aço certamente prejudicou o perfeito ajuste dos dados de ensaio em relação às hipóteses iniciais de comportamento do arranjo.

A não consideração de relações de escala mais precisas entre o prego, a cavilha e a espécie de madeira utilizados permite o surgimento de variáveis sobre as quais não se tem controle durante a fase de experimentação e análise de dados.

O próprio processo de montagem dos modelos deve ser acompanhado de maior cuidado. Após a confecção dos modelos, realizada com acompanhamento do autor, observou-se ser necessária a idealização de um gabarito de montagem que permita um mínimo de segurança quanto à possíveis êrros durante esta fase.

A execução dos ensaios deve ser precedida de uma avaliação cuidadosa das condições de vínculo.

A utilização do quadro-gabarito não garante per si o adequado comportamento das vinculações, visto ocorrer vínculos livremente apoiados ao invés de vínculos simplesmente apoiados, os quais mesmo sob condições de baixo nível de carregamento causam diferenças no comportamento estrutural, dificultando até a construção de modelos numéricos que bem representem as condições de ensaio. 
Deste modo, podem ser feitas as seguintes sugestões para modificação na metodologia utilizada:

- Uso de modelos reduzidos em menor escala. Os modelos utilizados na escala 1:3 são de difícil manipulação, por seu peso e suas dimensões. Assim, sugere-se o uso de modelos na escala 1:6, executando 8 modelos com o mesmo volume de madeira utilizado na construção de um único modelo na escala 1:3.

- A própria metodologia de ensaio deve ser modificada, utilizando pelo menos um modelo para a caracterização de cada configuração de solidarização entre as peças, para cada tipo de carregamento aplicado, levado até à ruptura, e com maior precisão na obtenção dos dados.

Aqui deve ser feita menção à pequena margem de informações obtida com a leitura de algumas flechas. Estas devem ser feitas utilizando-se transdutores indutivos em associação com a leitura de deformações com uso de strain gages, cujos pontos de leitura devem ser precedidos por cuidadoso estudo visando a fundamentação teórica do ensaio.

Esta fundamentação deve envolver, por exemplo, o modelamento matemático do problema da flexão do arranjo, cujo processo deve utilizar preferencialmente conceitos referentes ao equilíbrio entre o trabalho interno e o trabalho externo no sitema estrutural considerado (arranjo + condições de vínculo + condições de carregamento).

- Devem ser examinados outros tipos de conectores (pregos enrugados, cavilhas de diferentes espécies, parafusos atarrachantes e passantes, etc.) de modo a se avaliar um comportamento típico do arranjo, independente do conector utilizado, mas que permita determinar a eficiência de cada um.

Para tanto, a caracterização dos conectores deve ser realizada previamente, ou ser substituida pela adoção de resultados obtidos em outras pesquisas. 
- Após, ou mesmo simultaneamente, à caracterização do arranjo ortogonal, devem ser avaliadas possibilidades de pré-fabricação e processos construtivos adequados a seu uso na construção rápida de pequenas pontes, particularmente quanto à sua fixação nos outros elementos componentes da superestrutura.

Este arranjo deverá ser adequado para utilização em pontes pênseis em regiões de difícil acesso, como a Amazônia.

Estas pontes deverão ser projetadas visando sua pré-fabricação, de modo a facilitar o transporte e a execução em locais distantes dos grandes centros, com pequenas equipes de trabalho, treinadas para esta tarefa. 


\section{Obras consultadas e obras citadas}

ALMEIDA, S. M. B. (1989). Pontes estaiadas de madeira. São Paulo, 1989. 248p. Tese (Doutorado) - Escola Politécnica, Universidade de São Paulo.

ALMEIDA, P. A. O. (1990). Estruturas de grande porte de madeira composta. São Paulo, 1990. 277p. Tese (Doutorado) - Escola Politécnica, Universidade de São Paulo.

ALMEIDA, P. A . O. \& FUSCO, P. B. (1992). Dimensionamento das ligações pregadas e parafusadas baseado no método dos estados limites. In: ENCONTRO BRASILEIRO EM MADEIRAS E EM ESTRUTURAS DE MADEIRA, 4., 1992, São Carlos. Anais. São Carlos, Escola de Engenharia de São Carlos, Universidade de São Paulo, 1992. v.5, p. 79-88.

ASSOCIAÇÃO BRASILEIRA DE NORMAS TÉCNICAS. (1982). NBR-7190 Cálculo e execução de estruturas de madeira. Rio de Janeiro. (1984). NBR-7188 - Carga móvel em ponte rodoviária e passarela de pedestres. Rio de Janeiro. . (1984). NBR-8681 - Ações e segurança nas estruturas. Rio de Janeiro.

ASSAN, A. E. et al. (1970). Estruturas de madeira - Trabalho extra: Passarela. São Carlos, 1970. Não paginado. Memorial de cálculo (Curso de Graduação) Escola de Engenharia de São Carlos, Universidade de São Paulo. /Manuscrito/ BALLULA, J. W. et al. (1970). Estruturas de madeira - Trabalho extra: Cálculo de uma ponte. São Carlos, 1970. 11p. Memorial de cálculo (Curso de 
Graduação) - Escola de Engenharia de São Carlos, Universidade de São Paulo. /Mimeografado/

BENINI, C. H. (1988). Ponte pênsil de madeira: classificação estrutural da madeira. São Carlos, EESC-USP, 1988. 22p. (Relatório de Iniciação Científica LaMEM-SET-EESC-USP).

CALIL Jr., C.; LAHR, F. A. R.; DIAS, A. A. (1993). Passarela pênsil com vigas principais de madeira. In: ENCONTRO REGIONAL EM MADEIRAS E EM ESTRUTURAS DE MADEIRA, 1., 1993, São Paulo. Anais. São Paulo, Escola Politécnica, USP, 1993. Adendo, não paginado.

CARRASCO, E. V. M. (1983). Ligações de peças estruturais de madeira por pregos. In: ENCONTRO BRASILEIRO EM MADEIRAS E EM ESTRUTURAS DE MADEIRA, 1., 1983, São Carlos. Anais. São Carlos, Escola de Engenharia de São Carlos, USP, 1983. v.2, não paginado.

CHAHUD, E. (1985). Tração paralela em peças de madeira. São Carlos, 1985. 127p. Dissertação (Mestrado) - Escola de Engenharia de São Carlos, Universidade de São Paulo.

DIAS, A. A. (1982). Estudo experimental do modelo reduzido de uma ponte pênsil com viga de rigidez de madeira laminada. São Carlos, EESC-USP, 1982. 88p. (Relatório de Iniciação Científica LaMEM-SET-EESC-USP, 1).

(1982). Estudo experimental do modelo reduzido de uma ponte pênsil com viga de rigidez de madeira laminada. São Carlos, EESC-USP, 1982. 52 p. (Relatório de Iniciação Científica LaMEM-SET-EESC-USP, 3).

(1982). Estudo experimental do modelo reduzido de uma ponte pênsil com viga de rigidez de madeira laminada. São Carlos, EESC-USP, 1982.52 p. (Relatório de Iniciação Científica LaMEM-SET-EESC-USP, 4). 
(1983). Considerações teóricas a respeito de projetos de pontes pênseis de madeira. In: ENCONTRO BRASILEIRO EM MADEIRAS E EM ESTRUTURAS DE MADEIRA, 1., 1983, São Carlos. Anais. São Carlos, Escola de Engenharia de São Carlos, USP, 1983. v.5, não paginado.

(1983). Ensaio de um modelo de ponte pênsil de madeira. In: ENCONTRO BRASILEIRO EM MADEIRAS E EM ESTRUTURAS DE MADEIRA, 1., 1983, São Carlos. Anais. São Carlos: Escola de Engenharia de São Carlos, USP, 1983. v.5, não paginado.

(1987). Distribuição transversal de cargas em pontes de madeira. São

Carlos, 1987. 152p. Dissertação (Mestrado) - Escola de Engenharia de São Carlos, Universidade de São Paulo.

DEUSTSCHE NORMEN. (1952). DIN 52188 - Prüfung von holz zugwersuch. Berlin.

FREITAS, M. (1978). Pontes : Introdução e definições. São Paulo, EPUSP, 1978.

FUSCO, P. B. \& ALMEIDA, P. A. O. (1989). Estados limites de uniões pregadas de madeira. In: ENCONTRO BRASILEIRO EM MADEIRAS E EM ESTRUTURAS DE MADEIRA, 3., 1989, São Carlos, Anais. São Carlos, Escola de Engenharia de São Carlos, Universidade de São Paulo, 1989. v.3, p. 71-102.

GESUALDO, F. A. R. (1982). Ligação de peças estruturais de madeira por cavilhas partidas. São Carlos, 1982. 103p. Dissertação (Mestrado) - Escola de Engenharia de São Carlos, Universidade de São Paulo.

(1987). Deformações das ligações nas estruturas de madeira. São Carlos, 1987. 178p. Tese (Doutorado) - Escola de Engenharia de São Carlos, Universidade de São Paulo. 
GODOI, M. O. (1988). Ponte pênsil de madeira - detalhes construtivos. São Carlos, EESC-USP, 1988. (Relatório de Iniciação Cientifica LaMEM-SET-EESC-USP, 1.).

(1989). Ponte pênsil de madeira - detalhes construtivos. São Carlos, EESC-USP, 1989. (Relatório de Iniciação Cientifica LaMEM-SET-EESC-USP, 2.).

GRAVINA, P. B. J. (1948). Contribuição para a teoria e cálculo das pontes pênseis. São Paulo, EPUSP, 1948.

HELLMEISTER, J. C. (1973). Sobre a determinação das características físicas da madeira. São Carlos, 1973. 120p. Tese (Doutorado) - Escola de Engenharia de São Carlos, Universidade de São Paulo.

(1978). Pontes de eucalipto citriodora. São Carlos, 1978. 85p. Tese (Livre Docência) - Escola de Engenharia de São Carlos, Universidade de São Paulo.

HELLMEISTER, J. C.; LAHR, F. A. R.; CALIL Jr., C. (1983). Ponte pênsil com vigas principais, pilares e tabuleiro de madeira. In: ENCONTRO BRASILEIRO EM MADEIRAS E EM ESTRUTURAS DE MADEIRA, 1, 1983, São Carlos. Anais. São Carlos: Escola de Engenharia de São Carlos, USP, 1983. v.5, não paginado.

HELLMEISTER, J. C.; OLIVEIRA, E. S. (1975). Memória de cálculo da ponte de madeira do trecho Cambaratiba - Borborema. São Carlos, EESC-USP, 1975. (Relatório Técnico LaMEM-SET-EESC-USP).

HORTEGAL, I. R. (1979). Contribuição ao estudo das pontes pênseis de madeira. São Carlos, 1979. 216p. Dissertação (Mestrado) - Escola de Engenharia de São Carlos, Universidade de São Paulo. 
INSTITUTO DE PESQUISAS TECNOLÓGICAS DO ESTADO DE SÃO PAULO. (1986). Manual de preservação de madeiras. v.1. São Paulo, 1986.

KARLSEN, G. G. (1967). Wooden Structures. Moscou, Mir Publishers, 1967.

KOLLMANN, F. (1951). Technologie des holzes und der holzes werkstoffe. Berlin, Zweite Auflage - Erster Band - Springer Verlag, 1951,

LAHR, F. A. R. (1983). Sobre a determinação de propriedades de elasticidade da madeira. São Carlos, 1983.228p. Tese (Doutorado) - Escola de Engenharia de São Carlos, Universidade de São Paulo.

LASKUS, A. \& SCHÖDER, H. (1955). Holzern Brücken. Berlin, Verlag von Vilhelm Ernst \& Sohn, 1955.

LEONHARDT, F.; MÖNNIG, E. (1979). Construções de concreto. v.6. Rio de Janeiro, Interciência, 1979.

LOGSDON, N. B. (1982). Contribuição ao estudo das pontes de madeira. São Carlos, 1982. 370p. Dissertação (Mestrado) - Escola de Engenharia de São Carlos, Universidade de São Paulo.

MATTHIESEN, J. A. (1987). Contribuição ao estudo das pontes de eucalipto citriodora. São Carlos, 1987. 220p. Tese (Doutorado) - Escola de Engenharia de São Carlos, Universidade de São Paulo.

MARTINELLI, D. A. O.; MONTANARI, I.; SAVASSI, W. (1986). Placas elásticas. São Carlos, EESC/USP, 1986.

MENDES, A. P. (1984). Resistência da madeira ao cisalhamento. São Carlos, 1984. 157p. Dissertação (Mestrado) - Escola de Engenharia de São Carlos, Universidade de São Paulo. 
MONGES, V. A. (1991). Ponte pênsil de madeira - detalhes construtivos. São Carlos, EESC-USP, 1991. (Relatório de Iniciação Científica LaMEM-SETEESC-USP).

MORAES, F. V. C. (1990). Ponte pênsil de madeira - classificação estrutural da madeira. São Carlos, EESC-USP, 1990. (Relatório de Iniciação Científica LaMEM-SET-EESC-USP).

NAKAMURA, S. Y.; CALIXTO, F. L. (1989). Projeto de pontes pré-fabricadas em madeira para a Amazônia, classe 30, com vigas principais em treliça contínua. In: ENCONTRO BRASILEIRO EM MADEIRAS E EM ESTRUTURAS DE MADEIRA, 1989, São Carlos. Anais. São Carlos: Escola de Engenharia de São Carlos, USP, 1989. v.3, p.191-232.

NASCIMENTO, M. L. (1993). Sistemas estruturais e construtivos de pontes de madeira - ênfase em pontes laminadas protendidas. São Carlos, 1993. 149p. Dissertação (Mestrado) - Escola de Engenharia de São Carlos, Universidade de São Paulo.

PFEIL, W. (1983). Pontes em concreto armado. v.1. Rio de Janeiro, Livros Técnicos e Científicos S.A., 1983.

PIEDADE Jr., C. (1972). Ligações de Peroba Rosa e Pinho do Paraná com cavilhas de Eucalipto Citriodora. Botucatu, 1972. Tese (Doutorado) - Faculdade de Ciências Médicas e Biológicas de Botucatu.

PIGOZZO, J. C. (1982). Influência da umidade e da densidade na resistência à compressão da madeira. São Carlos, 1982. 142p. Dissertação (Mestrado) - Escola de Engenharia de São Carlos, Universidade de São Paulo.

PINTO, M. C. (1983). Flexão em peças de madeira. São Carlos, 1983. 108p. Dissertação (Mestrado) - escola de Engenharia de São Carlos, Universidade de São Paulo. 
PRATA, D. G. (1992). O conflito normativo e o calculista: as pontes de madeira no Brasil hoje. In: ENCONTRO BRASILEIRO EM MADEIRAS E EM ESTRUTURAS DE MADEIRA, 1992, São Carlos. Anais. São Carlos: Escola de Engenharia de São Carlos, USP, 1992. v.1, p.215-226.

(1995). Pontes protendidas de madeira. São Carlos, 1995. 311p. Tese

(Doutorado) - Escola de Engenharia de São Carlos, Universidade de São Paulo.

PUGSLEY, A.G. (1968). The theory of suspention bridges. London, Ed. Arnoldo, 1968.

RIBEIRO, G. O. (1986). Determinação das propriedades elásticas e de resistência dos compensados estruturais. São Carlos, 1986. 221p. Dissertação (Mestrado) Escola de Engenharia de São Carlos, Universidade de São Paulo.

SAP90 (1992). Structural Analysis Program by Finite Element. v1, 2, 3. Berkeley, Computers \& Structurs Inc, 1992.

SHIOGA, P. S. (1978). Vigas e postes de madeira para pontes rodoviárias e feroviárias. São Carlos, Escola de Engenharia de São Carlos, Universidade de São Paulo, 1978. (Relatório de Iniciação Científica LaMEM-SET-EESC-USP, 1).

SZÜCS, C.A. (1979). Ponte de madeira com vigas principais em treliça contínua. São Carlos, 1979. 220p. Dissertação (Mestrado) - Escola de Engenharia de São Carlos, Universidade de São Paulo.

TANAAMI, R. G. (1986). Influência da umidade e da densidade nas propriedades de resistência e elasticidade da madeira. São Carlos, 1986. 200p. - Escola de Engenharia de São Carlos, Universidade de São Paulo.

TIMOSHENKO, S. \& WOINWSKY-KRIEGER, S. (1959). Theory of plates and shells. New York, McGraw-Hill Book Company Inc., 1959. 
VASCONCELOS, A. C. (1993). Pontes brasileiras - Viadutos e passarelas notáveis. São Paulo, PINI, 1993.

VENEGAS, D. M. (1989). Estudo de detalhamento construtivo de ponte pênsil. São Carlos, Escola de Engenharia de São carlso, Universidade de São Paulo, 1989. 11p. (Relatório de Iniciação Científica LaMEM-SET-EESC-USP). 


\section{Anexo A}

Resultados dos ensaios de flexão dos sarrafos de Peroba Rosa*

\footnotetext{
*As dimensões das seções das peças $(b, d)$ e as flechas $(f)$ tem dimensão $\mathrm{cm}$, os momentos de inércia das seções (I) tem dimensão $\mathrm{cm}^{4}$, e o módulos de elasticidade longitudinal das peças tem dimensão $\mathrm{daN} / \mathrm{cm}^{2}$.
} 
Características das peças de Peroba Rosa

\begin{tabular}{|c|c|c|c|c|c|}
\hline peça & $b$ & $d$ & $f$ & $I$ & $E_{L}$ \\
\hline 1 & 2,005 & 4,995 & 0,6 & 3,36 & 137.270 \\
\hline 2 & 2,024 & 5,043 & 0,7 & 3,48 & 113.289 \\
\hline 3 & 1,968 & 5,026 & 0,5 & 3,19 & 173.117 \\
\hline 4 & 2,029 & 5,027 & 0,6 & 3,50 & 131.613 \\
\hline 5 & 2,015 & 5,031 & 0,5 & 3,43 & 161.123 \\
\hline 6 & 2,023 & 5,036 & 0,5 & 3,47 & 159.061 \\
\hline 7 & 1,987 & 5,051 & 0,6 & 3,30 & 139.471 \\
\hline 8 & 1,975 & 5,035 & 0,7 & 3,23 & 122.126 \\
\hline 9 & 1,902 & 5,041 & 0,8 & 2,89 & 119.500 \\
\hline 10 & 1,935 & 5,017 & 0,6 & 3,03 & 152.044 \\
\hline 11 & 1,980 & 5,023 & 0,6 & 3,25 & 141.741 \\
\hline 12 & 1,893 & 5,006 & 0,6 & 2,83 & 162.747 \\
\hline 13 & 1,978 & 5,043 & 0,7 & 3,25 & 121.378 \\
\hline 14 & 2,026 & 5,023 & 0,6 & 3,48 & 132.304 \\
\hline 15 & 1,996 & 5,050 & 0,7 & 3,35 & 117.960 \\
\hline 16 & 2,030 & 5,024 & 0,6 & 3,50 & 131.497 \\
\hline 17 & 1,974 & 5,040 & 0,5 & 3,23 & 171.066 \\
\hline 18 & 1,983 & 5,015 & 0,7 & 3,26 & 121.135 \\
\hline 19 & 2,086 & 5,021 & 0,6 & 3,80 & 121.261 \\
\hline 20 & 2,018 & 5,019 & 0,5 & 3,44 & 160.789 \\
\hline 21 & 2,018 & 5,027 & 0,6 & 3,44 & 133.777 \\
\hline 22 & 2,068 & 5,019 & 0,6 & 3,70 & 124.505 \\
\hline 23 & 2,022 & 5,017 & 0,7 & 3,46 & 114.214 \\
\hline 24 & 1,999 & 5,027 & 0,6 & 3,35 & 137.628 \\
\hline 25 & 2,029 & 5,004 & 1,1 & 3,48 & 72.119 \\
\hline 26 & 1,990 & 5,031 & 0,7 & 3,30 & 119.480 \\
\hline 27 & 2,093 & 5,052 & 0,5 & 3,86 & 143.174 \\
\hline 28 & 2012 & 5,025 & 0,6 & 3,41 & 135.031 \\
\hline 29 & 2,021 & 5,021 & 0,6 & 3,45 & 133.342 \\
\hline 30 & 2,091 & 5.012 & 0,5 & 3,82 & 144.732 \\
\hline 31 & 1,970 & 5,027 & 0,7 & 3,20 & 123.254 \\
\hline 32 & 1,992 & 5,021 & 0,7 & $3,3 I$ & 119.358 \\
\hline
\end{tabular}


continuação ...

\begin{tabular}{|c|c|c|c|c|c|}
\hline peça & b & $d$ & $f$ & $I$ & $E_{L}$ \\
\hline 33 & 1991 & 5,029 & 0,7 & 3,31 & 119.347 \\
\hline 34 & 1,997 & 5,007 & 0,5 & 3,32 & 166.312 \\
\hline 35 & 2,060 & 5,021 & 0,6 & 3,66 & 125.911 \\
\hline 36 & 2039 & 5,046 & 0,6 & 3,56 & 129.198 \\
\hline 37 & 2,051 & 5,033 & 0,4 & 3,62 & 190.907 \\
\hline 38 & 2,007 & 5,027 & 0,7 & 3,39 & 116.562 \\
\hline 39 & 2,080 & 5,064 & 0,7 & 3,80 & 103.950 \\
\hline 40 & 2,006 & 5,030 & 0,7 & 3,38 & 116.667 \\
\hline 41 & 1,985 & 5,021 & 0,8 & 3,27 & 105.547 \\
\hline 42 & 2,129 & 4,986 & 0,5 & 4,01 & 137.834 \\
\hline 43 & 2,092 & 5,042 & 0,6 & 3,85 & 119.720 \\
\hline 44 & 2,000 & 5,067 & 0,5 & 3,38 & 163.605 \\
\hline 45 & 2,095 & 5,001 & 0,5 & 3,83 & 144.221 \\
\hline 46 & 2,010 & 5,057 & 0,6 & 3,42 & 134.578 \\
\hline 47 & 2,012 & 5,058 & 0,6 & 3,43 & 134.151 \\
\hline 48 & 2,035 & 5,016 & 0,6 & 3,52 & 130.739 \\
\hline 49 & 2,031 & 5,030 & 0,7 & 3,51 & 112.411 \\
\hline 50 & 1,965 & 5,027 & 0,6 & 3,18 & 144.897 \\
\hline 51 & 1,900 & 2,083 & 0,7 & 1,19 & 331.557 \\
\hline 52 & 1,971 & 5,026 & 0,6 & 3,21 & 143.606 \\
\hline 53 & 1,950 & 5,015 & 0,7 & 3,10 & 127.389 \\
\hline 54 & 2,007 & 5,030 & 0,7 & 3,39 & 116.493 \\
\hline 55 & 2,069 & 5,080 & 0,6 & 3,75 & 122.832 \\
\hline 56 & 2,062 & 5,067 & 0,4 & 3,70 & 186.608 \\
\hline 57 & 1,995 & 5,007 & 0,6 & $3,3 I$ & 139.011 \\
\hline 58 & 1,949 & 5,027 & 0,6 & 3,10 & 148.495 \\
\hline 59 & 2,043 & 5,065 & 0,6 & 3,60 & 127.959 \\
\hline 60 & 1,968 & 5,024 & 0,7 & 3,19 & 123.704 \\
\hline 61 & 2,103 & 5,049 & 0,6 & 3,91 & 117.688 \\
\hline 62 & 2,011 & 5,038 & 0,7 & $3,4 I$ & 115.615 \\
\hline 63 & 2,081 & 5,104 & 0,6 & 3,83 & 120.151 \\
\hline 64 & $2 ; 084$ & 5,079 & 0,6 & 3,83 & $J 20.222$ \\
\hline
\end{tabular}


continuação ...

\begin{tabular}{|c|c|c|c|c|c|}
\hline peça & $\boldsymbol{b}$ & $d$ & $f$ & $I$ & $E_{L}$ \\
\hline 65 & 2,034 & 5,050 & 0,5 & 3,54 & 156.060 \\
\hline 66 & 2,018 & 5,024 & 0,7 & 3,44 & 114.735 \\
\hline 67 & 2,092 & 5,109 & 0,6 & 3,90 & 118.150 \\
\hline 68 & 1,853 & 5,060 & 0,9 & 2,68 & 114.442 \\
\hline 69 & 1,958 & 5,011 & 0,7 & 3,13 & 125.935 \\
\hline 70 & 2,010 & 5,022 & 0,5 & 3,40 & 162.619 \\
\hline 71 & 2,032 & 5,012 & 0,6 & 3,50 & 131.423 \\
\hline 72 & 1,967 & 5,043 & 0,7 & 3,20 & 123.426 \\
\hline 73 & 1,926 & 5,003 & 0,8 & 2,98 & 115.962 \\
\hline 74 & 1,980 & 5,024 & 0,7 & 3,25 & 121.468 \\
\hline 75 & 2,017 & 5,041 & 0,6 & 3,45 & 133.604 \\
\hline 76 & 1,974 & 5,005 & 0,7 & 3,21 & 123.045 \\
\hline 77 & 2,019 & 5,074 & 0,5 & 3,48 & 158.810 \\
\hline 78 & 2,000 & 5,028 & 0,6 & 3,35 & 137.395 \\
\hline 79 & 1,993 & 5,034 & 0,7 & 3,32 & 118.870 \\
\hline 80 & 2,089 & 5,004 & 0,6 & 3,80 & 121.150 \\
\hline & $\boldsymbol{b}$ & $d$ & $f$ & $I$ & $E_{L}$ \\
\hline $\boldsymbol{X}_{\text {Médio }}$ & 2,011 & 4,996 & 0,63 & 3,40 & 135.076 \\
\hline$s_{X}$ & 0,052 & 0,331 & 0,11 & 0,36 & 29.616 \\
\hline$x_{k_{5 \%}}$ & 1,926 & 4,452 & 0,45 & 2,81 & 86.357 \\
\hline$X_{k 95 \%}$ & 2,096 & 5,539 & 0,80 & 3,99 & 183.795 \\
\hline
\end{tabular}




\section{Anexo B}

Aplicação do método dos mínimos quadrados na análise dos resultados dos ensaios 
Seja um conjuto de pares de valores $\left(P_{i}, w_{i j}\right)$ referentes a uma tabela de resultados de ensaios, tais como apresentados no Quadro B1.

\begin{tabular}{ccccc}
\multicolumn{5}{c}{ Quadro B1: Pares de valores $\left(P_{i}, w_{i j}\right)}$. \\
\hline$P i$ & $w_{i j}$ \\
\hline$P_{1}$ & $w_{11}$ & $w_{12}$ & $\ldots$ & $w_{1 m}$ \\
$P_{2}$ & $w_{21}$ & $w_{22}$ & $\ldots$ & $w_{2 m}$ \\
$P_{3}$ & $w_{31}$ & $w_{32}$ & $\ldots$ & $w_{3 m}$ \\
$\ldots$ & $\ldots$ & $\ldots$ & $\ldots$ & $\ldots$ \\
$P_{n}$ & $w_{n 1}$ & $w_{n 2}$ & $\ldots$ & $w_{n m}$ \\
\hline
\end{tabular}

Seja $f(w)=a_{0} \cdot g o(w)+a l g \cdot 1(w)+\ldots+a_{w} \cdot g_{w}(w)$ uma função que aproxima os pares de pontos do Quadro B1, onde $f(w)$ é a função aproximadora, $g_{0}(w), g_{l}(w), \ldots$, $g_{w}(w)$ são funções formadoras de $f(w)$, e $a_{l}, a_{2}, \ldots, a_{w}$ são os coeficientes da equação.

Sejam os produtos escalares:

$$
\begin{aligned}
& \left\langle g_{s}, g_{t}\right\rangle=\sum_{\substack{s=l, q i=l, n \\
t=1, q j=l, m}} g_{s}\left(w_{i j}\right) \cdot g_{t}\left(w_{i j}\right)
\end{aligned}
$$

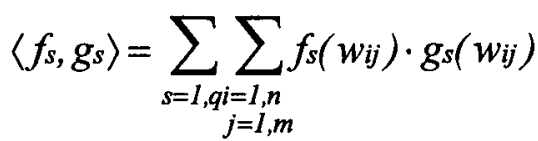

de tal modo que: 
$\begin{array}{cccccccc}<g o, g o> & <g o, g l> & \ldots & <g o, g k> & a l & <f, g o> \\ <g l, g o> & <g 1, g l> & \ldots & <g l, g k> & a l & & <f, g l> \\ \ldots & \ldots & \ldots & \ldots & . & \ldots\end{array}$

$<g w, g o>\quad\langle g w, g l>\ldots \quad<g w, g k>\quad$ al $\quad<f, g w>$

Assim, para o conjunto de pares de valores obtidos nos ensaios:

Quadro B2: Pares de valores obtidos nos ensaios.

\begin{tabular}{cccc}
\hline$P_{i}$ & & $w_{i j}$ & \\
\hline$P_{1}$ & $w_{11}$ & $w_{12}$ & $w_{13}$ \\
$P_{2}$ & $w_{21}$ & $w_{22}$ & $w_{23}$ \\
$P_{3}$ & $w_{31}$ & $w_{32}$ & $w_{33}$ \\
$P_{4}$ & $w_{41}$ & $w_{42}$ & $w_{43}$ \\
$P_{5}$ & $w_{51}$ & $w_{52}$ & $w_{53}$ \\
$P_{6}$ & $w_{61}$ & $w_{62}$ & $w_{63}$ \\
\hline
\end{tabular}

os quais queremos aproximar por meio de uma reta na forma $P(w)=k \cdot w$, daí:

$$
\begin{aligned}
& f(w)=P(w) \\
& g 0(w)=w \\
& a 0=k \\
& \left\langle g_{0,} g 0\right\rangle=\sum_{\substack{i=1,6 \\
j=1,3}} g 0\left(w_{i j}\right) \cdot g_{0}\left(w_{i j}\right)=\sum_{\substack{i=1,6 \\
j=1,3}} w_{i j} \cdot w_{i j}=\sum_{\substack{i=1,6 \\
j=1,3}} w_{i j}^{2} \\
& \left\langle f, g_{0}\right\rangle=\sum_{\substack{i=1,6 \\
j=1,3}} f\left(w_{j}\right) \cdot g_{0}\left(w_{i j}\right)=\sum_{\substack{i=1,6 \\
j=1,3}} P_{j}\left(w_{i 12}+w_{i j}\right.
\end{aligned}
$$




$$
\langle f, g 0\rangle=\sum_{i=1,6} P_{i} \cdot\left(w_{i 1}+w i 2+w_{i 3}\right)
$$

$$
\left\langle g 0, g_{0}\right\rangle \cdot a_{0}=\left\langle f, g_{0}\right\rangle \quad a_{0}=\frac{\left\langle f, g_{0}\right\rangle}{\left\langle g_{0}, g_{0}\right\rangle}
$$

$$
k=\frac{\sum_{\substack{i=1,6 \\ j=1,3}} P_{j} \cdot w_{i j}}{\sum_{\substack{i=1,6 \\ j=1,3}} w_{i j}^{2}}
$$

Deste modo, os dados dos ensaios realizados são organizados em tabelas conforme o Quadro B3.

Quadro B3.

\begin{tabular}{llll}
\hline$P_{i}$ & & $w_{i j}$ & \\
\hline$P_{1}$ & $w_{11}$ & $w_{12}$ & $w_{13}$ \\
$P_{2}$ & $w_{21}$ & $w_{22}$ & $w_{23}$ \\
$P_{3}$ & $w_{31}$ & $w_{32}$ & $w_{33}$ \\
$P_{4}$ & $w_{41}$ & $w_{42}$ & $w_{43}$ \\
$P_{5}$ & $w_{51}$ & $w_{52}$ & $w_{53}$ \\
$P_{6}$ & $w_{61}$ & $w_{62}$ & $w_{63}$ \\
\hline
\end{tabular}




\section{Anexo C}

Resultados dos ensaios de flexão do modelo pregado $1 A^{*}$

\footnotetext{
${ }^{*}$ As cargas $(P)$ tem dimensão daN, as flechas $\left(w_{l}, w_{2}, w_{3}\right)$ tem dimensão $10^{-2} \mathrm{~mm}$, e o coeficiente $k$, que relaciona $P$ e $w$, tem dimensão $100 \mathrm{daN} / \mathrm{mm}$.
} 
CARGA PONTUAL

PREGAÇÃOI

\begin{tabular}{|llll|}
\hline$P$ & $w_{1}$ & $w_{2}$ & $w_{3}$ \\
\hline 9,1 & 51 & 40 & 39 \\
18,3 & 117 & 108 & 110 \\
27,4 & 180 & 168 & 170 \\
36,6 & 239 & 225 & 226 \\
45,7 & 299 & 285 & 285 \\
54,8 & 352 & 340 & 342 \\
\hline \multicolumn{5}{|c}{0,1591} \\
\hline
\end{tabular}

PREGAÇÃO II

\begin{tabular}{|cccc|}
\hline$P$ & $w_{I}$ & $w_{2}$ & $w_{3}$ \\
\hline 9,1 & 24 & 15 & 17 \\
18,3 & 38 & 38 & 37 \\
27,4 & 58 & 58 & 55 \\
36,6 & 84 & 83 & 80 \\
45,7 & 110 & 110 & 108 \\
54,8 & 133 & 132 & 130 \\
\hline \multicolumn{5}{c}{0,4393} \\
\hline
\end{tabular}

PREGAÇÃO III

\begin{tabular}{|cccc|}
\hline$P$ & $w_{1}$ & $w_{2}$ & $w_{3}$ \\
\hline 9,1 & 24 & 31 & 25 \\
18,3 & 45 & 45 & 45 \\
27,4 & 70 & 69 & 77 \\
36,6 & 89 & 88 & 91 \\
45,7 & 110 & 109 & 108 \\
54,8 & 127 & 124 & 124 \\
\hline \multicolumn{5}{c}{0,4177} \\
\hline
\end{tabular}

CARGA 4 PONTOS

PREGAÇÃO I

\begin{tabular}{|cccc|}
\hline$P$ & $w_{1}$ & $w_{2}$ & $w_{3}$ \\
\hline 9,1 & 18 & 21 & 20 \\
18,3 & 40 & 38 & 39 \\
27,4 & 62 & 57 & 57 \\
36,6 & 82 & 77 & 77 \\
45,7 & 102 & 97 & 97 \\
54,8 & 124 & 116 & 118 \\
\hline \multicolumn{5}{c}{0,4622} \\
\hline
\end{tabular}

PREGAÇÃO II

\begin{tabular}{|cccc|}
\hline$P$ & $w_{1}$ & $w_{2}$ & $w_{3}$ \\
\hline 9,1 & 8 & 9 & 11 \\
18,3 & 20 & 20 & 18 \\
27,4 & 29 & 27 & 28 \\
36,6 & 38 & 38 & 37 \\
45,7 & 44 & 46 & 46 \\
54,8 & 55 & 55 & 54 \\
\hline \multicolumn{5}{|r}{0,9923} \\
\hline
\end{tabular}

PREGAÇÃO III

\begin{tabular}{|cccc|}
\hline$P$ & $w_{I}$ & $w_{2}$ & $w_{3}$ \\
\hline 9,1 & 13 & 10 & 14 \\
18,3 & 21 & 19 & 20 \\
27,4 & 33 & 33 & 31 \\
36,6 & 42 & 43 & 40 \\
45,7 & 52 & 50 & 50 \\
54,8 & 60 & 59 & 59 \\
\hline \multicolumn{5}{c}{0,8969} \\
\hline
\end{tabular}




\section{VÍNCULO 1 - FLECHA EM B}

CARGA LINEAR EXC.

PREGAÇÃOI

\begin{tabular}{|cccc|}
\hline$P$ & $w_{I}$ & $w_{2}$ & $w_{3}$ \\
\hline 9,1 & 6 & 6 & 6 \\
18,3 & 16 & 16 & 17 \\
27,4 & 23 & 23 & 25 \\
36,6 & 43 & 50 & 43 \\
45,7 & 67 & 69 & 66 \\
54,8 & 89 & 91 & 91 \\
\hline \multicolumn{5}{c}{0,6840} \\
\hline
\end{tabular}

PREGAÇÃO II

\begin{tabular}{|cccc|}
\hline$P$ & $w_{I}$ & $w_{2}$ & $w_{3}$ \\
\hline 9,1 & 12 & 11 & 10 \\
18,3 & 22 & 23 & 22 \\
27,4 & 34 & 35 & 35 \\
36,6 & 44 & 44 & 42 \\
45,7 & 50 & 52 & 50 \\
54,8 & 58 & 58 & 58 \\
\hline \multicolumn{5}{|c|}{0,8884} \\
\hline
\end{tabular}

PREGAÇÃO III

\begin{tabular}{|cccc|}
\hline$P$ & $w_{1}$ & $w_{2}$ & $w_{3}$ \\
\hline 9,1 & 13 & 16 & 13 \\
18,3 & 26 & 27 & 25 \\
27,4 & 40 & 40 & 39 \\
36,6 & 51 & 51 & 51 \\
45,7 & 62 & 62 & 61 \\
54,8 & 72 & 73 & 72 \\
\hline \multicolumn{5}{|c}{0,7340} \\
\hline
\end{tabular}


VÍNCULO 2 - FLECHA EMA

CARGA PONTUAL

PREGAÇÃOI

\begin{tabular}{|cccc|}
\hline$P$ & $w_{l}$ & $w_{2}$ & $w_{3}$ \\
\hline 9.1 & 43 & 53 & 50 \\
18.3 & 114 & 112 & 108 \\
27.4 & 173 & 167 & 165 \\
36.6 & 227 & 221 & 218 \\
45.7 & 284 & 280 & 274 \\
54.8 & 385 & 330 & 325 \\
\hline \multicolumn{5}{|c}{0,1612} \\
\hline
\end{tabular}

PREGAÇÃO II

\begin{tabular}{|cccc|}
\hline$P$ & $w_{l}$ & $w_{2}$ & $w_{3}$ \\
\hline 9.1 & 55 & 55 & 52 \\
18.3 & 102 & 101 & 98 \\
27.4 & 142 & 154 & 152 \\
36.6 & 207 & 205 & 207 \\
45.7 & 258 & 258 & 258 \\
54.8 & 309 & 311 & 310 \\
\hline \multicolumn{5}{|c}{0,1777} \\
\hline
\end{tabular}

PREGAÇÃO III

\begin{tabular}{|cccc|}
\hline$P$ & $w_{1}$ & $w_{2}$ & $w_{3}$ \\
\hline 9.1 & 47 & 46 & 52 \\
18.3 & 95 & 95 & 97 \\
27.4 & 146 & 147 & 147 \\
36.6 & 192 & 194 & 196 \\
45.7 & 242 & 245 & 244 \\
54.8 & 290 & 292 & 291 \\
\hline \multicolumn{5}{|c}{0,1881} \\
\hline
\end{tabular}

CARGA 4 PONTOS

PREGAÇÃO I

\begin{tabular}{|cccc|}
\hline$P$ & $w_{1}$ & $w_{2}$ & $w_{3}$ \\
\hline 9.1 & 37 & 35 & 35 \\
18.3 & 69 & 68 & 65 \\
27.4 & 105 & 105 & 108 \\
36.6 & 142 & 139 & 136 \\
45.7 & 179 & 172 & 172 \\
54.8 & 215 & 205 & 204 \\
\hline \multicolumn{5}{c}{0,2627} \\
\hline
\end{tabular}

PREGAÇÃO II

\begin{tabular}{|cccc|}
\hline$P$ & $w_{1}$ & $w_{2}$ & $w_{3}$ \\
\hline 9.1 & 39 & 38 & 43 \\
18.3 & 65 & 65 & 64 \\
27.4 & 99 & 99 & 105 \\
36.6 & 130 & 128 & 130 \\
45.7 & 158 & 160 & 160 \\
54.8 & 190 & 185 & 189 \\
\hline \multicolumn{5}{c}{0,2850} \\
\hline
\end{tabular}

PREGAÇÃO III

\begin{tabular}{|cccc|}
\hline$P$ & $w_{1}$ & $w_{2}$ & $w_{3}$ \\
\hline 9.1 & 29 & 31 & 34 \\
18.3 & 68 & 60 & 59 \\
27.4 & 96 & 95 & 92 \\
36.6 & 129 & 164 & 124 \\
45.7 & 164 & 157 & 159 \\
54.8 & 196 & 187 & 188 \\
\hline \multicolumn{5}{|c}{0,2817} \\
\hline
\end{tabular}




\section{VÍNCULO 2 - FLECHA EMA}

CARGA LINEAR EXC.

PREGACCÃO I

\begin{tabular}{|cccc|}
\hline$P$ & $w_{1}$ & $w_{2}$ & $w_{3}$ \\
\hline 9.1 & 60 & 56 & 53 \\
18.3 & 120 & 114 & 120 \\
27.4 & 193 & 188 & 190 \\
36.6 & 255 & 249 & 253 \\
45.7 & 325 & 311 & 316 \\
54.8 & 380 & 373 & 373 \\
\hline \multicolumn{5}{|c}{0,1455} \\
\hline
\end{tabular}

PREGAÇ̃̃O II

\begin{tabular}{|cccc|}
\hline$P$ & $w_{I}$ & $w_{2}$ & $w_{3}$ \\
\hline 9.1 & 62 & 52 & 53 \\
18.3 & 97 & 93 & 98 \\
27.4 & 150 & 145 & 145 \\
36.6 & 192 & 190 & 190 \\
45.7 & 230 & 237 & 228 \\
54.8 & 277 & 278 & 274 \\
\hline \multicolumn{5}{|c}{0,1947} \\
\hline
\end{tabular}

\section{PREGAÇÃO III}

\begin{tabular}{|cccc|}
\hline$P$ & $w_{1}$ & $w_{2}$ & $w_{3}$ \\
\hline 9.1 & 68 & 60 & 64 \\
18.3 & 132 & 130 & 128 \\
27.4 & 202 & 198 & 196 \\
36.6 & 265 & 260 & 260 \\
45.7 & 367 & 322 & 324 \\
54.8 & 389 & 382 & 385 \\
\hline \multicolumn{5}{|c}{0,1391} \\
\hline
\end{tabular}




\section{VÍNCULO 2 - FLECHA EM B}

CARGA PONTUAL

PREGAÇÃOI

\begin{tabular}{|cccc|}
\hline$P$ & $w_{1}$ & $w_{2}$ & $w_{3}$ \\
\hline 9.1 & 38 & 47 & 45 \\
18.3 & 105 & 100 & 96 \\
27.4 & 160 & 153 & 150 \\
36.6 & 200 & 203 & 200 \\
45.7 & 260 & 258 & 251 \\
54.8 & 297 & 302 & 298 \\
\hline \multicolumn{5}{|c}{0,1812} \\
\hline
\end{tabular}

PREGACÃO II

\begin{tabular}{|cccc|}
\hline$p$ & $w_{1}$ & $w_{2}$ & $w_{3}$ \\
\hline 9.1 & 65 & 60 & 58 \\
18.3 & 115 & 110 & 110 \\
27.4 & 164 & 168 & 168 \\
36.6 & 228 & 223 & 223 \\
45.7 & 278 & 274 & 274 \\
54.8 & 328 & 326 & 323 \\
\hline \multicolumn{5}{|c}{0,1658} \\
\hline
\end{tabular}

PREGAÇÃO III

\begin{tabular}{|cccc|}
\hline$P$ & $w_{1}$ & $w_{2}$ & $w_{3}$ \\
\hline 9.1 & 44 & 42 & 46 \\
18.3 & 89 & 87 & 88 \\
27.4 & 138 & 138 & 137 \\
36.6 & 179 & 179 & 180 \\
45.7 & 227 & 227 & 225 \\
54.8 & 272 & 271 & 270 \\
\hline \multicolumn{5}{|c}{0,2024} \\
\hline
\end{tabular}

CARGA 4 PONTOS

PREGAÇAOI I

\begin{tabular}{|cccc|}
\hline$P$ & $w_{l}$ & $w_{2}$ & $w_{3}$ \\
\hline 9.1 & 36 & 24 & 28 \\
18.3 & 50 & 52 & 52 \\
27.4 & 80 & 85 & 90 \\
36.6 & 115 & 115 & 116 \\
45.7 & 151 & 147 & 151 \\
54.8 & 180 & 175 & 179 \\
\hline \multicolumn{5}{c}{0,3116} \\
\hline
\end{tabular}

PREGAÇÃO II

\begin{tabular}{|cccc|}
\hline$P$ & $w_{I}$ & $w_{2}$ & $w_{3}$ \\
\hline 9.1 & 45 & 44 & 54 \\
18.3 & 78 & 175 & 68 \\
27.4 & 115 & 118 & 130 \\
36.6 & 152 & 150 & 155 \\
45.7 & 185 & 188 & 195 \\
54.8 & 228 & 218 & 325 \\
\hline \multicolumn{5}{|c}{0,2150} \\
\hline
\end{tabular}

PREGAÇÃO III

\begin{tabular}{|cccc|}
\hline$P$ & $w_{l}$ & $w_{2}$ & $w_{3}$ \\
\hline 9.1 & 23 & 25 & 28 \\
18.3 & 51 & 51 & 54 \\
27.4 & 79 & 80 & 78 \\
36.6 & 109 & 107 & 106 \\
45.7 & 137 & 133 & 135 \\
54.8 & 164 & 160 & 159 \\
\hline \multicolumn{5}{|c}{0,3412} \\
\hline
\end{tabular}


VÍNCULO 2 - FLECHA EM B

CARGA LINEAR EXC.

\begin{tabular}{|cccc|}
\hline \multicolumn{5}{c|}{ PREGAÇAOI } \\
\hline$P$ & $w_{1}$ & $w_{2}$ & $w_{3}$ \\
\hline 9.1 & 32 & 33 & 31 \\
18.3 & 60 & 61 & 63 \\
27.4 & 97 & 97 & 97 \\
36.6 & 134 & 136 & 137 \\
45.7 & 183 & 178 & 185 \\
54.8 & 220 & 219 & 219 \\
\hline \multicolumn{5}{|c}{0,2580} \\
\hline
\end{tabular}

PREGAÇÃO II

\begin{tabular}{|cccc|}
\hline$P$ & $w_{I}$ & $w_{2}$ & $w_{3}$ \\
\hline 9.1 & 114 & 95 & 93 \\
18.3 & 172 & 158 & 164 \\
27.4 & 248 & 245 & 244 \\
36.6 & 318 & 318 & 313 \\
45.7 & 375 & 388 & 376 \\
54.8 & 454 & 458 & 453 \\
\hline \multicolumn{5}{|c}{0,1175} \\
\hline
\end{tabular}

PREGAÇÃO III

\begin{tabular}{|cccc|}
\hline$P$ & $w_{1}$ & $w_{2}$ & $w_{3}$ \\
\hline 9.1 & 43 & 40 & 43 \\
18.3 & 85 & 84 & 81 \\
27.4 & 133 & 133 & 129 \\
36.6 & 177 & 178 & 173 \\
45.7 & 224 & 221 & 222 \\
54.8 & 267 & 262 & 264 \\
\hline \multicolumn{5}{|c}{0,2076} \\
\hline
\end{tabular}




\section{VÍNCULO 2 - FLECHA EMC}

CARGA PONTUAL

PREGAÇÃOI

\begin{tabular}{|cccc|}
\hline$P$ & $w_{l}$ & $w_{2}$ & $w_{3}$ \\
\hline 9.1 & 26 & 31 & 34 \\
18.3 & 74 & 71 & 71 \\
27.4 & 121 & 116 & 117 \\
36.6 & 174 & 167 & 168 \\
45.7 & 217 & 223 & 225 \\
54.8 & 269 & 277 & 275 \\
\hline \multicolumn{5}{|c}{0,2092} \\
\hline
\end{tabular}

PREGAÇÃO II

\begin{tabular}{|cccc|}
\hline$P$ & $w_{1}$ & $w_{2}$ & $w_{3}$ \\
\hline 9.1 & 66 & 64 & 63 \\
18.3 & 121 & 118 & 118 \\
27.4 & 166 & 174 & 175 \\
36.6 & 242 & 230 & 233 \\
45.7 & 290 & 285 & 289 \\
54.8 & 340 & 340 & 341 \\
\hline \multicolumn{5}{c}{0,1586} \\
\hline
\end{tabular}

PREGAÇÃO III

\begin{tabular}{|cccc|}
\hline$P$ & $w_{1}$ & $w_{2}$ & $w_{3}$ \\
\hline 9.1 & 50 & 48 & 53 \\
18.3 & 100 & 99 & 100 \\
27.4 & 153 & 154 & 153 \\
36.6 & 203 & 204 & 204 \\
45.7 & 257 & 257 & 255 \\
54.8 & 305 & 305 & 304 \\
\hline \multicolumn{5}{|c|}{0,1794} \\
\hline
\end{tabular}

CARGA 4 PONTOS

PREGAÇAO I

\begin{tabular}{|cccc|}
\hline$P$ & $w_{1}$ & $w_{2}$ & $w_{3}$ \\
\hline 9.1 & 37 & 36 & 35 \\
18.3 & 70 & 72 & 66 \\
27.4 & 107 & 108 & 108 \\
36.6 & 144 & 142 & 137 \\
45.7 & 188 & 179 & 176 \\
54.8 & 218 & 210 & 207 \\
\hline \multicolumn{5}{c}{0,2567} \\
\hline
\end{tabular}

PREGAÇÃO II

\begin{tabular}{|cccc|}
\hline$P$ & $w_{1}$ & $w_{2}$ & $w_{3}$ \\
\hline 9.1 & 46 & 45 & 53 \\
18.3 & 82 & 82 & 81 \\
27.4 & 119 & 124 & 135 \\
36.6 & 166 & 164 & 169 \\
45.7 & 203 & 198 & 205 \\
54.8 & 243 & 236 & 243 \\
\hline \multicolumn{5}{|c}{0,2240} \\
\hline
\end{tabular}

PREGAÇÃO III

\begin{tabular}{|cccc|}
\hline$P$ & $w_{I}$ & $w_{2}$ & $w_{3}$ \\
\hline 9.1 & 31 & 34 & 35 \\
18.3 & 66 & 65 & 62 \\
27.4 & 103 & 103 & 98 \\
36.6 & 140 & 135 & 134 \\
45.7 & 177 & 171 & 170 \\
54.8 & 213 & 205 & 102 \\
\hline \multicolumn{5}{c}{0,2759} \\
\hline
\end{tabular}


VÍNCULO 2 - FLECHA EM C

CARGA LINEAR EXC.

PREGAÇÃO I

\begin{tabular}{|cccc|}
\hline$P$ & $w_{1}$ & $w_{2}$ & $w_{3}$ \\
\hline 9.1 & 32 & 7 & 27 \\
18.3 & 63 & 35 & 62 \\
27.4 & 99 & 73 & 98 \\
36.6 & 131 & 106 & 131 \\
45.7 & 174 & 140 & 166 \\
54.8 & 204 & 174 & 200 \\
\hline \multicolumn{5}{c}{0.2884} \\
\hline
\end{tabular}

PREGAÇ̃̃O II

\begin{tabular}{|cccc|}
\hline$P$ & $w_{1}$ & $w_{2}$ & $w_{3}$ \\
\hline 9.1 & 60 & 50 & 49 \\
18.3 & 99 & 94 & 98 \\
27.4 & 154 & 150 & 149 \\
36.6 & 201 & 200 & 199 \\
45.7 & 243 & 250 & 240 \\
54.8 & 295 & 298 & 291 \\
\hline \multicolumn{5}{|c}{0.1851} \\
\hline
\end{tabular}

PREGACCAO III

\begin{tabular}{|llll|}
\hline$P$ & $w_{1}$ & $w_{2}$ & $w_{3}$ \\
\hline 9.1 & 43 & 41 & 45 \\
18.3 & 86 & 87 & 85 \\
27.4 & 136 & 136 & 135 \\
36.6 & 182 & 184 & 181 \\
45.7 & 235 & 231 & 234 \\
54.8 & 279 & 274 & 279 \\
\hline \multicolumn{5}{c}{0.1988} \\
\hline
\end{tabular}




\section{Anexo D}

Resultados dos ensaios de flexão do modelo pregado $1 B^{*}$

${ }^{*}$ As cargas $(P)$ tem dimensão daN, as flechas $\left(w_{1}, w_{2}, w_{3}\right)$ tem dimensão $10^{-2} \mathrm{~mm}$, e o coeficiente $k$, que relaciona $P$ e $w$, tem dimensão $100 \mathrm{daN} / \mathrm{mm}$. 


\section{VÍNCULO 1 - FLECHA EM B}

CARGA PONTUAL

PREGACAOA I

\begin{tabular}{|cccc|}
\hline$P$ & $w_{1}$ & $w_{2}$ & $w_{3}$ \\
\hline 9,1 & 4 & $l$ & $l$ \\
18,3 & 32 & 31 & 27 \\
27,4 & 71 & 65 & 67 \\
36,6 & 102 & 97 & 98 \\
45,7 & 132 & 127 & 127 \\
54,8 & 160 & 155 & 155 \\
\hline \multicolumn{5}{c}{0,3636} \\
\hline
\end{tabular}

PREGAÇÃO II

\begin{tabular}{|cccc|}
\hline$P$ & $w_{1}$ & $w_{2}$ & $w_{3}$ \\
\hline 9,1 & 39 & 24 & 21 \\
18,3 & 56 & 51 & 48 \\
27,4 & 79 & 77 & 78 \\
36,6 & 104 & 103 & 106 \\
45,7 & 132 & 131 & 130 \\
54,8 & 159 & 157 & 153 \\
\hline \multicolumn{5}{c}{0,3496} \\
\hline
\end{tabular}

PREGAÇÃO III

\begin{tabular}{|cccc|}
\hline$P$ & $w_{1}$ & $w_{2}$ & $w_{3}$ \\
\hline 9,1 & 29 & 29 & 27 \\
18,3 & 52 & 49 & 48 \\
27,4 & 75 & 72 & 70 \\
36,6 & 97 & 93 & 93 \\
45,7 & 120 & 116 & 116 \\
54,8 & 142 & 139 & 137 \\
\hline \multicolumn{5}{|c}{0,3873} \\
\hline
\end{tabular}

CARGA 4 PONTOS

PREGAÇAOI

\begin{tabular}{|cccc|}
\hline$P$ & $w_{1}$ & $w_{2}$ & $w_{3}$ \\
\hline 9,1 & 3 & 6 & 7 \\
18,3 & 10 & 13 & 15 \\
27,4 & 21 & 22 & 25 \\
36,6 & 30 & 32 & 34 \\
45,7 & 40 & 41 & 43 \\
54,8 & 50 & 49 & 50 \\
\hline \multicolumn{5}{c}{1,1296} \\
\hline
\end{tabular}

PREGAÇÃO II

\begin{tabular}{|cccc|}
\hline$P$ & $w_{1}$ & $w_{2}$ & $w_{3}$ \\
\hline 9,1 & 12 & 13 & 18 \\
18,3 & 24 & 24 & 28 \\
27,4 & 40 & 36 & 38 \\
36,6 & 52 & 48 & 48 \\
45,7 & 62 & 59 & 59 \\
54,8 & 72 & 70 & 69 \\
\hline \multicolumn{5}{c}{0,7551} \\
\hline
\end{tabular}

PREGAÇÃO III

\begin{tabular}{|cccc|}
\hline$P$ & $w_{1}$ & $w_{2}$ & $w_{3}$ \\
\hline 9,1 & 12 & 11 & 13 \\
18,3 & 21 & 21 & 22 \\
27,4 & 32 & 33 & 34 \\
36,6 & 45 & 44 & 45 \\
45,7 & 56 & 56 & 57 \\
54,8 & 67 & 67 & 67 \\
\hline \multicolumn{5}{|c}{0,8182} \\
\hline
\end{tabular}




\section{VÍNCULO 1 - FLECHA EM B}

CARGA LINEAR EXC.

\begin{tabular}{|cccc|}
\hline \multicolumn{5}{c|}{ PREGAÇAOI } \\
\hline$P$ & $w_{1}$ & $w_{2}$ & $w_{3}$ \\
\hline 27,4 & 0 & 0 & 1 \\
36,6 & 1 & $I$ & 2 \\
45,7 & 3 & 2 & 4 \\
54,8 & 4 & 5 & 6 \\
63,9 & 13 & 20 & 16 \\
73,1 & 28 & 32 & 32 \\
\hline \multicolumn{5}{c}{2,9876} \\
\hline
\end{tabular}

PREGAÇÃO II

\begin{tabular}{|cccc|}
\hline$P$ & $w_{I}$ & $w_{2}$ & $w_{3}$ \\
\hline 9,1 & 18 & 19 & 18 \\
18,3 & 29 & 34 & 33 \\
27,4 & 50 & 53 & 52 \\
36,6 & 68 & 70 & 70 \\
45,7 & 85 & 87 & 88 \\
54,8 & 99 & 100 & 99 \\
\hline \multicolumn{5}{|c}{0,5381} \\
\hline
\end{tabular}

\section{PREGAÇÃO III}

\begin{tabular}{|cccc|}
\hline$P$ & $w_{1}$ & $w_{2}$ & $w_{3}$ \\
\hline 9,1 & 8 & 8 & 9 \\
18,3 & 23 & 22 & 24 \\
27,4 & 37 & 37 & 37 \\
36,6 & 51 & 50 & 52 \\
45,7 & 66 & 64 & 65 \\
54,8 & 78 & 78 & 78 \\
\hline \multicolumn{5}{c}{0,7139} \\
\hline
\end{tabular}




\section{VÍNCULO 2 - FLECHA EMA}

CARGA PONTUAL

PREGAÇÃO I

\begin{tabular}{|llll|}
\hline$P$ & $w_{1}$ & $w_{2}$ & $w_{3}$ \\
\hline 9,1 & 53 & 55 & 54 \\
18,3 & 110 & 118 & 113 \\
27,4 & 172 & 170 & 158 \\
36,6 & 230 & 218 & 205 \\
45,7 & 275 & 268 & 253 \\
54,8 & 322 & 310 & 300 \\
\hline \multicolumn{5}{|c}{0,1714} \\
\hline
\end{tabular}

PREGAÇÃO II

\begin{tabular}{|cccc|}
\hline$P$ & $w_{I}$ & $w_{2}$ & $w_{3}$ \\
\hline 9,1 & 80 & 80 & 70 \\
18,3 & 148 & 130 & 129 \\
27,4 & 224 & 195 & 196 \\
36,6 & 295 & 260 & 262 \\
45,7 & 370 & 325 & 370 \\
54,8 & 425 & 394 & 390 \\
\hline \multicolumn{5}{|c}{0,1327} \\
\hline
\end{tabular}

PREGAÇÃO III

\begin{tabular}{|cccc|}
\hline$P$ & $w_{1}$ & $w_{2}$ & $w_{3}$ \\
\hline 9,1 & 50 & 50 & 48 \\
18,3 & 103 & 100 & 100 \\
27,4 & 158 & 160 & 160 \\
36,6 & 215 & 212 & 210 \\
45,7 & 272 & 265 & 263 \\
54,8 & 330 & 320 & 320 \\
\hline \multicolumn{5}{|c|}{0,1713} \\
\hline
\end{tabular}

CARGA 4 PONTOS

PREGAÇÃO I

\begin{tabular}{|cccc|}
\hline$P$ & $w_{l}$ & $w_{2}$ & $w_{3}$ \\
\hline 9,1 & 35 & 42 & 42 \\
18,3 & 70 & 80 & 78 \\
27,4 & 115 & 118 & 115 \\
36,6 & 153 & 152 & 150 \\
45,7 & 188 & 186 & 184 \\
54,8 & 228 & 218 & 218 \\
\hline \multicolumn{5}{|c}{0,2441} \\
\hline
\end{tabular}

PREGAÇÃO II

\begin{tabular}{|cccc|}
\hline$P$ & $w_{1}$ & $w_{2}$ & $w_{3}$ \\
\hline 9,1 & 44 & 44 & 45 \\
18,3 & 82 & 80 & 80 \\
27,4 & 126 & 114 & 120 \\
36,6 & 166 & 158 & 158 \\
45,7 & 211 & 200 & 200 \\
54,8 & 254 & 236 & 238 \\
\hline \multicolumn{5}{|c}{0,2256} \\
\hline
\end{tabular}

PREGAÇÃO III

\begin{tabular}{|cccc|}
\hline$P$ & $w_{1}$ & $w_{2}$ & $w_{3}$ \\
\hline 9,1 & 40 & 40 & 35 \\
18,3 & 83 & 76 & 73 \\
27,4 & 130 & 120 & 118 \\
36,6 & 170 & 162 & 155 \\
45,7 & 210 & 203 & 195 \\
54,8 & 243 & 243 & 235 \\
\hline \multicolumn{5}{c}{0,2266} \\
\hline
\end{tabular}


VÍNCULO 2 - FLECHA EMA

CARGA LINEAR EXC.

PREGAÇÃO I

\begin{tabular}{|cccc|}
\hline$P$ & $w_{1}$ & $w_{2}$ & $w_{3}$ \\
\hline 9,1 & 144 & 145 & 152 \\
18,3 & 245 & 230 & 240 \\
27,4 & 360 & 350 & 338 \\
36,6 & 460 & 433 & 438 \\
45,7 & 560 & 533 & 540 \\
54,8 & 680 & 630 & 638 \\
\hline \multicolumn{5}{c}{0,0824} \\
\hline
\end{tabular}

PREGAÇÃO II

\begin{tabular}{|cccc|}
\hline$P$ & $w_{l}$ & $w_{2}$ & $w_{3}$ \\
\hline 9,1 & 50 & 65 & 74 \\
18,3 & 135 & 160 & 185 \\
27,4 & 235 & 255 & 275 \\
36,6 & 314 & 335 & 360 \\
45,7 & 405 & 425 & 455 \\
54,8 & 495 & 500 & 531 \\
\hline \multicolumn{5}{c}{0,1078} \\
\hline
\end{tabular}

PREGAÇÃO III

\begin{tabular}{|cccc|}
\hline$P$ & $w_{1}$ & $w_{2}$ & $w_{3}$ \\
\hline 9,1 & 80 & 78 & 78 \\
18,3 & 154 & 150 & 148 \\
27,4 & 234 & 202 & 230 \\
36,6 & 320 & 308 & 305 \\
45,7 & 394 & 383 & 384 \\
54,8 & 468 & 460 & 453 \\
\hline \multicolumn{5}{c}{0,1189} \\
\hline
\end{tabular}




\section{VÍNCULO 2 - FLECHA EMB}

CARGA PONTUAL

PREGAÇÃOI

\begin{tabular}{|cccc|}
\hline$P$ & $w_{1}$ & $w_{2}$ & $w_{3}$ \\
\hline 9,1 & 64 & 64 & 68 \\
18,3 & 143 & 148 & 152 \\
27,4 & 218 & 227 & 227 \\
36,6 & 287 & 298 & 296 \\
45,7 & 358 & 265 & 359 \\
54,8 & 417 & 425 & 425 \\
\hline \multicolumn{5}{|c}{0,1295} \\
\hline
\end{tabular}

PREGAÇÃO II

\begin{tabular}{|cccc|}
\hline$P$ & $w_{l}$ & $w_{2}$ & $w_{3}$ \\
\hline 9,1 & 65 & 80 & 66 \\
18,3 & 125 & 127 & 122 \\
27,4 & 190 & 184 & 183 \\
36,6 & 247 & 241 & 241 \\
45,7 & 311 & 297 & 300 \\
54,8 & 362 & 352 & 352 \\
\hline \multicolumn{5}{|c}{0,1512} \\
\hline
\end{tabular}

PREGAÇÃO III

\begin{tabular}{|cccc|}
\hline$P$ & $w_{l}$ & $w_{2}$ & $w_{3}$ \\
\hline 9,1 & 42 & 48 & 44 \\
18,3 & 97 & 98 & 92 \\
27,4 & 154 & 156 & 154 \\
36,6 & 208 & 206 & 203 \\
45,7 & 264 & 258 & 254 \\
54,8 & 313 & 309 & 302 \\
\hline \multicolumn{5}{|c}{0,1782} \\
\hline
\end{tabular}

CARGA 4 PONTOS

PREGACAOA I

\begin{tabular}{|cccc|}
\hline$P$ & $w_{I}$ & $w_{2}$ & $w_{3}$ \\
\hline 9,1 & 31 & 40 & 38 \\
18,3 & 68 & 77 & 75 \\
27,4 & 111 & 114 & 112 \\
36,6 & 147 & 147 & 144 \\
45,7 & 183 & 178 & 177 \\
54,8 & 222 & 211 & 210 \\
\hline \multicolumn{5}{|c}{0,2528} \\
\hline
\end{tabular}

PREGACCÃO II

\begin{tabular}{|cccc|}
\hline$P$ & $w_{1}$ & $w_{2}$ & $w_{3}$ \\
\hline 9,1 & 38 & 36 & 38 \\
18,3 & $7 I$ & 68 & 68 \\
27,4 & 106 & 96 & 102 \\
36,6 & 138 & 132 & 131 \\
45,7 & 173 & 165 & 164 \\
54,8 & 206 & 195 & 195 \\
\hline \multicolumn{5}{|c}{0,2731} \\
\hline
\end{tabular}

PREGAÇÃO III

\begin{tabular}{|cccc|}
\hline$P$ & $w_{1}$ & $w_{2}$ & $w_{3}$ \\
\hline 9,1 & 44 & 48 & 45 \\
18,3 & 97 & 97 & 96 \\
27,4 & 154 & 149 & 153 \\
36,6 & 209 & 204 & 205 \\
45,7 & 255 & 256 & 251 \\
54,8 & 311 & 304 & 302 \\
\hline \multicolumn{5}{|c}{0,1798} \\
\hline
\end{tabular}


VÍNCULO 2 - FLECHA EM B

CARGA LINEAR EXC.

PREGACÃOI

\begin{tabular}{|cccc|}
\hline$P$ & $w_{1}$ & $w_{2}$ & $w_{3}$ \\
\hline 9,1 & 48 & 48 & 47 \\
18,3 & 102 & 98 & 97 \\
27,4 & 164 & 157 & 152 \\
36,6 & 248 & 205 & 203 \\
45,7 & 269 & 262 & 259 \\
54,8 & 333 & 318 & 315 \\
\hline \multicolumn{5}{c}{0,1713} \\
\hline
\end{tabular}

PREGAÇÃO II

\begin{tabular}{|cccc|}
\hline$P$ & $w_{I}$ & $w_{2}$ & $w_{3}$ \\
\hline 9,1 & 56 & 56 & 56 \\
18,3 & 109 & 107 & 107 \\
27,4 & 170 & 168 & 165 \\
36,6 & 220 & 220 & 218 \\
45,7 & 285 & 280 & 277 \\
54,8 & 338 & 325 & 318 \\
\hline \multicolumn{5}{|c|}{0,1657} \\
\hline
\end{tabular}

PREGAÇÃO III

\begin{tabular}{|cccc|}
\hline$P$ & $w_{I}$ & $w_{2}$ & $w_{3}$ \\
\hline 9,1 & 48 & 44 & 46 \\
18,3 & 94 & 92 & 92 \\
27,4 & 147 & 143 & 143 \\
36,6 & 208 & 201 & 198 \\
45,7 & 256 & 248 & 249 \\
54,8 & 304 & 302 & 292 \\
\hline \multicolumn{5}{|c}{0,1837} \\
\hline
\end{tabular}


CARGA PONTUAL

PREGAÇÃOI

\begin{tabular}{|cccc|}
\hline$P$ & $w_{1}$ & $w_{2}$ & $w_{3}$ \\
\hline 9,1 & 45 & 47 & 50 \\
18,3 & 97 & 93 & 93 \\
27,4 & 130 & 117 & 117 \\
36,6 & 153 & 145 & 142 \\
45,7 & 190 & 175 & 175 \\
54,8 & 250 & 227 & 227 \\
\hline \multicolumn{5}{c}{0,2364} \\
\hline
\end{tabular}

PREGAÇÃO II

\begin{tabular}{|cccc|}
\hline$P$ & $w_{I}$ & $w_{2}$ & $w_{3}$ \\
\hline 9,1 & 70 & 90 & 70 \\
18,3 & 140 & 141 & 130 \\
27,4 & 215 & 208 & 200 \\
36,6 & 283 & 275 & 270 \\
45,7 & 357 & 238 & 335 \\
54,8 & 416 & 400 & 398 \\
\hline \multicolumn{5}{|c}{0,1361} \\
\hline
\end{tabular}

PREGAÇÃO III

\begin{tabular}{|cccc|}
\hline$P$ & $w_{I}$ & $w_{2}$ & $w_{3}$ \\
\hline 9,1 & 58 & 60 & 58 \\
18,3 & 122 & 121 & 120 \\
27,4 & 192 & 195 & 195 \\
36,6 & 262 & 260 & 260 \\
45,7 & 335 & 330 & 325 \\
54,8 & 405 & 395 & 392 \\
\hline \multicolumn{5}{c}{0,1395} \\
\hline
\end{tabular}

CARGA 4 PONTOS

PREGAÇÃO I

\begin{tabular}{|cccc|}
\hline$P$ & $w_{1}$ & $w_{2}$ & $w_{3}$ \\
\hline 9,1 & 25 & 33 & 31 \\
18,3 & 55 & 66 & 64 \\
27,4 & 94 & 105 & 102 \\
36,6 & 135 & 140 & 137 \\
45,7 & 172 & 174 & 173 \\
54,8 & 216 & 208 & 206 \\
\hline \multicolumn{5}{|c}{0,2654} \\
\hline
\end{tabular}

PREGAÇÃO II

\begin{tabular}{|cccc|}
\hline$P$ & $w_{1}$ & $w_{2}$ & $w_{3}$ \\
\hline 9,1 & 44 & 44 & 45 \\
18,3 & 88 & 88 & 85 \\
27,4 & 138 & 125 & 128 \\
36,6 & 178 & 172 & 165 \\
45,7 & 228 & 210 & 208 \\
54,8 & 268 & 258 & 252 \\
\hline \multicolumn{5}{|c}{0,2114} \\
\hline
\end{tabular}

PREGAÇÃO III

\begin{tabular}{|cccc|}
\hline$P$ & $w_{1}$ & $w_{2}$ & $w_{3}$ \\
\hline 9,1 & 57 & 55 & 54 \\
18,3 & 130 & 125 & 125 \\
27,4 & 214 & 201 & 208 \\
36,6 & 290 & 282 & 285 \\
45,7 & 358 & 350 & 345 \\
54,8 & 428 & 415 & 410 \\
\hline \multicolumn{5}{c}{0,1311} \\
\hline
\end{tabular}


VÍNCULO 2 - FLECHA EM C

CARGA LINEAR EXC.

PREGACC̃O I

\begin{tabular}{|cccc|}
\hline$P$ & $w_{1}$ & $w_{2}$ & $w_{3}$ \\
\hline 9,1 & 39 & 49 & 42 \\
18,3 & 94 & 95 & 88 \\
27,4 & 148 & 130 & 120 \\
36,6 & 185 & 165 & 153 \\
45,7 & 220 & 268 & 286 \\
54,8 & 255 & 230 & 220 \\
\hline \multicolumn{5}{c}{0,2038} \\
\hline
\end{tabular}

PREGAÇÃO II

\begin{tabular}{|cccc|}
\hline$P$ & $w_{1}$ & $w_{2}$ & $w_{3}$ \\
\hline 9,1 & 55 & 53 & 55 \\
18,3 & 112 & 108 & 108 \\
27,4 & 180 & 185 & 170 \\
36,6 & 245 & 238 & 240 \\
45,7 & 315 & 305 & 305 \\
54,8 & 335 & 354 & 353 \\
\hline \multicolumn{5}{c}{0,1538} \\
\hline
\end{tabular}

PREGAÇÃO III

\begin{tabular}{|cccc|}
\hline$P$ & $w_{1}$ & $w_{2}$ & $w_{3}$ \\
\hline 9,1 & 50 & 50 & 48 \\
18,3 & 106 & 106 & 102 \\
27,4 & 170 & 165 & 165 \\
36,6 & 240 & 233 & 226 \\
45,7 & 298 & 290 & 286 \\
54,8 & 356 & 351 & 343 \\
\hline \multicolumn{5}{c}{0,1583} \\
\hline
\end{tabular}




\section{Anexo E}

Resultados dos ensaios de flexão do modelo cavilhado*

\footnotetext{
${ }^{*}$ As cargas $(P)$ tem dimensão daN, as flechas $\left(w_{1}, w_{2}, w_{3}\right)$ tem dimensão $10^{-2} \mathrm{~mm}$, e o coeficiente $k$, que relaciona $P$ e $w$, tem dimensão $100 \mathrm{daN} / \mathrm{mm}$.
} 
VÍNCULO 1 - FLECHA EM B

PONTUAL

\begin{tabular}{|cccc|}
\hline$P$ & $w_{1}$ & $w_{2}$ & $w_{3}$ \\
\hline 9,1 & 16 & 21 & 19 \\
18,3 & 36 & 40 & 41 \\
27,4 & 58 & 62 & 61 \\
36,6 & 80 & 84 & 82 \\
45,7 & 100 & 102 & 101 \\
54,8 & 121 & 124 & 121 \\
\hline \multicolumn{5}{c}{0,4510} \\
\hline
\end{tabular}

4 PONTOS

\begin{tabular}{|cccc|}
\hline$P$ & $w_{1}$ & $w_{2}$ & $w_{3}$ \\
\hline 9,1 & 10 & 10 & 10 \\
18,3 & 19 & 19 & 19 \\
27,4 & 29 & 29 & 30 \\
36,6 & 39 & 39 & 40 \\
45,7 & 50 & 50 & 49 \\
54,8 & 60 & 60 & 59 \\
\hline \multicolumn{5}{c}{0,9241} \\
\hline
\end{tabular}

LINEAR EXC.

\begin{tabular}{|cccc|}
\hline$P$ & $w_{1}$ & $w_{2}$ & $w_{3}$ \\
\hline 9,1 & 12 & 15 & 10 \\
18,3 & 24 & 28 & 27 \\
27,4 & 41 & 42 & 42 \\
36,6 & 57 & 58 & 54 \\
45,7 & 70 & 73 & 71 \\
54,8 & 84 & 84 & 84 \\
\hline \multicolumn{5}{|c}{0,6510} \\
\hline
\end{tabular}


VÍNCULO 2 - FLECHA EMA

PONTUAL

\begin{tabular}{|cccc|}
\hline$P$ & $w_{1}$ & $w_{2}$ & $w_{3}$ \\
\hline 9,1 & 66 & 80 & 71 \\
18,3 & 131 & 138 & 128 \\
27,4 & 200 & 210 & 202 \\
36,6 & 275 & 280 & 270 \\
45,7 & 362 & 353 & 360 \\
54,8 & 431 & 424 & 430 \\
\hline \multicolumn{5}{c}{0,1296} \\
\hline
\end{tabular}

4 PONTOS

\begin{tabular}{|cccc|}
\hline$p$ & $w_{l}$ & $w_{2}$ & $w_{3}$ \\
\hline 9,1 & 50 & 40 & 46 \\
18,3 & 82 & 84 & 75 \\
27,4 & 128 & 128 & 106 \\
36,6 & 175 & 166 & 160 \\
45,7 & 225 & 212 & 205 \\
54,8 & 265 & 260 & 245 \\
\hline \multicolumn{4}{c}{0,2157} \\
\hline
\end{tabular}

LINEAR EXC

\begin{tabular}{|cccc|}
\hline$P$ & $w_{1}$ & $w_{2}$ & $w_{3}$ \\
\hline 9,1 & 145 & 134 & 128 \\
18,3 & 300 & 264 & 260 \\
27,4 & 395 & 370 & 360 \\
36,6 & 490 & 455 & 449 \\
45,7 & 573 & 545 & 545 \\
54,8 & 651 & 620 & 612 \\
\hline \multicolumn{5}{|c}{0,0809} \\
\hline
\end{tabular}


VÍNCULO 2 - FLECHA EM B

PONTUAL

\begin{tabular}{|cccc|}
\hline$P$ & $w_{1}$ & $w_{2}$ & $w_{3}$ \\
\hline 9,1 & 9 & 26 & 27 \\
18,3 & 56 & 69 & 67 \\
27,4 & 105 & 119 & 117 \\
36,6 & 154 & 167 & 166 \\
45,7 & 211 & 217 & 222 \\
54,8 & 259 & 266 & 268 \\
\hline \multicolumn{5}{c}{0,2164} \\
\hline
\end{tabular}

4 PONTOS

\begin{tabular}{|cccc|}
\hline$P$ & $w_{1}$ & $w_{2}$ & $w_{3}$ \\
\hline 9,1 & 31 & 27 & 31 \\
18,3 & 53 & 56 & 52 \\
27,4 & 87 & 88 & 83 \\
36,6 & 121 & 115 & 116 \\
45,7 & 154 & 147 & 143 \\
54,8 & 184 & 179 & 172 \\
\hline \multicolumn{5}{|c}{0,3106} \\
\hline
\end{tabular}

LINEAR EXC.

\begin{tabular}{|cccc|}
\hline$P$ & $w_{1}$ & $w_{2}$ & $w_{3}$ \\
\hline 9,1 & 38 & 43 & 35 \\
18,3 & 97 & 93 & 81 \\
27,4 & 152 & 149 & 134 \\
36,6 & 204 & 197 & 197 \\
45,7 & 253 & 258 & 253 \\
54,8 & 298 & 304 & 292 \\
\hline \multicolumn{5}{|c}{0,1839} \\
\hline
\end{tabular}


VÍNCULO 2 - FLECHA EMC

PONTUAL

\begin{tabular}{|cccc|}
\hline$P$ & $w_{I}$ & $w_{2}$ & $w_{3}$ \\
\hline 9,1 & 48 & 58 & 57 \\
18,3 & 102 & 110 & 102 \\
27,4 & 162 & 170 & 166 \\
36,6 & 224 & 230 & 222 \\
45,7 & 290 & 290 & 280 \\
54,8 & 351 & 348 & 336 \\
\hline \multicolumn{5}{|c}{0,1608} \\
\hline
\end{tabular}

4 PONTOS

\begin{tabular}{|cccc|}
\hline$P$ & $w_{1}$ & $w_{2}$ & $w_{3}$ \\
\hline 9,1 & 41 & 36 & 42 \\
18,3 & 76 & 80 & 74 \\
27,4 & 125 & 125 & 118 \\
36,6 & 176 & 166 & 163 \\
45,7 & 225 & 210 & 203 \\
54,8 & 266 & 254 & 243 \\
\hline \multicolumn{5}{c}{0,2171} \\
\hline
\end{tabular}

LINEAR EXC.

\begin{tabular}{|cccc|}
\hline$P$ & $w_{l}$ & $w_{2}$ & $w_{3}$ \\
\hline 9,1 & 36 & 34 & 34 \\
18,3 & 82 & 78 & 77 \\
27,4 & 131 & 133 & 131 \\
36,6 & 184 & 182 & 186 \\
45,7 & 231 & 241 & 241 \\
54,8 & 288 & 288 & 282 \\
\hline \multicolumn{5}{|c}{0,1962} \\
\hline
\end{tabular}


Anexo $F$

Modelos numéricos de placa isótropa - Arquivos SAP90 


\section{Modelos com $v=0,00$}

Placa isótropa - $t=10 \mathrm{~mm}$ - Coef.Poisson=0,0 - Apoio 4 lados

C This is file 00-10-1 written by SAPIN on Mon Jun 12 11:38:51 1995

C Units are $\mathrm{kg} \mathrm{mm}$

SYSTEM

$R=0 \quad L=3 \quad C=0 \quad V=0 \quad T=0.0001 \quad P=0 \quad W=0 Z=0$

GRID

$X N=14 Y N=14 \mathrm{ZN}=1$

070.71141 .42212 .13282 .84353 .55424 .26494 .97

565.68636 .39707 .1777 .81848 .52919 .2299

0 70.71 141.42 212.13 282.84353.55 424.26 494.97

565.68636 .39707 .1777 .81848 .52919 .2299

0

JOINTS

$14 X=919.2299 Y=0 \quad Z=0$

$183 X=0 \quad Y=919.2299 \mathrm{Z}=0$

$196 X=919.2299 Y=919.2299 Z=0$

$1 \quad X=0 \quad Y=0 \quad Z=0 Q=1,14,183,196,1,14$

\section{SHELL}

$N M=1 O=0$

$1 E=1350.8 \quad U=0 \quad W=0 \quad M=0 \quad T A=0$

$1 J Q=1,15,2,16$ ETYPE $=0 \quad M=1 \quad T Z=0 \quad T H=10,0 \quad L P=0 \quad G=13,13$

\section{RESTRAINTS}

$11 \perp R=1,1,1,0,0,0$

$2141 \quad R=1,0,1,0,0,0$

$1841951 \quad R=1,0,1,0,0,0$

$1518314 R=0,1,1,0,0,0$

$\begin{array}{llll}28 & 182 \quad 14 & R=0,1,1,0,0,0\end{array}$

$196196 I R=0,0,1,0,0,0$

\section{LOADS}

91 91 $1 \quad L=1 F=0,0,-25,0,0,0$

$9292 \quad l \quad L=1 \quad F=0,0,-25,0,0,0$

$1051051 L=1 F=0,0,-25,0,0,0$

$1061061 L=1 F=0,0,-25,0,0,0$

$6161 \quad I \quad L=2 F=0,0,-25,0,0,0$

$131 \quad 131 \quad 1 \quad L=2 F=0,0,-25,0,0,0$

$136136 \quad 1 \quad L=2 F=0,0,-25,0,0,0$

$66 \quad 66 \quad 1 \quad L=2 F=0,0,-25,0,0,0$

$9191 \quad 1 \quad L=3 F=0,0,-2.5,0,0,0$

$105105 \quad 1 \quad L=3 F=0,0,-2.5,0,0,0$

$9292 \quad I \quad L=3 \quad F=0,0,-7.5,0,0,0$

$93931 L=3 \quad F=0,0,-7.5,0,0,0$

$9494 \quad 1 \quad L=3 F=0,0,-7.5,0,0,0$

$95951 L=3 F=0,0,-7.5,0,0,0$

$9696 \quad l \quad L=3 \quad F=0,0,-7.5,0,0,0$

$97971 L=3 \quad F=0,0,-7.5,0,0,0$

$106106 \quad I \quad L=3 F=0,0,-7.5,0,0,0$

107107 I $L=3 F=0,0,-7.5,0,0,0$

$1081081 L=3 \quad F=0,0,-7.5,0,0,0$

$1091091 \quad L=3 \quad F=0,0,-7.5,0,0,0$

$1101101 L=3 F=0,0,-7.5,0,0,0$

III $1111 L=3 F=0,0,-7.5,0,0,0$

\section{SELECT}

$N T=1 \mathrm{ID}=91,91,1 \mathrm{SW}=1$

$N T=1 \quad I D=92,92,1 \quad \mathrm{SW}=1$

$N T=I I D=105,105,1 \mathrm{SW}=1$

$N T=1 \quad I D=106,106,1 S W=1$ 


\section{Modelos com $v=0,33$}

Placa isótropa - $t=10 \mathrm{~mm}$ - Coef.Poisson=0,33 Apoio 4 lados

C This is file 03-10-1 written by SAPIN on Mon Jun 12 21:42:00 1995

C Units are $\mathrm{kg} \mathrm{mm}$

SYSTEM

$R=0 \quad L=3 \quad C=0 \quad V=0 T=0.0001 \quad P=0 \quad W=0 Z=0$

GRID

$X N=14 Y N=14 Z N=1$

0 70.71 141.42212 .13282 .84353 .55424 .26494 .97

565.68636 .39707 .1777 .81848 .52919 .2299

0 70.71 141.42 212.13 282.84 353.55 424.26 494.97

565.68636 .39707 .1777 .81848 .52919 .2299

0

JOINTS

$14 X=919.2299 \quad Y=0 Z=0$

$183 \quad X=0 \quad Y=919.2299 Z=0$

$196 X=919.2299 Y=919.2299 Z=0$

$1 \quad X=0 \quad Y=0 \quad Z=0 \quad Q=1,14,183,196,1,14$

SHELL

$N M=1 O=0$

I $E=1350.8 \quad U=0.3333 \quad W=0 M=0 T A=0$

$1 J Q=1,15,2,16$ ETYPE $=0 M=1 \quad T Z=0 \quad T H=10,0 \quad L P=0 \quad G=13,13$

\section{RESTRAINTS}

$\begin{array}{lllll}1 & 1 & 1 & R=1,1,1,0,0,0 \\ 2 & 14 & 1 & R=1,0,1,0,0,0 \\ 184 & 195 & 1 & R=1,0,1,0,0,0 \\ 15 & 183 & 14 & R=0,1,1,0,0,0 \\ 28 & 182 & 14 & R=0,1,1,0,0,0 \\ 196 & 196 & 1 & R=0,0,1,0,0,0\end{array}$

LOADS

$9191 \quad 1 \quad L=I F=0,0,-25,0,0,0$

$92921 \quad L=1 F=0,0,-25,0,0,0$

$1051051 \quad L=1 F=0,0,-25,0,0,0$

$1061061 L=1 F=0,0,-25,0,0,0$

$6161 \quad 1 \quad L=2 F=0,0,-25,0,0,0$

$1311311 \quad L=2 F=0,0,-25,0,0,0$

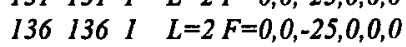

$66 \quad 66 \quad l \quad L=2 F=0,0,-25,0,0,0$

$91911 L=3 F=0,0,-2.5,0,0,0$

$1051051 L=3 F=0,0,-2.5,0,0,0$

$92921 L=3 F=0,0,-7.5,0,0,0$

9393 I $L=3 F=0,0,-7.5,0,0,0$

$949411 \quad L=3 F=0,0,-7.5,0,0,0$

$9595 \quad l \quad L=3 \quad F=0,0,-7.5,0,0,0$

9696 I $L=3 F=0,0,-7.5,0,0,0$

$9797 \quad 1 \quad L=3 \quad F=0,0,-7.5,0,0,0$

$106106 \quad L \quad L=3 F=0,0,-7.5,0,0,0$

$1071071 L=3 F=0,0,-7.5,0,0,0$

$1081081 \quad L=3 \quad F=0,0,-7.5,0,0,0$

109109 I $L=3 F=0,0,-7.5,0,0,0$

$1101101 \quad L=3 \quad F=0,0,-7.5,0,0,0$

$1111111 L=3 F=0,0,-7.5,0,0,0$

\section{SELECT}

$N T=1 \quad I D=91,91,1 \quad S W=1$

$N T=1 \quad I D=92,92,1 \quad S W=1$

$N T=1 \quad I D=105,105,1 \mathrm{SW}=1$

$N T=1 \quad I D=106,106,1 \quad S W=1$ 


\section{Anexo G}

Modelos numéricos de placa isótropa - Resultados obtidos*

\footnotetext{
* A carga total $P$, aplicada em cada modelo, é igual a 100 daN. As flechas $\left(w_{A}, w_{B}, w_{C}\right)$ tem
} dimensão $\mathrm{mm}$, e o coeficiente $k$, que relaciona $P$ e $w$, tem dimensão $100 \mathrm{daN} / \mathrm{mm}$. 
Placa isótropa com coeficiente de Poisson $v=0$

\begin{tabular}{ccccccc}
\hline \multicolumn{5}{c}{ Flecha } & \multicolumn{3}{c}{$k$} \\
\hline $\boldsymbol{d}$ & Pontual & 4 Pontos & Lin. exc. & Pontual & 4 Pontos & Lin. exc. \\
\hline 10 & 8,3021 & 5,0360 & 5,2311 & 0,1205 & 0,1986 & 0,1912 \\
20 & 1,0778 & 0,6295 & 0,6539 & 0,9278 & 1,5886 & 1,5293 \\
30 & 0,3075 & 0,1865 & 0,1858 & 3,2520 & 5,3619 & 5,3821 \\
40 & 0,1297 & 0,0787 & 0,0817 & 7,7101 & 12,7065 & 12,2399 \\
\hline
\end{tabular}

Placa isótropa com coeficiente de Poisson $v=0,33$

\begin{tabular}{ccccccc}
\hline \multicolumn{4}{c}{ Flecha } & \multicolumn{3}{c}{$k$} \\
\hline$d$ & Pontual & 4 Pontos & Lin. exc. & Pontual & 4 Pontos & Lin. exc. \\
\hline 10 & 7,3835 & 4,4785 & 4,6519 & 0,1354 & 0,2233 & 0,2150 \\
20 & 0,9229 & 0,5598 & 0,5578 & 1,0835 & 1,7864 & 1,7928 \\
30 & 0,2735 & 0,1659 & 0,1653 & 3,6563 & 6,0277 & 6,0496 \\
40 & 0,1154 & 0,0700 & 0,0697 & 8,6655 & 14,2857 & 14,3472 \\
\hline
\end{tabular}

